\title{
Energy Requirement for Rock Breakage in Laboratory Experiments and Engineering Operations: A Review
}

\author{
Zong-Xian Zhang ${ }^{1}\left[\right.$ D $\cdot$ Finn Ouchterlony ${ }^{2}$ (D)
}

Received: 21 April 2021 / Accepted: 15 October 2021 / Published online: 30 October 2021

(c) The Author(s) 2021

\begin{abstract}
Based on the review of a wide range of literature, this paper finds that: (1) the average specific surface energy of various single crystals is only $0.8 \mathrm{~J} / \mathrm{m}^{2}$. (2) The average specific fracture energy of the rocks with a pre-crack under static cleavage tests is $4.6 \mathrm{~J} / \mathrm{m}^{2}$. (3) The average specific fracture energy of the rocks with a pre-cut notch but with no pre-crack under static tensile fracture (mode I) tests is $4.6 \mathrm{~J} / \mathrm{m}^{2}$. (4) The average specific fracture energies of regular rock specimens with neither pre-made crack nor pre-cut notch are 26.6, 13.9 and $25.7 \mathrm{~J} / \mathrm{m}^{2}$ under uniaxial compression, tension and shear tests, respectively. (5) The average specific fracture energy of irregular single quartz particles under uniaxial compression is $13.8 \mathrm{~J} /$ $\mathrm{m}^{2}$. (6) The average specific fracture energy of particle beds under drop weight tests is $74.0 \mathrm{~J} / \mathrm{m}^{2}$. (7) The average specific fracture energy of multi-particles in milling tests is $72.5 \mathrm{~J} / \mathrm{m}^{2}$. (8) The average specific energy of rocks in percussive drilling is $399 \mathrm{~J} / \mathrm{m}^{3}$, that in full-scale cutting is $131 \mathrm{~J} / \mathrm{m}^{3}$, and that in rotary drilling is $157 \mathrm{~J} / \mathrm{m}^{3}$. (9) The average energy efficiency of milling is only $1.10 \%$. (10) The accurate measurements of specific fracture energy in blasting are too few to draw reliable conclusions. In the last part of the paper, the effects of inter-granular displacement, loading rate, confining pressure, surface area measurement, premade crack, attrition and thermal energy on the specific fracture energy of rock are discussed.
\end{abstract}

Keywords Rock $\cdot$ Fracture energy $\cdot$ Crushing $\cdot$ Blasting $\cdot$ Drilling $\cdot$ Cutting $\cdot$ Energy efficiency

\section{List of symbols}

$A_{0} \quad$ Nominal (or projected) area of fracture surface in half of the symmetrically broken specimen (or the main crack), $\mathrm{m}^{2}$

$G_{\mathrm{c}} \quad$ Critical energy release rate, $\mathrm{J} / \mathrm{m}^{2}$

$K_{\text {Ic }} \quad$ Mode I fracture toughness, MPa $\mathrm{m}^{1 / 2}$

$w_{\mathrm{f}} \quad$ Specific fracture energy per unit of true surface area, $\mathrm{J} / \mathrm{m}^{2}$

$w_{\mathrm{f}}^{\mathrm{o}} \quad$ Specific fracture energy per unit of nominal surface area, $\mathrm{J} / \mathrm{m}^{2}$

$w_{\mathrm{fv}} \quad$ Specific fracture energy per unit of true volume, $\mathrm{J} /$ $\mathrm{m}^{3}$

$\gamma_{\mathrm{fp}} \quad$ Specific energy used in creating fracture process zone, $\mathrm{J} / \mathrm{m}^{2}$

Zong-Xian Zhang

zongxian.zhang@oulu.fi

Finn Ouchterlony

finn.ouchterlony@unileoben.ac.at

1 Oulu Mining School, University of Oulu, Oulu, Finland

2 Department of Mining Engineering, Montanuniversitaet Leoben, Leoben, Austria $\gamma_{\mathrm{p}} \quad$ Specific energy dissipated in plastic deformation, $\mathrm{J} / \mathrm{m}^{2}$

$A \quad$ True area of fracture surface in half of the symmetrically broken specimen (or the main crack), $\mathrm{m}^{2}$

DCB Double cantilever beam

$G \quad$ Energy release rate $G$ at (incipient) crack growth, $\mathrm{J} / \mathrm{m}^{2}$ or $\mathrm{N} / \mathrm{m}$

NB Notched beam

OGC Obreimoff-Gilman cleavage

$U \quad$ External energy (mainly mechanical work) performed one or more a fracturing bodies, $\mathrm{J}$

$\gamma \quad$ Surface energy of (single crystal) material per unit of true surface area, $\mathrm{J} / \mathrm{m}^{2}$

\section{Introduction}

Rock fracture occurs in various engineering operations such as rock drilling, cutting, boring, crushing, grinding and blasting, and it requires energy. For example, the mining industry over the world expends a vast amount of energy and meanwhile releases a huge amount of $\mathrm{CO}_{2}$ every year. In 
the USA, the mining industry expended approximately 1310 billion MJ/year (BCS 2007). In Canada, the annually used energy in mining was approximately $11 \%$ of the total annual energy consumption in the country in the year 2009 (Natural Resources Canada 2011). Unfortunately, the energy efficiency is extremely low in mining operations. For instance, the energy efficiency is about $10 \%$ in percussive rock drilling (Carrol 1985), 3-5\% in rock crushing (Prasher 1987), $1 \%$ in ball and rod milling (or grinding) (Chi et al. 1996; Alvarado et al. 1998; Fuerstenau and Abouzeid 2002), and about 6\% in rock blasting (Ouchterlony et al. 2003; Sanchidrián et al. 2007). These low energy efficiencies result in a huge amount of energy wastage and make mining operations much worse than other industrial sectors in terms of energy utilization. For example, in Canada, the energy used in mining was about $30 \%$ of the energy used in all industrial sectors in 2009, but the GDP contribution from mining was only about $18 \%$. Another example is that the average annual consumption of raw minerals in Europe was 10 ton per person (Moser 2004). About 50\% was produced by blasting. In aggregate quarries $10-15 \%$ of the rock blasted could not be sold, as the material was too fine. This 'fines problem' resulted in that about 450 million tons of rock fines was put on waste dumps every year. Evidently, it is very important to increase the energy efficiencies of the operations mentioned above. At the same time, it is necessary to distribute the input energy better between sub-operations so that unwanted products like energy consuming fines could be reduced in aggregate industry.

In addition to various rock destructions mentioned above, rock fracture happens in many disasters such as earthquakes, slope failure, excavation-induced rock mass collapse or caving, rock bursts and seismic events. All these events are dependent on the fracture energy of rock. Moreover, optimal rock fragmentation with reasonable energy utilization can increase the ore recovery ratio in mining, for example, by correct primer placement in sublevel caving (Zhang 2005, 2014, 2016). Similarly, effective rock fracture may improve the ore recovery ratio through effective separation of minerals along their grain boundaries in mineral processing.

To increase the energy efficiencies, it is necessary to figure out the minimum energy required to fracture small rock specimens used in the laboratory and the actual fracture energy used in the aforementioned engineering operations. In view of this background, this paper reviews the experimental results from previous studies on rock fracture in both small- and full-scale experiments. It deals with the following topics: the specific surface energies of single crystals; the specific fracture energies of regular rock specimens for strength and fracture toughness tests; the specific fracture energies of irregular single particles; the specific fracture energies of particle beds; the specific energy in full-scale experiments for rock drilling, cutting, blasting, crushing and grinding; the differences between the specific fracture energy values from different experiments in both small-scale and full-scale experiments. In the last part of the paper the factors influencing the specific fracture energy of rock are discussed.

\section{Definitions of Surface Energy and Fracture Energy}

The fracture of a material breaks the bonds between atoms (or the interfaces between molecules). To create a new surface area, a certain amount of energy must be supplied. This energy is called surface energy or surface tension. Surface tension refers to the liquid state, while surface energy refers to solids. In this paper, surface tension will not be discussed.

\subsection{Specific Surface Energy}

Surface energy is also called surface free energy or interfacial free energy. Surface energy quantifies the disruption of interatomic (or intermolecular) bonds that occur when a surface is created. The surface energy can be defined as the work required to separate a crystal into two parts along a plane (Gilman 1960). The surface energy of a material is often expressed by $\gamma$ with a unit of $\mathrm{J} / \mathrm{m}^{2}$. Accordingly, surface energy is also called specific surface energy. In this paper, specific surface energy is used from now on. Determination of specific surface energy of solids can be traced back to Hertz (1881) who measured the surface energy of solids by indentation. This technique was adopted later by investigators such as Roesler (1956). Since the 1930's other techniques such as Obreimoff's method (Obreimoff 1930) and Gilman's method (Gilman 1960), which is based on Obreimoff's method, have been developed to determine the specific surface energy of crystals and solids including rocks. Gilman's method is shown in Fig. 1. In general, specific surface energy $\gamma$ is calculated from the external energy $\mathrm{U}$ needed to propagate a stable tensile fracture through the rock and from the area of the newly created fracture surface, as follows (e.g. Friedman et al. 1972):

$U=2 A \gamma$

where $A$ is the area of fracture surface in one half of the symmetrically broken specimen. In Gilman's method, an initial crack or notch must be made before the testing for $\gamma$ is carried out. Gilman (1960) used a mechanical system with a wedge to make the initial crack by controlling the crack propagation. The true length of the initial crack is an issue to discuss since the measured length depends on whether macro- or micro-scale is used in the measurements. 


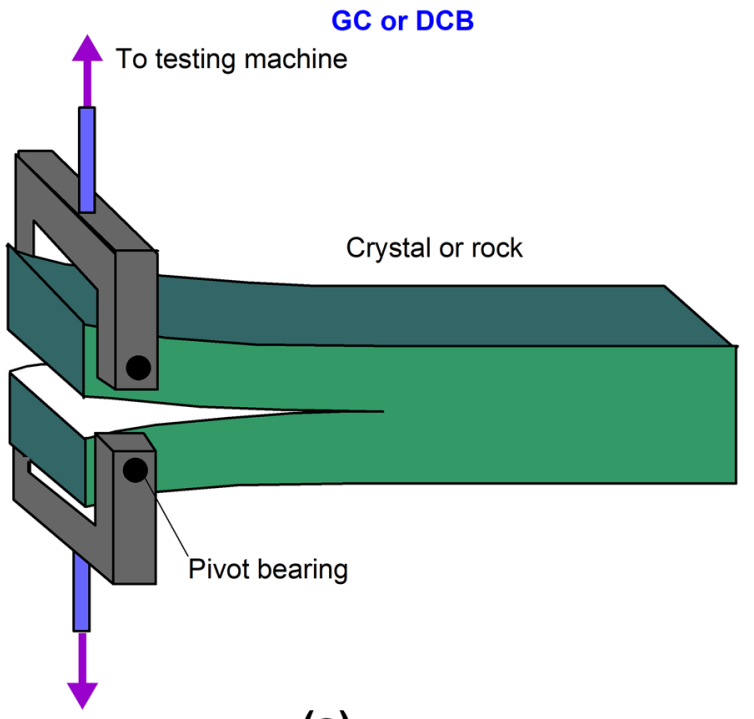

(a)
NB or 3PB

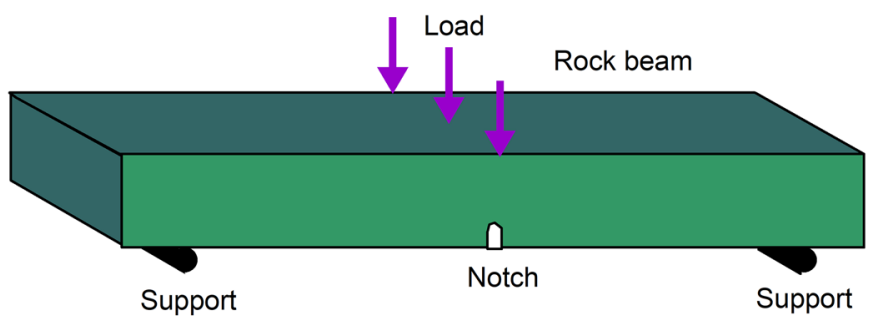

Fig. 1 Gilman cleavage (GC) method or double cantilever beam (DCB) method (a) and notched beam (NB) or three point bending (3 PB) method (b) used to determine the specific fracture energy of a crystal

Since different names such as fracture energy, fracture surface energy, cleavage energy, etc. are used in various publications to express the same meaning as surface energy, in this paper $\gamma$ is only used to express the specific surface energy of single crystals.

\subsection{Specific Fracture Energy}

The fracture energy of a solid was defined as the energy used by the formation of a new surface of unit area in the fracture process (Nakayama 1965). In this paper, $w_{f}\left[\mathrm{~J} / \mathrm{m}^{2}\right]$ is used to represent the fracture energy per unit of true new surface area, and it is called specific fracture energy. In terms of this definition, the specific fracture energy $w_{\mathrm{f}}$ has the same meaning as the specific surface energy $\gamma$ mentioned earlier. However, there are some differences between $w_{\mathrm{f}}$ and $\gamma$. (1) $\gamma$ is used for a single crystal, while $w_{\mathrm{f}}$ can be used for polycrystalline rocks. (2) For single crystals, a new surface is created along a plane of crystals, but for polycrystalline specimens, a new surface is created not only along grain boundaries but also through grains, see Fig. 2. (3) $w_{\mathrm{f}}$ includes the energy used in crack branching during rock fracture (Bieniawski 1968; Zhang et al. 1999, 2000, 2001), besides surface and other energies. However, the $\gamma$ of a crystal does not necessarily involve the energy in crack branching since no such branching occurs if the loading is slow enough and aligned with the symmetry planes of the crystal, which it normally is. In many references such as Friedman et al. (1972), effective (or nominal) fracture energy $w_{\mathrm{f}}^{\mathrm{o}}$ was used and determined by means of nominal or projected fracture surface area rather than the true surface area.

\subsection{Energy Release Rate G}

Since Griffith's theory (Griffith 1924) is only valid for elastic fracture, Irwin (1948) and Orowan (1948) independently modified the Griffith theory to account for materials that are capable of plastic flow. Accordingly, the specific fracture energy $w_{\mathrm{f}}$ is not equal to the specific surface energy $\gamma$, but much greater than $\gamma$ since $w_{\mathrm{f}}$ includes the plastic work and other effects. Irwin (1956) proposed an energy approach for fracture that is essentially equivalent to the Griffith strength equation (Griffith 1921, 1924), and introduced the energy release rate $G\left[\mathrm{~J} / \mathrm{m}^{2}\right.$ or $\left.\mathrm{N} / \mathrm{m}\right]$ as a measure of the energy available for a virtual increment of crack extension. Notice that a crack has two opposite surfaces, e.g. an upper surface and a lower one for a horizontal crack. $G$ is also called the crack extension force or the crack driving force. When $G$ reaches a critical value $G_{\mathrm{c}}$, crack extension occurs, i.e. (Anderson 2005)

$G_{\mathrm{c}}=2 w_{\mathrm{f}}$

It is to note that here $G_{\mathrm{c}}\left[\mathrm{J} / \mathrm{m}^{2}\right]$ should be based on the true fracture surface area rather than the nominal one as in ordinary fracture tests. The $w_{\mathrm{f}}$ could include the surface energy in creating new surfaces, the energy in plastic deformation (or viscoelastic or viscoplastic deformation), the energy in intergranular displacement, the energy in crack branching, and the energy used in friction between two crack surfaces. The last one may be very large in mode II and mode III shear fracture. Anderson (2005) described solid fracture using three models: (a) fracture model of an ideal 


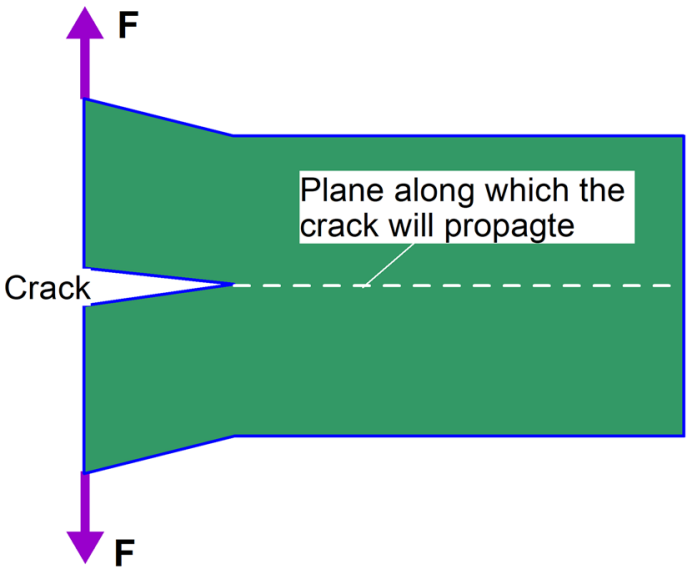

(a)

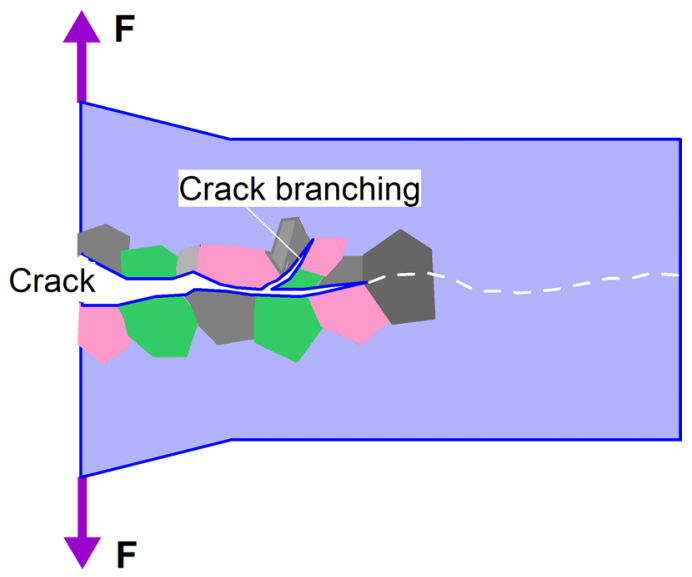

(b)

Fig. 2 Diagram of $\gamma$ measurement of single crystals (a) and $w_{\mathrm{f}}$ measurement of ordinary rock specimens (b)

brittle material, (b) fracture model of a quasi-brittle elastoplastic fracture, and (c) fracture model of a brittle material with crack meandering and branching. For the first model only specific surface energy $\gamma$ exists, while the other energy components used with plastic deformation, friction, etc. are zero, i.e.,

$w_{\mathrm{f}}=\gamma$ (for linear elastic brittle fracture)

For the model of quasi-brittle elastic-plastic fracture, the specific fracture energy is

$w_{\mathrm{f}}=\gamma+\gamma_{\mathrm{p}}$ (for quasi-brittle elastoplastic fracture)

where $\gamma_{\mathrm{p}}\left[\mathrm{J} / \mathrm{m}^{2}\right]$ is the energy dissipated in plastic deformation. For the model of brittle material with crack meandering and branching, the specific fracture energy is, assuming a polycrystalline material made of one mineral and with equally straight grain boundaries

$w_{\mathrm{f}}=\gamma \frac{A}{A_{0}}$ (for a brittle material with crack meandering and branching)

(Johansson and Persson 1970; Persson et al. 1994; Zhang 2016), possibly involving flow during blasting. In most cases of rock fracture, a fracture process zone, analogous to the plastic zone in metals (Labuz et al. 1985), appears surrounding the tip of the crack. Figure 2 illustrates this fracture process zone in mode I fracture. Such a fracture process zone in rock material was initially found and investigated in 1970-80's (e.g. Friedman et al. 1972; Hoagland et al. 1973; Ouchterlony 1982; Labuz et al. 1985; Atkinson 1987).

The fracture process zone is composed of numerous microcracks created by highly concentrated stresses. The energy used in creating the fracture process zone per nominal area $A_{\mathrm{o}}$ can be expressed by $\gamma_{\mathrm{fp}}\left[\mathrm{J} / \mathrm{m}^{2}\right]$, similar to $\gamma_{\mathrm{p}}$ in elastoplastic fracture. Considering other mechanisms of energy dissipation, the specific fracture energy can be described by where $A\left[\mathrm{~m}^{2}\right]$ is total true area of main crack and branching cracks in one side of the main crack, and $A_{0}\left[\mathrm{~m}^{2}\right]$ is the projected or nominal area of one side of the main crack.

Xia (2006), taking earthquake as an example, divided $G_{\mathrm{c}}$, into three parts, namely surface energy, frictional fracture energy, and the damage zone energy. In rock fracture, plastic deformation as occurring in metals is seldom observed, but it may appear in some cases such as percussive drilling, blasting, and deep hole drilling. In the percussive drilling the rock beneath a button in a drill bit is highly compacted (e.g. Xu and Yu 1984; Zhang 2016); in rock blasting the rock in the walls of blastholes are shattered by shock waves $w_{\mathrm{f}}=\gamma \frac{A}{A_{\mathrm{o}}}+\gamma_{\mathrm{fp}}+\gamma_{\mathrm{o}}$

where $\gamma_{o}\left[\mathrm{~J} / \mathrm{m}^{2}\right]$ denotes energy used in intergranular displacement, friction, phase transformation, strain corrosion and other unknown energies, evaluated per nominal area. Other parameters have the same meaning as before. Equation (6) is a general description to rock fracture energy under any loading conditions including static and dynamic loading conditions and mode I, II and III cracks. On crack branching, Moavenzadeh and Kuguel (1969) found that concrete specimens exhibited side cracks (those side cracks were due 
Fig. 3 Rock fracture model under static loading (upper) and dynamic loading (lower). The fracture process zone and cracks are not in scale
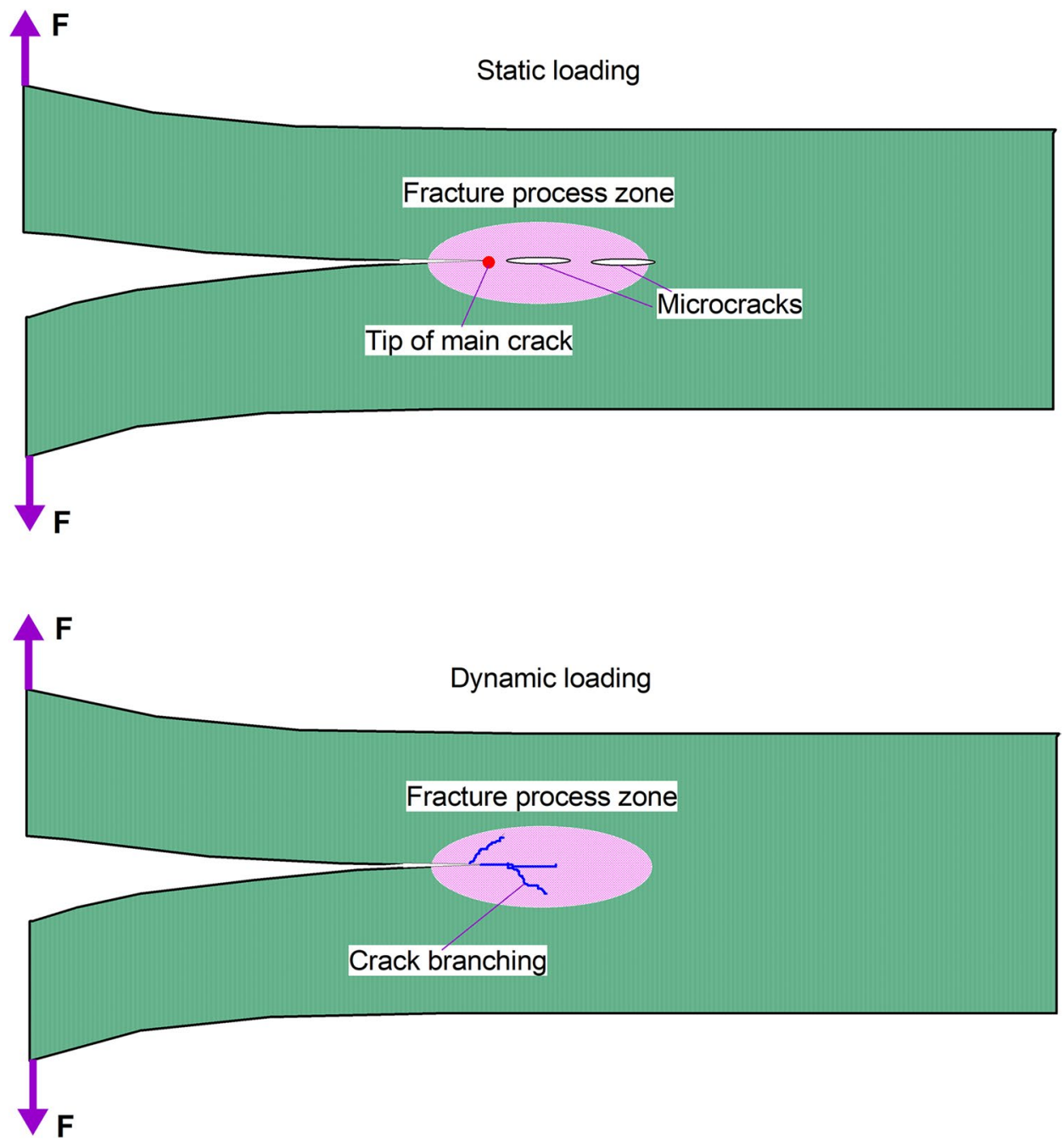

to the aggregates, so they were not same as branching cracks in rock fracture under dynamic loads), but that cement and mortar specimens did not. They found this side crack area in a specimen was about 20 times the nominal cross-sectional area of the specimen (Fig. 3).

\section{Specific Surface Energy $\gamma$ of Single Crystals}

\subsection{The $\gamma$ Measured from Single Crystals}

A crystal is a natural solid mineral whose constituents such as atoms, molecules, or ions are arranged in a highly ordered microscopic structure, forming a crystal lattice that extends in all directions. Many rocks are composed of a single crystal or multiple crystals (such as calcite and quartzite) and other minerals. In the methods for measuring the $\gamma$ of a single crystal using mechanical loading, the single crystal is cut to the shape of a rectangular bar and a long flat crack is introduced into the bar along a cleavage plane (e.g. Gilman 1960; Brace and Walsh 1962). For crystals with good cleavage this is a cleavage crack. For instance, the surfaces of the cracks produced in quartz were mirror smooth and probably did not deviate more than a few degrees from the desired plane (Brace and Walsh 1962). Therefore, it is important to achieve a cleavage in determining the $\gamma$ of a crystal by mechanical loading method. Table 1 summarizes the results of the measured $\gamma$ from a number of single crystals by using different cleavage methods and accurate surface area measurement. It can be found that the $\gamma$ of calcite varies from 0.23 to $0.35 \mathrm{~J} / \mathrm{m}^{2}$, and that of quartz does from 0.41 to $1.03 \mathrm{~J} / \mathrm{m}^{2}$. Note that as the $\gamma$ of a single crystal is measured, the nominal surface area of the plane along which the crystal is separated is usually used and the measurement of the area was performed, e.g. by a micrometer (Gilman 1960). The $\gamma$ values of crystals $\mathrm{LiF}$ (100), $\mathrm{CaF}_{2}$ (111), $\mathrm{BaF}_{2}$ (111), $\mathrm{Zn}$ (0001), GaAs (110) and glass are all smaller than $0.86 \mathrm{~J} / \mathrm{m}^{2}$. The crystals with an $\gamma>1.1 \mathrm{~J} / \mathrm{m}^{2}$ are $\mathrm{MgO}$ (100), Si (111), Si (110), GaP (110), mica and Orthoclase (001), and the maximum surface 
Table 1 Specific surface energy $\gamma$ of single crystals

\begin{tabular}{|c|c|c|c|c|c|c|c|}
\hline Test method & Crystal & $\gamma\left(\mathrm{J} / \mathrm{m}^{2}\right)$ & $\begin{array}{l}\text { Specimen } \\
L(\mathrm{~mm})\end{array}$ & $\begin{array}{l}\text { Specimen } \\
H(\mathrm{~mm})\end{array}$ & $\begin{array}{l}\text { Specimen } \\
W(\mathrm{~mm})\end{array}$ & Note & References \\
\hline OGC & $\mathrm{CaCO}_{3}(1011)$ & 0.35 & 40 & $3-4$ & 16 & Room temp & Santhanam and Gupta (1968) \\
\hline OGC & $\mathrm{CaCO}_{3}(10 \overline{1} 0)$ & 0.23 & $20-60$ & $20-60$ & $2-6$ & $-196^{\circ} \mathrm{C}$ & Gilman (1960) \\
\hline OGC & Quartz $(11 \overline{2} 0)$ & 0.76 & $14-30$ & $7-15$ & $6-15$ & Room temp & Brace and Walsh (1962) \\
\hline OGC & Quartz $(10 \overline{1} 1)$ & 0.41 & $14-30$ & $7-15$ & $6-15$ & Room temp & Brace and Walsh (1962) \\
\hline OGC & Quartz ( $(\overline{1} 010)$ & 0.5 & $14-30$ & $7-15$ & $6-15$ & Room temp & Brace and Walsh (1962) \\
\hline OGC & 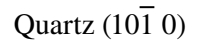 & 1.03 & $14-30$ & $7-15$ & $6-15$ & Room temp & Brace and Walsh (1962) \\
\hline OGC & $\operatorname{LiF}(100)$ & 0.34 & $20-60$ & $20-60$ & $2-6$ & $-196^{\circ} \mathrm{C}$ & Gilman (1960) \\
\hline OGC & $\mathrm{CaF}_{2}(111)$ & 0.45 & $20-60$ & $20-60$ & $2-6$ & $-196{ }^{\circ} \mathrm{C}$ & Gilman (1960) \\
\hline OGC & $\mathrm{BaF}_{2}(111)$ & 0.28 & $20-60$ & $20-60$ & $2-6$ & $-196^{\circ} \mathrm{C}$ & Gilman (1960) \\
\hline OGC & $\mathrm{Zn}(0001)$ & 0.11 & $20-60$ & $20-60$ & $2-6$ & $-196{ }^{\circ} \mathrm{C}$ & Gilman (1960) \\
\hline OGC & $\mathrm{MgO}(100)$ & 1.20 & $20-60$ & $20-60$ & $2-6$ & $-196^{\circ} \mathrm{C}$ & Gilman (1960) \\
\hline OGC & Si (111) & 1.24 & $20-60$ & $20-60$ & $2-6$ & $-196^{\circ} \mathrm{C}$ & Gilman (1960) \\
\hline SD & Si (111) & 1.14 & 15 & 2 & 5 & $20^{\circ} \mathrm{C}$ & Messmer and Bilello (1981) \\
\hline SD & Si (110) & 1.90 & 15 & 2 & 5 & $20^{\circ} \mathrm{C}$ & Messmer and Bilello (1981) \\
\hline $\mathrm{OC}$ & Mica & 1.50 & 50 & $0.2-0.5$ & 20 & Room temp & Obreimoff (1930) \\
\hline Tension & Glass & 0.54 & 51 & $0.05-0.25 / \mathrm{d}$ & & $15^{\circ} \mathrm{C}$ & Griffith (1921) \\
\hline SD & GaAs (110) & 0.86 & 15 & 2 & 5 & $20^{\circ} \mathrm{C}$ & Messmer and Bilello (1981) \\
\hline SD & GaP (110) & 1.90 & 15 & 2 & 5 & $20^{\circ} \mathrm{C}$ & Messmer and Bilello (1981) \\
\hline OGC & Orthoclase (001) & 7.77 & $14-30$ & $7-15$ & $6-15$ & Room temp & Brace and Walsh (1962) \\
\hline
\end{tabular}

$L, H$ and $W$ are the length, height (thickness) and width of specimen, respectively

$O C$ Obreimoff cleavage, $O G C$ Obreimoff-Gilman cleavage, $S D$ spark discharge with mechanical cleavage

energy is $7.77 \mathrm{~J} / \mathrm{m}^{2}$ from Orthoclase (001). Brace \& Walsh (1962) explained that: (1) the cracks in the orthoclase specimens were propagating not on one but on several cleavage planes. (2) The cleavage process in natural orthoclase may be augmented by factors such as plastic flow or a blocking effect on crack propagation by submicroscopic domains of soda-rich feldspar. These are two main reasons resulting in a $\gamma$ value of $7.77 \mathrm{~J} / \mathrm{m}^{2}$, a figure which is undoubtedly too high. Except for the $\gamma$ value of Orthoclase, the $\gamma$ values of other crystals in Table 1 are shown in Fig. 4 where both median and average $\gamma$ values are given.

Notice that there are other methods for measuring $\gamma$. For example, Atkinson \& Avdis (1980) used a Vickers indenter (VI) to measure the $\gamma$ values of microcline, galena, spinel and $\mathrm{CaCO}_{3}$, and Field and Freeman (1981) employed a Hertzian indenter to determine the $\gamma$ of diamond. Some measured results from these two methods are close to the cleavage methods (e.g. for $\mathrm{CaCO}_{3}$ ) but the rest are not. One reason is that for the two indenter methods, the specific surface energy is determined by the crack length, indentation force and other parameters, without exact measurement of total fracture surface area. Therefore, their $\gamma$ data are not included in this study. Even though a cleavage method is used, an incorrect result may be obtained. For example, Hartley \& Wilshaw (1973) used Obreimoff-Gilman cleavage method and got a much higher $\gamma$ value of quartz crystal, $11.5 \mathrm{~J} / \mathrm{m}^{2}$ due to the incorrect uncracked length ahead of the cleavage crack. Their $\gamma$ data is not included in Table 1 either. Specific surface energy of a material can be also determined by contact angle measurements (Zgura et al. 2013; Suzuki et al. 2014). The surface energies of fused quartz plates $(23 \times 32 \mathrm{~mm})$ pre-treated at $240{ }^{\circ} \mathrm{C}$ and $1000{ }^{\circ} \mathrm{C}$ were found to be $0.07 \mathrm{~J} / \mathrm{m}^{2}$ and $0.06 \mathrm{~J} / \mathrm{m}^{2}$ respectively (Suzuki et al. 2014), while the surface energy of Synthetic quartz varied from 0.03 to $0.07 \mathrm{~J} / \mathrm{m}^{2}$ (Zgura et al. 2013). Considering the contact angle method does not use mechanical loading, their results are not included in Table 1.

Only the $\gamma$ values measured by cleavage methods are included in Fig. 4. In a brief summary, the measured average $\gamma$ value is $0.29 \mathrm{~J} / \mathrm{m}^{2}$ for crystal calcite, $0.59 \mathrm{~J} / \mathrm{m}^{2}$ for quartz (under room temperature), and $1.43 \mathrm{~J} / \mathrm{m}^{2}$ for $\mathrm{Si}$. The average $\gamma$ value of all crystals excluding orthoclase in Table 1 is $0.77 \mathrm{~J} / \mathrm{m}^{2}$.

Previous studies mentioned above indicated that many factors influence the surface energy of a crystal. These will be discussed in the following. 
Fig. 4 Box-Whisker plot for specific surface energy $\gamma$ of crystals. The specific meaning of the box diagram: the upper and lower vertices of each box plot represent the maximum and minimum values among the surface energy data, respectively; the upper and lower sides of each box represent the lower limit of the top quartile and the upper limit of the bottom quartile of the surface energy data; the line in the middle of each box represents the median (50th percentile) value of the dataset for surface energy; the small square in each box represents the arithmetic average (mean) of the surface energy data marked in the box plot

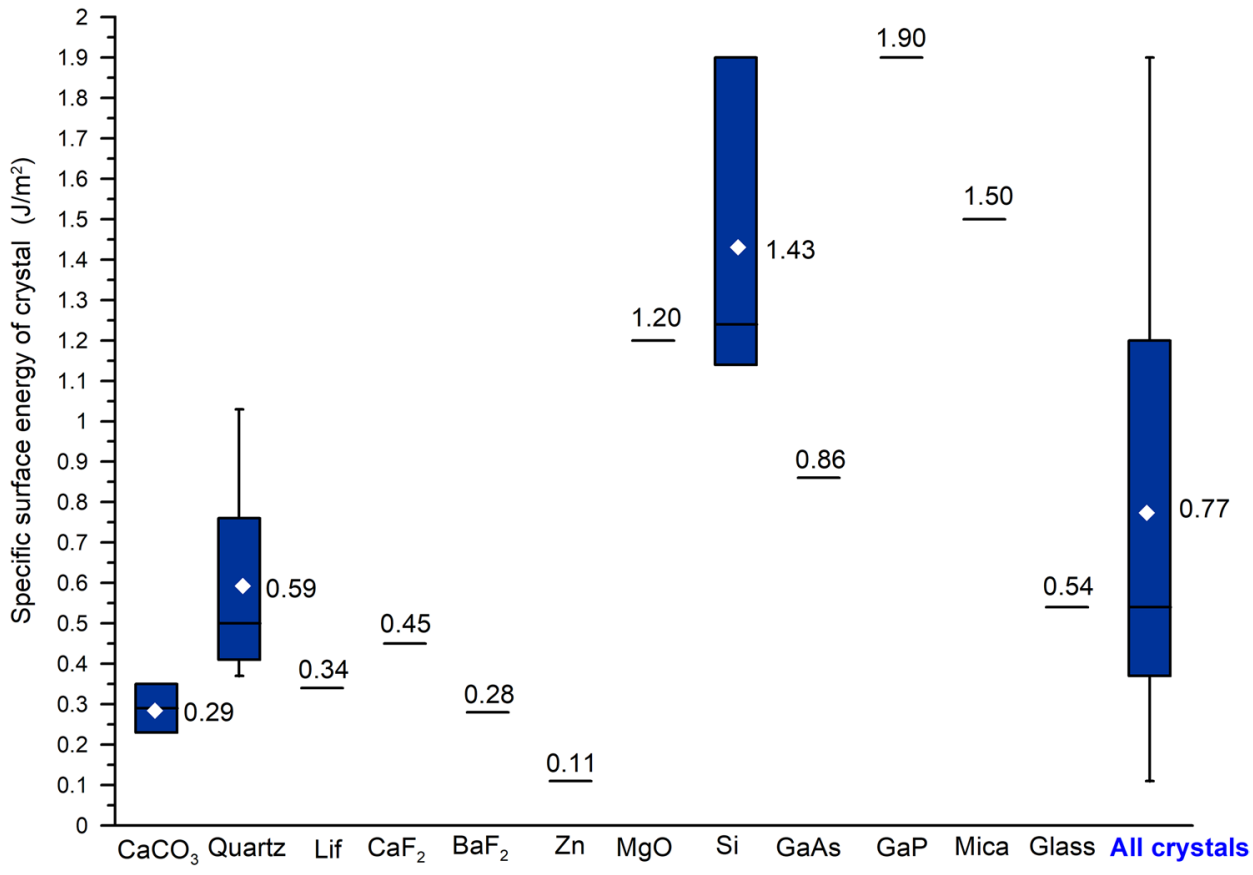

\subsection{Factors Influencing Specific Surface Energy of Crystals}

\subsubsection{Loading Rate}

It was found that the $\gamma$ of glass specimens increases with an increasing loading rate (Roesler 1956) or crack propagation velocity (Shand 1961). Interestingly, later experiments showed that rock fracture toughness, which is related to fracture energy, increased with an increasing loading rate, too (e.g. Zhang et al. 1999, 2000, 2001; Dai et al. 2010; Dai and Xia 2013).

\subsubsection{Sizes of Crystals and Specimen Fabrication}

The sizes of crystal specimens for determining $\gamma$ are indicated in Table 1, showing that the sizes of the crystal specimens are not much smaller than the sizes of the specimens used for testing rock strengths and fracture toughness in laboratory.

The crystal specimens were fabricated by a low speed diamond saw in combination with mechanical and chemical polishing to remove the associated cutting damage (Gilman 1960; Santhanam and Gupta 1968; Messmer and Bilello 1981). The specimens from Santhanam and Gupta (1968) were polished first mechanically and then chemically in a mixture of alcohol and concentrated $\mathrm{HC} 1$, followed by a thorough rinse with water and alcohol, and finally dried with an air blast. Two holes at the location of pivot bearing in Fig. 1, each $1 \mathrm{~mm}$ in diameter, were drilled at a specified distance from one end of the crystal by a high-speed drill press. Before initiating the desired crack, each crystal was annealed in vacuum at $400{ }^{\circ} \mathrm{C}$ for $2 \mathrm{~h}$ and furnace cooled. A small crack was initiated by pressing a hardened steel wedge in a jig. The fractured surfaces of the crystal were examined microscopically. Note that while the annealing of crystals for initiating the desired crack at $400{ }^{\circ} \mathrm{C}$ may not affect the surface fracture energy of the quartz crystals, this temperature should not be used for annealing a rock specimen since $400{ }^{\circ} \mathrm{C}$ could cause thermal damage in the rock. This temperature is high enough to create thermal cracks in many rocks which significantly decreases their strength and toughness (e.g. Heuze 1983; Homand-Etienne and Houpert 1989; Zhang 2016).

\subsubsection{Initial Crack}

To determine $\gamma$, a designed crack is usually initiated in the specimen before the test for $\gamma$. In Gilman's method a designed crack is made with a jig (Gilman 1960; Santhanam and Gupta 1968). However, to measure rock fracture toughness by some methods such as Short Rod specimen (Ouchterlony 1988) and chevron notched Brazilian disc (Fowell 1995), an initial crack is formed during the fracture toughness tests. 


\subsubsection{Temperature}

The measurements (Gilman 1960) indicated that $\gamma$ increased rapidly with increasing temperature for the metallic crystals, $\mathrm{Zn}$ and $\mathrm{Fe}(3 \% \mathrm{Si})$, and the increase was related with increasing plastic flow in these crystals. Therefore, doing measurement at temperatures down to- $-196{ }^{\circ} \mathrm{C}$ was made to avoid plastic flow of the materials (Brace and Walsh 1962). In contrast, the effective surface energy of $\mathrm{LiF}$ and $\mathrm{MgO}$ was only moderately dependent on temperature, indicating that some metallic crystals are sensitive to temperature, but fluorides and oxides not.

\subsubsection{Confining Pressure}

The twinning experiments for single calcite crystals (Turner et al. 1954) showed that at room temperature, the plastic deformation of the crystals was visible as a shortening or elongation of the crystals between 2 and 20\%. Such large plastic deformation is possibly related to the high confining pressure. In addition to single crystals, it will be found later that the confining pressure also affects fracture energy of the rock specimens.

\subsubsection{Composition and Environment Effect}

Fracture of single crystal quartz and glasses was strongly influenced by water, aqueous solutes, and organic solvents (Parks 1984). A small amount of cadmium (0.1\%) markedly increased the cleavage surface energy of zinc (Gilman (1960), indicating that chemical environment affected the specific surface energy. This effect explains why chemical additions play an important role in mineral processing. The environment condition also has a large impact on the $\gamma$ values in Table 1. For example, Shand (1961) reported that the $\gamma$ of glass in vacuum was nearly 15 times greater than that in air at very low crack propagation velocity.

\subsubsection{Testing Methods}

The $\gamma$ values of silicate glass from conical indentation (Roesler 1956) were found to be higher than those by the cantilever technique, probably due to the glass's compaction by the indenter, and more irreversible inelastic deformation in the sample (Lowrison 1974). Similar results from Atkinson and Avdis (1980) and Field and Freeman (1981) have been mentioned in Sect. 3.1. In brief, the specific surface energies of crystals depend on measurement method.

From now on, different rock specimens will be involved, as follows: (1) for uniaxial tensile strength (UTS) or uniaxial

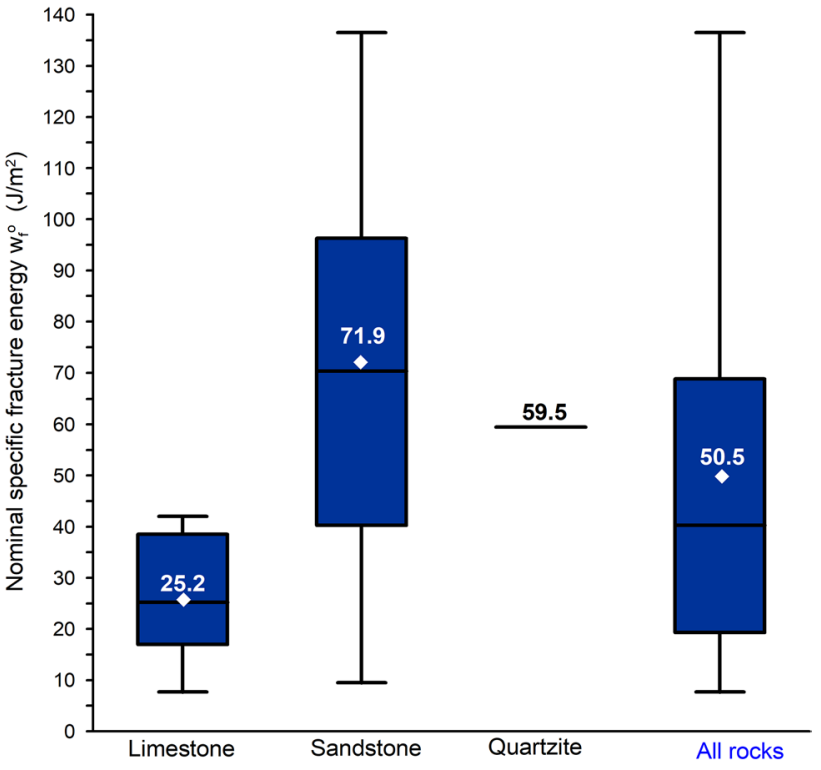

Fig. 5 Box-Whisker plot for nominal specific fracture energy $w_{\mathrm{f}}^{\mathrm{o}}$ of rocks under room temperature and uniaxial loading conditions (based on the data in Table 2). The specific meaning of Box-Whisker plot is explained in Fig. 4

compression strength (UCS) tests cylindrical samples are normally used. For the UTS tests parallelepiped or dogboned ones are occasionally employed, while an indirect testing method, the Brazilian one, is often used. (2) For fracture energy tests regular specimens with a starter crack ahead of a starter notch are normally used, e.g. the DCB (double cantilever beam) and OGC (Obreimoff-Gilman cleavage) specimen. Both load and displacement need to be measured in order to calculate the work of the load (external forces). (3) For fracture toughness tests only standardized regular specimens with starter notches and made-form rock cores are used (Ouchterlony 1988; Fowell 1995). (4) Irregularly formed specimens or lumps are mainly used to determine the comminution energy in (compressive) crushing and grinding.

\section{Specific Fracture Energy Measured by Methods for Specific Surface Energy of Crystals}

The results presented in this section come from the methods for determining the $\gamma$ of crystals. The results from Perkins and Bartlet (1963) and Perkins and Krech (1966) were obtained with a starter crack that was introduced in $3 \mathrm{~PB}$ rock specimens before the test for fracture energy, while the results from Friedman et al. (1972) were determined by notched beams. 
Table 2 Nominal specific fracture energy $w_{\mathrm{f}}^{\mathrm{o}}$ of rocks using the method for specific surface energy in laboratory at room temperature and zero confining pressure

\begin{tabular}{|c|c|c|c|c|c|}
\hline Test method & Rock & $w_{f}^{o}\left(\mathrm{~J} / \mathrm{m}^{2}\right)$ & $w_{f}^{*}\left(\mathrm{~J} / \mathrm{m}^{2}\right)$ & $w_{f}\left(\mathrm{~J} / \mathrm{m}^{2}\right)$ & Reference \\
\hline OGC & Carthage limestone & 38.5 & & 3.5 & Perkins and Bartlet (1963) \\
\hline OGC & Lueders limestone & 19.3 & & 1.8 & Perkins and Bartlet (1963) \\
\hline OGC & Indiana limestone & 42.0 & & 3.8 & Perkins and Bartlet (1963) \\
\hline OGC & Austin limestone & 7.7 & & 0.7 & Perkins and Bartlet (1963) \\
\hline OGC & Arizona sandstone & 136.5 & & 12.4 & Perkins and Bartlet (1963) \\
\hline OGC & Milsap sandstone & 113.8 & & 10.3 & Perkins and Bartlet (1963) \\
\hline OGC & Colorado sandstone & 96.3 & & 8.8 & Perkins and Bartlet (1963) \\
\hline OGC & Woodbine sandstone & 9.5 & & 0.9 & Perkins and Bartlet (1963) \\
\hline OGC & Torpedo sandstone & 61.3 & & 5.6 & Perkins and Bartlet (1963) \\
\hline OGC & Boise sandstone & 40.3 & & 3.7 & Perkins and Bartlet (1963) \\
\hline OGC & Lueders limestone (oil base fluid) & 17.0 & & 1.5 & Perkins and Krech (1966) \\
\hline OGC & Carthage limestone (oil base fluid) & 35.0 & & 3.2 & Perkins and Krech (1966) \\
\hline OGC & Tennessee sandstone (oil base fluid) & 88.0 & & 8.0 & Perkins and Krech (1966) \\
\hline NB & Lueders limestone (5) & 15.7 & 10.9 & 1.4 & Friedman et al. (1972) \\
\hline NB & Indiana limestone (5) & 27.5 & 17.5 & 2.5 & Friedman et al. (1972) \\
\hline NB & Coconino sandstone (4) & 32.8 & 24.8 & 3.0 & Friedman et al. (1972) \\
\hline NB & Tennessee sandstone & 68.8 & 38.1 & 6.3 & Friedman et al. (1972) \\
\hline \multirow[t]{2}{*}{ NB } & Chilhowee quartzite (4) & 59.5 & 49.8 & 5.4 & Friedman et al. (1972) \\
\hline & Average & 50.5 & & 4.6 & \\
\hline
\end{tabular}

The specific fracture energy is estimated by $w_{\mathrm{f}}=w_{\mathrm{f}}^{0} / 11 ; w_{\mathrm{f}}^{*}$ is the specific fracture energy measured at small magnitude by Friedman et al (1972) $N B$ notched beam; the numbers in the brackets are the quantity of rock speciemns (see also Tables 6,11 and 13)

\subsection{Specific Fracture Energy of Rocks}

The specific fracture energy of a rock specimen is denoted $w_{\mathrm{f}}$ and the corresponding fracture surface area should be the true fracture surface area, like for $\gamma$. When the nominal fracture surface area is used, the resulting specific fracture energy is denoted $w_{\mathrm{f}}^{\mathrm{o}}$. Summarized $w_{\mathrm{f}}^{\mathrm{o}}$ values of various rocks come from Perkins and Bartlet (1963), Perkins and Krech (1966) and Friedman et al. (1972) and they are presented in Table 2 and Fig. 5. It can be concluded: (1) for sedimentary rocks such as limestone and sandstone, their $w_{\mathrm{f}}^{\mathrm{o}}$ values vary within a large range. (2) For specimens of the same type of rock, the variations are relatively much smaller. (3) The average $w_{\mathrm{f}}^{o}$ of Chilowee quartz specimens is $59.5 \mathrm{~J} / \mathrm{m}^{2}$, about 100 times greater than the average $\gamma\left(=0.59 \mathrm{~J} / \mathrm{m}^{2}\right)$ of the single quartz crystals (Fig. 4 and Table 1). These results indicate that the $w_{\mathrm{f}}^{\mathrm{o}}$ of the rocks tested is one to two magnitudes greater than the $\gamma$ of a quartz crystal. Thus, it is very interesting to investigate the reason why there is such a large difference. Friedman et al. (1972) measured the lengths along the irregular fracture surfaces of the rock specimens at $100 \times$ magnification with the aid of a calibrated eyepiece-micrometer. The cumulative lengths along the irregular surfaces were divided by the nominal lengths to obtain a ratio by which the nominal fracture surface area was corrected. These ranged from 120 to 170 per cent of the nominal fracture surface areas. According to the corrected surface areas, the specific fracture energy values of those rock specimens were determined (Friedman et al. 1972) and listed in the column for $w_{\mathrm{f}}^{*}$ in Table 2 . Since the magnification $100 \times$ is not large enough to determine the true fracture surface area, the $w_{\mathrm{f}}^{*}$ values in Table 2 must be smaller than the true $w_{\mathrm{f}}$ values. Accordingly, the true $w_{\mathrm{f}}$ values is estimated by $w_{\mathrm{f}}=w_{\mathrm{f}}^{0} / 11$, which is explained in Sect. 12.1.

\subsection{Factors Influencing the Nominal Specific Fracture Energy}

\subsubsection{Physical and Chemical Effect}

Orowan (1948), Irwin (1956) and Wiederhorn (1966) found that the measured specific fracture energy of many solids, was affected by irreversible effects occurring at the crack tip. These effects may be a physical effect or a chemical one such as phase transformation or strain corrosion due to the adsorption of vapours at the crack tip. 


\subsubsection{Loading Rate}

Baker and Preston (1946), Charles (1958), Wiederhorn (1966), and Gillis and Gilman (1964) reported that loading rate had a marked effect on the fracture of soda-lime glass, and Fuerstenau and Abouzeid (2002) showed that the fracture energy of soda-lime glass increased with an increasing loading rate.

\subsubsection{Crack Branching}

Crack branching, also called crack forking or bifurcation, was found in glass by Schardin (1959) and in rocks by Bieniawski (1968). Zhang et al. (1999, 2000, 2001) reported that crack branching was correlated with dynamic loads and high loading rates. Since crack branching creates additional fracture surface area, the specific fracture energy $w_{\mathrm{f}}$ must be greater than the nominal specific fracture energy $w_{\mathrm{f}}^{\mathrm{o}}$ when crack branching appears.

\subsubsection{Specimen Size and Measurement Method}

In the notched beam tests by Friedman et al. (1972), the specimens were $14 \mathrm{~mm}$ thick, $25 \mathrm{~mm}$ wide and long enough to be supported and loaded in the parallel-beam device along two outside line loads spaced $102 \mathrm{~mm}$ apart. In the tests by Perkins and Bartlett (1963), similar to Gilman's method, the cleavage rock specimens were $76 \mathrm{~mm}$ or $51 \mathrm{~mm}$ thick, and $152 \mathrm{~mm}$ or $102 \mathrm{~mm}$ wide respectively, with an unknown length. Table 2 gives the $w_{\mathrm{f}}^{\mathrm{o}}$ values of Lueders limestone and Indiana limestone as 19.3 and $42.0 \mathrm{~J} / \mathrm{m}^{2}$ from Perkins and Bartlett (1963), while the corresponding values of these two rocks are 15.7 and $27.5 \mathrm{~J} / \mathrm{m}^{2}$ from Friedman et al. (1972), respectively. The different $w_{\mathrm{f}}^{\mathrm{o}}$ values of the same rock from two different references may have several reasons. Two reasons are the different specimen sizes and the different measurement methods used in these two studies.

\subsubsection{Starter Crack or Notch}

In the notched beam (see Fig. 1) tests by Friedman et al. (1972), the notches were produced by a saw cut $(0.9-\mathrm{mm}$ blade) that created a notch width of $1.5 \mathrm{~mm}$ and a U-shaped profile. Friedman et al. (1972) found that the $w_{\mathrm{f}}^{\mathrm{o}}$ decreased markedly with increasing notch depth until the depth exceeded about 35 per cent of the beam thickness and then remained essentially constant for greater depths. Moreover, fracture at shallow notch depths was catastrophic, became semi-stable with increasing depth and was stable only when the depth exceeded about 25 per cent of the thickness. It was not stated whether a starter crack was or not made after the notch was produced by saw cutting. In the tests by Nakayama (1965) using notched beam specimens, vertical cracks at the centres of the glass specimens were introduced by the following thermal shock technique: (1) cutting scratch was made with a glass cutter. (2) The specimen was heated to about $100{ }^{\circ} \mathrm{C}$ in a drying oven and then the cut portion was chilled by contact with a wet cloth. The depth of the cutting scratch was extended to about 3-5 mm. (3) The cut portion at the surface of the specimen was intermittently flash-heated by a gas flame. By this process, the pre-existing crack was extended to any required depth. Such a notch is similar to the chevron notches used in rock fracture toughness testing (Ouchterlony 1988).

Hoagland et al. (1973) employed double-cantilever-beam specimens with a $0.4-\mathrm{mm}$-wide slot by saw cut to facilitate starting a crack having the desired orientation relative to the bedding plane. Prior to testing, the specimens were baked at $110{ }^{\circ} \mathrm{C}$ to minimize the possible effects of differences in moisture content from one specimen to another. In a brief summary, the experimental results mentioned above are not sufficiently many to conclude whether a premade-starter crack used in Gilman's cleavage method affects or does not affect the measured fracture energy. To determine this, it is necessary to do new tests employing two different versions of rock specimen type, one type with sharp starter cracks and the other type with a blunt tipped notch.

\subsubsection{Temperature}

Temperature affects fracture energy of a rock considerably. The test result from Hoagland et al. (1973) in Table 3 indicates that the $w_{\mathrm{f}}^{\mathrm{o}}$ of Salem limestone at $-196^{\circ} \mathrm{C}$ is $0.85 \times w_{\mathrm{f}}^{\mathrm{o}}$ for the same rock at $22{ }^{\circ} \mathrm{C}$, while the $w_{\mathrm{f}}^{\mathrm{o}}$ of Berea sandstone at $-196{ }^{\circ} \mathrm{C}$ is about $0.50 \times w_{\mathrm{f}}^{0}$ at $22^{\circ} \mathrm{C}$. However, the effect of temperature on rock fracture energy is not always the same, in particular under dynamic loading conditions (e.g. Zhang et al. 2001; Zhang 2016).

\subsubsection{Confining Pressure}

Measurements by Perkins and Krech (1966) on side-notched DCB specimens indicated that the $w_{\mathrm{f}}^{\mathrm{o}}$ values of three rocks were much higher under $20 \mathrm{MPa}$ confining pressure than those under zero confining pressure, see Tables 2 and 3 and Fig. 6. An interesting result shown in Fig. 6 is that under zero confining pressure Tennessee sandstone has the largest fracture energy, while Lueders limestone has the smallest one. However, under $20 \mathrm{MPa}$ confining pressure, Lueders limestone has the largest fracture energy, while Carthage limestone has the smallest one. In other words, the effect of confining pressure on $w_{\mathrm{f}}^{\mathrm{o}}$ is large but not systematic. For instance, under $20 \mathrm{MPa}$ confining pressure, the $w_{\mathrm{f}}^{\mathrm{o}}$ of Lueders limestone is 12.9 times larger than that under zero confining pressure. Thus, it is necessary to further investigate the effect of confining pressure on the fracture energy of rock. 
Table 3 Nominal specific fracture energy $w_{\mathrm{f}}^{\mathrm{o}}$ of rock specimens with either confining pressure or bedding at different orientations tested in laboratory

\begin{tabular}{lllll}
\hline Test method & Type of rock & $w_{\mathrm{f}}^{\mathrm{o}}\left(\mathrm{J} / \mathrm{m}^{2}\right)$ & Confinement and bedding & References \\
\hline GC & Lueders limestone & 219 & $20 \mathrm{MPa}$ & Perkins and Krech (1966) \\
GC & Carthage limestone & 159 & $20 \mathrm{MPa}$ & Perkins and Krech (1966) \\
GC & Tennes $\gamma$ sandstone & 201 & $20 \mathrm{MPa}$ & Perkins and Krech (1966) \\
NB & Salem limestone & $50-75$ & $A Y$ & Hoagland et al. (1973) \\
NB & Salem limestone & $195-230$ & $B X$ & Hoagland et al. (1973) \\
NB & Salem limestone & $90-110$ & $C Z$ & Hoagland et al. (1973) \\
NB & Salem limestone & 85 & $-196^{\circ} \mathrm{C} ; C Z$ & Hoagland et al. (1973) \\
NB & Salem limestone & 40 & Wet, $-196{ }^{\circ} \mathrm{C} ; C Z$ & Hoagland et al. (1973) \\
NB & Salem limestone & $50-230$ & Different directions to bedding & Hoagland et al. (1973) \\
NB & Berea sandstone & $600-750$ & $B X$ & Hoagland et al. (1973) \\
NB & Berea sandstone & $1120-1580$ & $C Z$ & Hoagland et al. (1973) \\
NB & Berea sandstone & $465-520$ & $A Y$ & Hoagland et al. (1973) \\
NB & Berea sandstone & $150-270$ & $-196{ }^{\circ} \mathrm{C} ; A Y$ & Hoagland et al. (1973) \\
NB & Berea sandstone & 300 & Wet; $-196{ }^{\circ} \mathrm{C} ; B X$ & Hoagland et al. (1973) \\
\hline
\end{tabular}

If not specified, the measurement was carried out at room temperature, dry condition and zero confining pressure

The letters $A, B$, and $C$ denote orientation of bedding planes and $X, Y$, and $Z$ denote crack propagation direction in a coordinate system of $X, Y$, and $Z$. Bedding planes $A, B$ and $C$ are parallel to plane $X Y, X Z$ and $Y Z$ respectively. For example, $A Y$ means that the bedding plane is parallel to plane $X Y$ and crack propagation is in $Y$ direction

GC Gilman cleavage

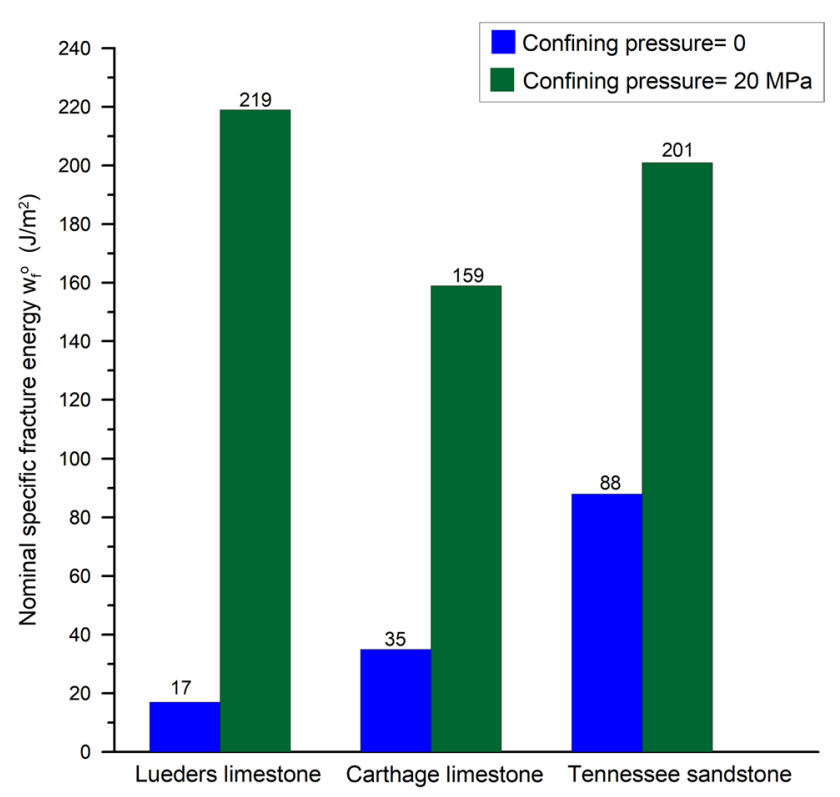

Fig. 6 Nominal specific fracture energy $w_{\mathrm{f}}^{\mathrm{o}}$ of three rocks at zero and $20 \mathrm{MPa}$ confining pressure (based on the data from Perkins and Krech (1966))

\subsubsection{Intergranular Displacement}

According to X-ray diffraction studies of changes in residual strain adjacent to tensile fractures in sandstone and also from thin-section studies of strained specimens, Friedman et al. (1972) found that intergranular displacements took place in a region as much as $5 \mathrm{~mm}$ wide on each side of the fractures. They concluded that such intergranular displacements were the main reason for the big discrepancy between the nominal specific fracture energy of a rock specimen and that of a crystal.

\subsubsection{Measurement of Fracture Surface Area}

Friedman et al. (1972) found that the true fracture surface area is always larger because the surface is irregular. As mentioned in Sect. 4.1, the small discrepancy between the corrected area and the nominal one they found is probably due to that the 100 magnification used by them is not large enough. The detailed measurements of the surface topography at magnification up to 2000 indicated that the total surface area was about 11 times the projected area of fracture (Hoagland et al. 1973). Interestingly, in the experiments with concrete, Moavenzadeh and Kuguel (1969) found that the true fracture surface area was about 12 times the nominal (or projected) fracture surface area. In summary, the precision of measuring fracture surface areas influences the values of measured specific fracture energy. By means of modern experimental equipment such as scanning electronic microscope (SEM), profilometer, micro-computed tomography (micro-CT), etc., surface area can be measured with high accuracy. 


\subsubsection{Orientation of Structure}

Orientation of a bedding in one limestone and one sandstone plays an important role in their $w_{\mathrm{f}}^{\mathrm{o}}$ values (Hoagland et al. 1973). For example, as shown in Table 3, under dry condition, the $w_{\mathrm{f}}^{\mathrm{o}}$ of Salem limestone varies from 50 to $230 \mathrm{~J} / \mathrm{m}^{2}$ in different orientations, while that of Berea sandstone varies from 150 to $1580 \mathrm{~J} / \mathrm{m}^{2}$ in different orientations. The latter values differ by a factor of ten due to different orientations.

\subsubsection{Moisture}

Moisture has a certain impact on fracture energy, and the $w_{\mathrm{f}}^{\mathrm{o}}$ values for wet specimens are about 50\% lower than the values for dry Salem limestone (CZ orientation) and dry Berea sandstone (BX) for the same orientation, see Table 3.

\subsection{Comparison of Nominal Specific Fracture Energy $w_{f}^{0}$ and Specific Surface Energy $\gamma$}

On the basis of above description, there are at least two reasons why the $w_{\mathrm{f}}^{\mathrm{o}}$ of a rock specimen is much larger than the $\gamma$ of a single crystal, as follows:

1. In the fracture of a rock specimen, crack meandering occurs, i.e. cracks propagate along a curved path or a path of piecewise straight with different directions rather than a straight path as in the fracture of a single crystal. As a result, true fracture surface area is much larger in the fracture of a rock specimen than that in the fracture of a single crystal.

2. Crack branching or side cracks appears in the fracture of a rock specimen from or close to a fracture surface under dynamic loads, but these have not been found in the fracture of a single crystal.

\section{Specific Fracture Energy from Fracture Toughness Tests Using Standard Methods}

\subsection{Quasi-Static Tests}

Fracture toughness of rock can be measured by different test methods (e.g. Ouchterlony 1982, 1988; Fowell 1995; Wang et al. 2004; Kuruppu et al. 2014; Zhou et al. 2012). In a fracture toughness test, $w_{\mathrm{f}}$ can be determined by Eq. (2) as long as $G_{c}$ is measured on the basis of true surface area. Otherwise, if only nominal fracture surface area rather than true area is available, can the $w_{\mathrm{f}}^{\mathrm{o}}$ of a rock specimen be determined. In Table 4 and Fig. 7 the $w_{\mathrm{f}}^{\mathrm{o}}$ values of 12 rocks were determined via mode I fracture testing under quasi-static loading conditions, and each $w_{\mathrm{f}}^{\mathrm{o}}$ data was an average value of one group tests. Table 4 and Fig. 7 indicate that: (1) the

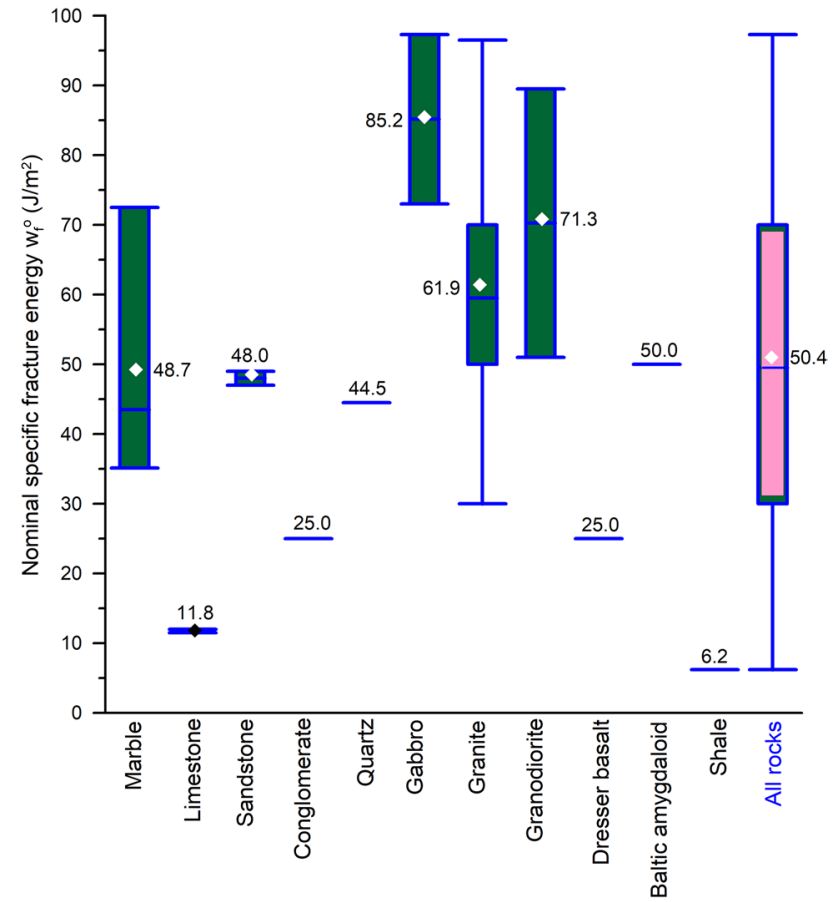

Fig. 7 Box-Whisker plot for nominal specific facture energy $w_{\mathrm{f}}^{\mathrm{o}}$ of various rocks from different testing methods of mode I fracture toughness (based on the data in Table 4 where the source of the data is given). The specific meaning of Box-Whisker plot is explained in Fig. 4

$w_{\mathrm{f}}^{\mathrm{o}}$ values of all rocks are smaller than $100 \mathrm{~J} / \mathrm{m}^{2}$. (2) Different rocks have different $w_{\mathrm{f}}^{\mathrm{o}}$ values. (3) The average $w_{\mathrm{f}}^{\mathrm{o}}$ of all rocks in Table 4 and Fig. 7 is equal to $50.4 \mathrm{~J} / \mathrm{m}^{2}$ which is very close to $50.5 \mathrm{~J} / \mathrm{m}^{2}$, the average $w_{\mathrm{f}}^{\mathrm{o}}$ of all rocks tested by the methods for determining $\gamma$, see Table 2 and Fig. 5 .

Semi-circular bending (SCB) test was used to measure the $w_{\mathrm{f}}^{\mathrm{o}}$ of mix asphalt mixtures under mode I and mode II fracture conditions dealing with three different temperatures at which the specimens were tested (Fakhri et al. 2018a, b). Different fracture modes such as mode I, mode II and mode I/II were realized by changing the distance between two bottom loading support components in the edge-cracked SCB specimen. The average $w_{\mathrm{f}}^{\mathrm{o}}$ of each fracture mode of asphalt specimens is presented in Fig. 8, showing that both fracture mode and temperature have a great impact on the $w_{\mathrm{f}}^{\mathrm{o}}$ values of the asphalt specimens. In particular, the $w_{\mathrm{f}}^{\mathrm{o}}$ of mode I specimens is only $23-31 \%$ of the $w_{\mathrm{f}}^{\mathrm{o}}$ of model II, meaning that mode I fracture is the most energy-efficient method for fracturing the asphalt, compared with either mode II or mode I/II. However, the $w_{\mathrm{f}}^{\mathrm{o}}$ values of the asphalt under mode I at three temperatures are much higher than the $w_{\mathrm{f}}^{\mathrm{o}}$ values of most rocks (even hard rocks like gabbro and granite) in Table 4. The reason for such a high fracture energy of the asphalt is unknown. 
Fig. 8 Nominal specific fracture energy $w_{\mathrm{f}}^{\mathrm{o}}$ of 18 asphalt specimens under mode I, mode II and mode I/II testing conditions involved different temperatures of 5,15 and $25^{\circ} \mathrm{C}$ (based on the data by Fakhri et al. 2018a, b)
Table 4 Nominal specific fracture energy $w_{\mathrm{f}}^{\mathrm{o}}$ of fracture toughness specimens under quasi-static loads

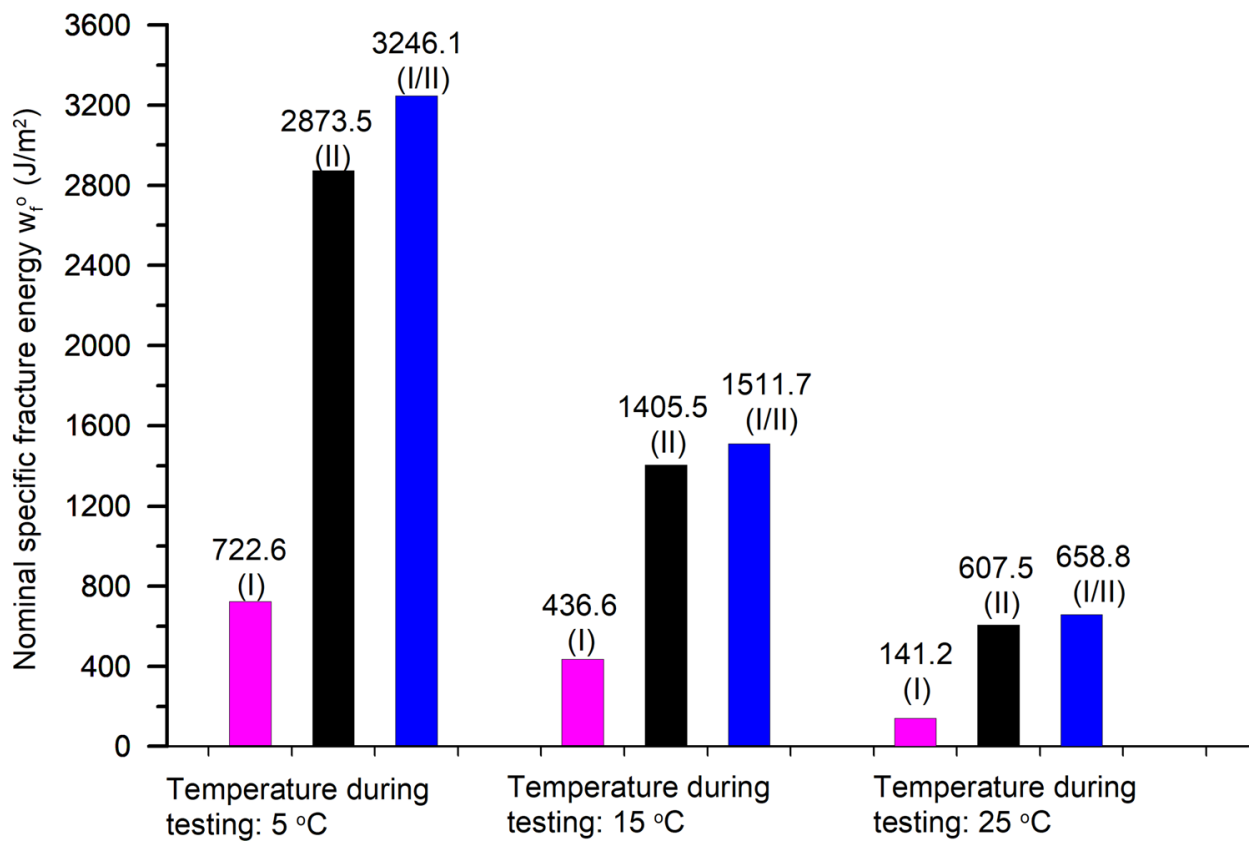

\begin{tabular}{|c|c|c|c|c|c|}
\hline Specimen no & Test method & $w_{\mathrm{f}}^{\mathrm{o}}\left(\mathrm{J} / \mathrm{m}^{2}\right)$ & $w_{\mathrm{f}}\left(\mathrm{J} / \mathrm{m}^{2}\right)$ & Heat-treated & References \\
\hline Shale & SCB & 6.2 & 0.6 & No & Mahanta et al. (2017) \\
\hline Carrara marble & CENBB & 35.1 & 3.2 & No & Cooper (1977) \\
\hline Ekeberg marble & SECRBB & 72.5 & 6.6 & No & Ouchterlony (1980) \\
\hline Lasa marble & CENBB & 41.0 & 3.7 & No & Cooper (1977) \\
\hline Fangshan marble & SR & 46.0 & 4.2 & $200^{\circ} \mathrm{C}$ & Zhang et al. (2001) \\
\hline Holston limestone & CNRBT & 11.5 & 1.0 & No & Krech (1974) \\
\hline Solnhofen limestone & CENBB & 12.0 & 1.1 & No & Cooper (1977) \\
\hline Alpnach sandstone & CENBB & 47.0 & 4.3 & No & Cooper (1977) \\
\hline Val dilliez sandstone & CENBB & 49.0 & 4.5 & No & Cooper (1977) \\
\hline Calumet and Hecla conglomerate & RBT & 25.0 & 2.3 & No & Krech (1974) \\
\hline Sioux quartzite & CNRBT & 44.5 & 4.0 & No & Krech (1974) \\
\hline Fangshan gabbro & SR & 97.3 & 8.8 & No & Zhang et al. (2000) \\
\hline Fangshan gabbro & SR & 73.0 & 6.6 & $600^{\circ} \mathrm{C}$ & Zhang et al. (2001) \\
\hline Barre granite & RBT & 30.0 & 2.7 & No & Krech (1974) \\
\hline Bohus granite & CENBB & 58.0 & 5.3 & No & Cooper (1977) \\
\hline Bohus granite & CNRBB & 50.0 & 4.5 & No & Olofsson (1978) \\
\hline Mieville granite & CENBB & 96.5 & 8.8 & No & Cooper (1977) \\
\hline Stripa granite & CNRBB & 59.5 & 5.4 & No & Olofsson (1978) \\
\hline Stripa granite & SECRBB & 70.0 & 6.4 & No & Swan (1980) \\
\hline Westerly granite & CBRBT & 69.5 & 6.3 & No & Krech (1974) \\
\hline Finnsjön granodiorite & CNRBB & 89.5 & 8.1 & No & Olofsson (1978) \\
\hline St Cloud gray granodiorite & RBT & 51.0 & 4.6 & No & Krech (1974) \\
\hline Dresser basalt & CNRBT & 25.0 & 2.3 & No & Krech (1974) \\
\hline Baltic amygdaloid & CNRBT & 50.0 & 4.5 & No & Krech (1974) \\
\hline Average & & 50.4 & 4.6 & & \\
\hline
\end{tabular}

The specific fracture energy is estimated by $w_{\mathrm{f}}=w_{\mathrm{f}}^{0} / 11$

$C E N B B$ chevron edge notch beam under three point bending, $C N R B$ circumferentially notched round bar, $C N R B B$ CNRB under three point bending, CNRBT CNRB in uniaxial tension, $R B T$ round bar in uniaxial tension, $S C B$ semicircular bending, $S E N B$ single edge notch beam with rectangular cross section, $S E N B B$ SENB under three point bending, SECRB single edge crack round bar, SECRBB SECRB under three point bending 
Fig. 9 Nominal specific fracture energy $w_{\mathrm{f}}^{\mathrm{o}}$ of gabbro and marble vs. loading rate (based on the data from Zhang et al. 2000, 2001)

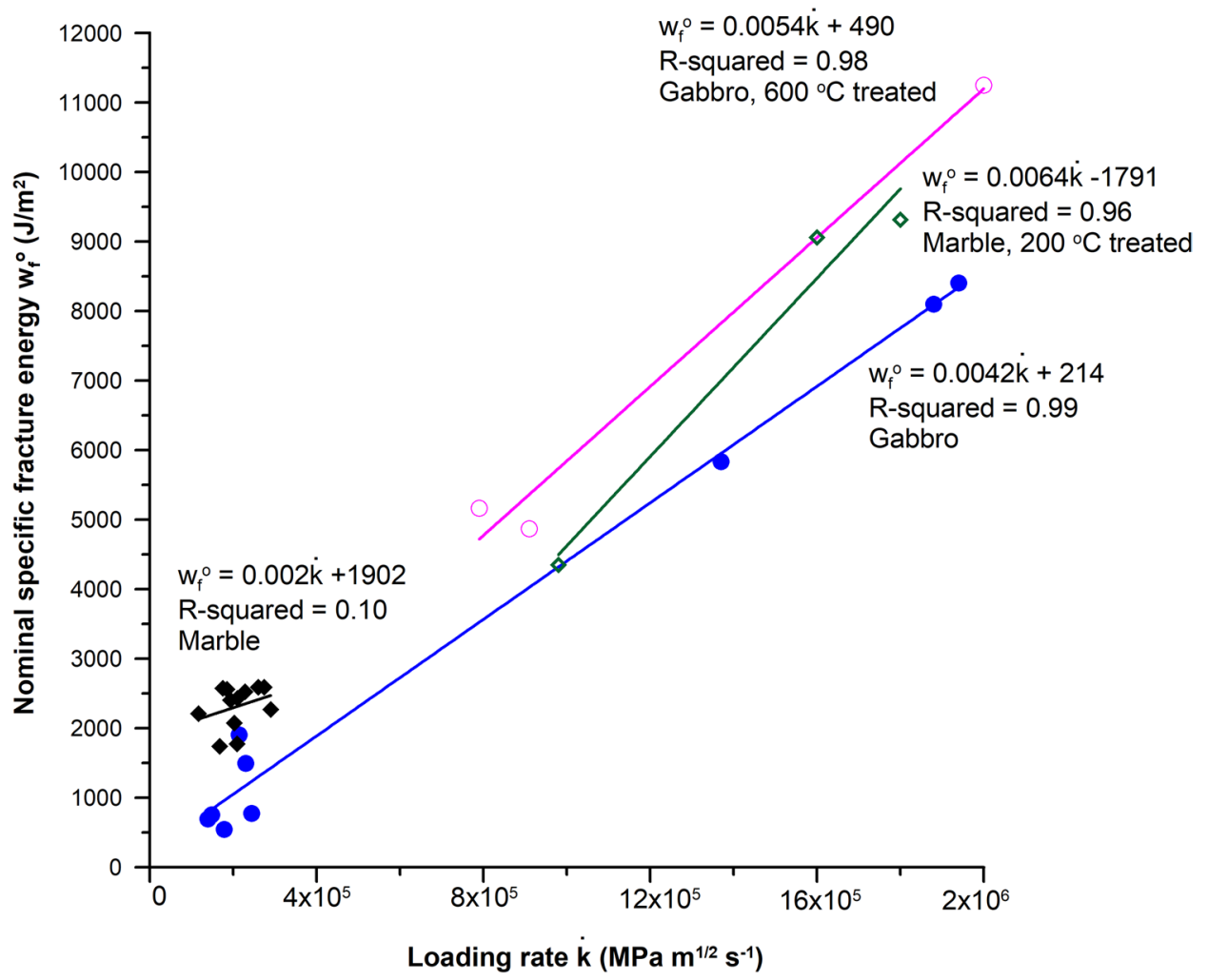

\subsection{Dynamic Tests}

In rock fracture tests using the split Hopkinson pressure bar, the absorbed energy of a specimen was first assumed to be equal to the surface energy used for fracturing the rock, i.e. kinetic energy of flying fragments and other energies were ignorable. Thus, the $w_{\mathrm{f}}^{\mathrm{o}}$ of the specimen could be determined from the known nominal fracture surface area of the specimen. The testing results achieved in this way showed that dynamic loading yields much greater $w_{\mathrm{f}}^{\mathrm{o}}$ than static loading does (Zhang et al. 2000, 2001), as shown in Table 5 and Fig. 9 where the $w_{\mathrm{f}}^{\mathrm{o}}$ values of one gabbro ( $G$ in short) and one marble ( $\mathrm{M}$ in short) are given under dynamic loads. In addition, the results from heat-treated specimens of these two rocks are also included. According to Table 5 and Fig. 9, it can be concluded that: (1) the $w_{\mathrm{f}}^{\mathrm{o}}$ values of the non-heat-treated gabbro, the heat-treated gabbro at $600{ }^{\circ} \mathrm{C}$, the heat-treated marble at $200{ }^{\circ} \mathrm{C}$ and the non-heat-treated marble are all linearly dependent on loading rates. (2) The $w_{\mathrm{f}}^{\mathrm{o}}$ values of the specimens under dynamic loads are much higher than the $w_{\mathrm{f}}^{\mathrm{o}}$ values of the specimens under static loads. (3) The heat-treated gabbro has a larger $w_{\mathrm{f}}^{\mathrm{o}}$ than non-heat treated gabbro at a constant loading rate, meaning that more energy is required to create per square meter of surface area in the heat-treated gabbro, see Fig. 9.

The loading rate dependence of $w_{\mathrm{f}}^{\mathrm{o}}$ is complicated by the fact that at higher loading rates under dynamic loading crack branching occurs, i.e., more fracture surface areas are created (Zhang et al. 2000, 2001), and these surface areas due to crack branching are not included in the nominal fracture surface areas in Table 5. In addition, other factors may also affect specific fracture surface energy such as crack meandering, intergranular displacement, friction, etc. under dynamic loading condition.

\section{Specific Fracture Energy from Compression and Torsional Tests with Regular Specimens}

\subsection{Uniaxial Compression Tests}

Compression tests with regular cylindrical basalt specimens by Lindholm et al. (1974) indicated that the energy input required to fracture basalt in compression increased with decreasing temperature and increasing strain rate, and the energy to fracture the rock largely increased with increasing confining pressure. Static compression tests with regular cylindrical specimens by Xie et al. (2009) showed that as more energy was absorbed by a rock specimen, more and smaller fragments were produced from the specimen. Gong et al. (2020) found that there was a critical absorbed energy of $0.36-0.41 \mathrm{MJ} / \mathrm{m}^{3}$ for the granite tested in a Hopkinson pressure bar. As the absorbed energy by a rock specimen was smaller than this critical energy, the rock specimen would 
Table 5 Nominal specific fracture energy $w_{\mathrm{f}}^{\mathrm{o}}$ of fracture toughness specimens measured under dynamic loads

\begin{tabular}{|c|c|c|c|c|c|}
\hline Specimen no & $\begin{array}{l}\text { Loading rate } \\
\left(\mathrm{MPa} \mathrm{m}^{1 / 2} / \mathrm{s}\right)\end{array}$ & $w_{\mathrm{f}}^{\mathrm{o}}\left(\frac{\mathrm{J}}{\mathrm{m}^{2}}\right)$ & $w_{\mathrm{f}}\left(\frac{\mathrm{J}}{\mathrm{m}^{2}}\right)_{*}$ & Heat-treated & Reference \\
\hline G30 & 139,000 & 692 & 63 & No & Zhang et al. (2000) \\
\hline G28 & 148,000 & 754 & 69 & No & Zhang et al. (2000) \\
\hline G19 & 178,000 & 545 & 50 & No & Zhang et al. (2000) \\
\hline G29 & 214,000 & 1904 & 173 & No & Zhang et al. (2000) \\
\hline G33 & 244,000 & 777 & 71 & No & Zhang et al. (2000) \\
\hline G16 & 230,000 & 1496 & 136 & No & Zhang et al. (2000) \\
\hline G36 & $1,370,000$ & 5838 & 531 & No & Zhang et al. (2000) \\
\hline G39 & $1,880,000$ & 8101 & 736 & No & Zhang et al. (2000) \\
\hline G38 & $1,940,000$ & 8403 & 764 & No & Zhang et al. (2000) \\
\hline G600-6 & 910,000 & 4868 & 442 & $600^{\circ} \mathrm{C}$ & Zhang et al. (2001) \\
\hline G600-7 & 790,000 & 5166 & 470 & $600^{\circ} \mathrm{C}$ & Zhang et al. (2001) \\
\hline G600-10 & $2,000,000$ & 11,249 & 1023 & $600^{\circ} \mathrm{C}$ & Zhang et al. (2001) \\
\hline M214 & 202,000 & 2075 & 189 & No & Zhang et al. (2000) \\
\hline M215 & 167,000 & 1741 & 158 & No & Zhang et al. (2000) \\
\hline M213 & 228,000 & 2527 & 230 & No & Zhang et al. (2000) \\
\hline M212 & 193,000 & 2407 & 219 & No & Zhang et al. (2000) \\
\hline M211 & 210,000 & 2429 & 221 & No & Zhang et al. (2000) \\
\hline M228 & 185,000 & 2560 & 233 & No & Zhang et al. (2000) \\
\hline M227 & 260,000 & 2590 & 235 & No & Zhang et al. (2000) \\
\hline M223 & 209,000 & 1776 & 161 & No & Zhang et al. (2000) \\
\hline M222 & 116,000 & 2212 & 201 & No & Zhang et al. (2000) \\
\hline M221 & 290,000 & 2268 & 206 & No & Zhang et al. (2000) \\
\hline M225 & 175,000 & 2576 & 234 & No & Zhang et al. (2000) \\
\hline M226 & 274,000 & 2591 & 235 & No & Zhang et al. (2000) \\
\hline M200-10 & $1,800,000$ & 9313 & 847 & $200^{\circ} \mathrm{C}$ & Zhang et al. (2001) \\
\hline M200-11 & 980,000 & 4353 & 396 & $200^{\circ} \mathrm{C}$ & Zhang et al. (2001) \\
\hline M200-12 & $1,600,000$ & 9061 & 824 & $200^{\circ} \mathrm{C}$ & Zhang et al. (2001) \\
\hline
\end{tabular}

* The specific fracture energy in this table is estimated by $w_{\mathrm{f}}=w_{\mathrm{f}}^{\mathrm{o}} / 11$ not be broken. Yang et al. (2019) reported that the average crushed size of shale specimens decreased but the fractal dimension of them increased with increasing dissipated energy in a Hopkinson pressure bar tests.

Sadrai et al. (2006) conducted static compression tests of four single cylindrical tuff specimens. The total energy provided to a single specimen by the testing machine was taken as the energy used in creating the total fracture surface area of the specimen which was measured by using a laser profilometer to obtain $w_{\mathrm{f}}$. The results are shown in Table 6. Barber and Griffith (2016) carried out experiments of Arkansas Novaculite (AN) and Westerly Granite (WG) specimens under dynamic uniaxial compressive loading, and found that the $w_{\mathrm{f}}$ of one WG specimen is $26.8 \mathrm{~J} / \mathrm{m}^{2}$. Note that the small fragments with about $1.6 \%$ of total weight of the specimen were lost when all fragments were collected after testing, meaning that actual $w_{\mathrm{f}}$ should be smaller than $26.8 \mathrm{~J} / \mathrm{m}^{2}$.
According to the tests of direct uniaxial tensile strength of cylindrical Fangshan marble (Yu et al. 1998), the average $w_{\mathrm{f}}^{\mathrm{o}}$ of the marble specimens was $153 \mathrm{~J} / \mathrm{m}^{2}$ under static load, while the average $w_{\mathrm{f}}^{\text {o }}$ became $491 \mathrm{~J} / \mathrm{m}^{2}$ under dynamic loads (average strain rate about $2.4 \times 10^{1} / \mathrm{s}$ ).

One result from Sadrai et al. (2006) is that the surface area of broken particles smaller than $0.42 \mathrm{~mm}$ makes up about $34-60 \%$ of the total fracture surface area of each rock sample, indicating that small particles are extremely important in determining total fracture surface area or surface fracture energy. This finding is similar to that by Moser and Grasedieck (2004) who reported that $85 \%$ of the input energy in blasting tests was used in producing particles smaller than $1 \mathrm{~mm}$ in diameter.

Fracture energy of siltstone under dynamic compression in a Hopkinson pressure bar was determined by Weng et al. (2019), using the same assumption as in dynamic fracture tests in Sect. 5.2. That is to say, the absorbed energy of a specimen was taken as the dissipated energy 
Table 6 Specific fracture surface energy of regular rock specimens under compression tests and tensile tests

\begin{tabular}{llllll}
\hline Rock & $w_{\mathrm{f}}^{\mathrm{o}}\left(\mathrm{J} / \mathrm{m}^{2}\right)$ & $w_{\mathrm{f}}\left(\mathrm{J} / \mathrm{m}^{2}\right)$ & $\begin{array}{l}\text { Determination } \\
\text { of surface area }\end{array}$ & Testing method and specimen & References \\
\hline Tuff (4) & 26.6 & Profilometer & SC; cylinder & Sadrai et al. (2006) \\
Granite & & 26.8 & Gas adsorption & DC; cylinder; SR <900/s & Barber and Griffith (2016) \\
Marble & 153 & $13.9^{\mathrm{a}}$ & Nominal area & ST; cylinder & Yu et al. (1998) \\
Marble & 491 & & Nominal area & DT; cylinder; SR =24/s & Yu et al. (1998) \\
\hline
\end{tabular}

$S C$ static compression, $D C$ dynamic compression, $S T$ static tension, $D T$ dynamic tension, $S R$ strain rate

${ }^{\mathrm{a} C a l c u l a t e d}$ by $w_{\mathrm{f}}=w_{\mathrm{f}}^{\mathrm{o}} / 11$

\begin{tabular}{llllll}
\hline Test method & Rock & Temperature $\left({ }^{\circ} \mathrm{C}\right)$ & $w_{\mathrm{f}}^{\mathrm{o}}\left(\frac{\mathrm{J}}{\mathrm{m}^{2}}\right)$ & $w_{\mathrm{f}}\left(\frac{\mathrm{J}}{\mathrm{m}^{2}}\right)$ & References \\
\hline Torsion & Limestone & Room & 190.0 & 17.3 & Cox and Scholz (1985) \\
Torsion & Granite & Room & 375.0 & 34.1 & Cox and Scholz (1985) \\
\hline
\end{tabular}

Note that $w_{\mathrm{f}}$ was calculated by $w_{\mathrm{f}}=w_{\mathrm{f}}^{\mathrm{o}} / 11$
Table 7 Nominal specific fracture energy $w_{\mathrm{f}}^{\mathrm{o}}$ of rock under pure shear loading with no confining pressure (Cox and Scholz 1985)

\begin{tabular}{|c|c|c|c|c|c|c|}
\hline Test method & Rock & $\sigma_{3}(\mathrm{MPa})$ & Temperature $\left({ }^{\circ} \mathrm{C}\right)$ & $w_{\mathrm{f}}^{\mathrm{o}}\left(\frac{\mathrm{J}}{\mathrm{m}^{2}}\right)$ & $w_{\mathrm{f}}\left(\frac{\mathrm{J}}{\mathrm{m}^{2}}\right)$ & References \\
\hline Triaxial compression & Westerly granite & 80 & 150 & 16,500 & & Wong (1982) \\
\hline Triaxial compression & Westerly granite & 80 & 350 & 11,500 & & Wong (1982) \\
\hline Triaxial compression & Westerly granite & 250 & 150 & 25,500 & & Wong (1982) \\
\hline Triaxial compression & Westerly granite & 250 & 350 & 11,000 & & Wong (1982) \\
\hline Triaxial compression & Westerly granite & 250 & 350 & 8500 & & Wong (1982) \\
\hline Triaxial compression & Westerly granite & 250 & 350 & 6500 & & Wong (1982) \\
\hline Triaxial compression & Westerly granite & 250 & 550 & 11,500 & & Wong (1982) \\
\hline Biaxial compression $^{\mathrm{a}}$ & Sandstone & $20 / 10$ & Room & & 1945.3 & Liu et al. (2020) \\
\hline Biaxial compression & Sandstone & $30 / 10$ & Room & & 2145.3 & Liu et al. (2020) \\
\hline Biaxial compression & Sandstone & $40 / 10$ & Room & & 1606.5 & Liu et al. (2020) \\
\hline Biaxial compression & Sandstone & $40 / 20$ & Room & & 2352.9 & Liu et al. (2020) \\
\hline Biaxial compression & Sandstone & $40 / 30$ & Room & & 2843.5 & Liu et al. (2020) \\
\hline Biaxial compression & Sandstone & $40 / 40$ & Room & & 4694.6 & Liu et al. (2020) \\
\hline Biaxial compression & Sandstone & $20 / 20$ & Room & & 2839.3 & Liu et al. (2020) \\
\hline Average of biaxial data & & & & & 2632.5 & \\
\hline
\end{tabular}

Table 8 Specific fracture energy from bi- and tri-axial compression tests

${ }^{a}$ One test (S1) by Liu et al. (2020) is not included in Table 8 due to its extremely high $w_{\mathrm{f}}$ value which is not explained and not accounted in the average value by Liu et al. (2020)

for rock fragmentation, while the kinetic energy of flying fragments and other energies were neglected. Unlike the studies mentioned above, Weng et al. (2019) used a different specific fracture energy. We use $w_{\mathrm{fv}}$ to express this specific fracture energy in the unit of $\mathrm{MJ} / \mathrm{m}^{3}$. Their measured results indicate that the specific fracture energy $w_{\mathrm{fv}}$ increases with an increasing strain rate at all temperatures they tested. For example, the $w_{\mathrm{fv}}$ of one of five siltstone specimens at $18{ }^{\circ} \mathrm{C}$ temperature (during testing) was $0.73 \mathrm{MJ} / \mathrm{m}^{3}$ at the strain rate $68.3 / \mathrm{s}$, but for another one at $222.8 / \mathrm{s}$ it was $1.62 \mathrm{MJ} / \mathrm{m}^{3}$.

\subsection{Torsional (Pure Shear) Tests}

Experiments by Tapponier and Brace (1976), Janach (1977), Kranz (1979) and Lankford (1981) indicate that rock failure in tensile, shear, and compressive strength tests mainly results from tensile micro-cracks induced by stresses. Cox and Scholz (1985) measured the $w_{\mathrm{f}}^{\mathrm{o}}$ of one granite and one limestone using circumferentially notched cylindrical specimens loaded in static pure torsion with a nominal crack surface area. The result is shown in Table 7. It can be found that 
Table 9 Specific fracture surface energy $w_{\mathrm{f}}$ of single quartz samples under slow compression ( Source: Axelson and Piret (1950)

\begin{tabular}{llllllll}
\hline Specimen no & $w_{\mathrm{f}}\left(\frac{\mathrm{J}}{\mathrm{m}^{2}}\right)$ & Specimen no & $w_{\mathrm{f}}\left(\frac{\mathrm{J}}{\mathrm{m}^{2}}\right)$ & Specimen no & $w_{\mathrm{f}}\left(\frac{\mathrm{J}}{\mathrm{m}^{2}}\right)$ & Specimen no & $w_{\mathrm{f}}\left(\frac{\mathrm{J}}{\mathrm{m}^{2}}\right)$ \\
\hline SQ10 & 3.8 & SQ13 & 9.2 & SQ14 $^{\mathrm{a}}$ & 16.5 & SQ19 & 36.0 \\
SQ6 $^{\mathrm{a}}$ & 5.4 & SQ16 & 10.1 & $\mathrm{SQ}^{\mathrm{a}}{ }^{\mathrm{a}}$ & 17.1 & $\mathrm{SQ7}$ & 57.4 \\
$\mathrm{SQ}^{\mathrm{a}}$ & 5.4 & $\mathrm{SQ}^{\mathrm{a}}$ & 12.7 & $\mathrm{SQ12}$ & 18.0 & Average & 16.4 \\
$\mathrm{SQ15}^{\mathrm{a}}$ & 7.0 & $\mathrm{SQ}^{\mathrm{a}}$ & 14.2 & $\mathrm{SQ18}$ & 18.5 & Average without SQ7 & 13.8 \\
$\mathrm{SQ17}^{\mathrm{a}}$ & 8.2 & $\mathrm{SQ9}^{\mathrm{a}}$ & 14.1 & $\mathrm{SQ11}$ & 24.3 & & \\
\hline
\end{tabular}

$S Q$ single quartz

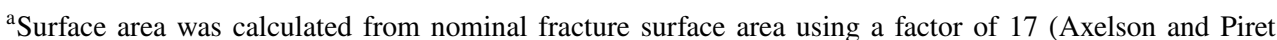
1950) the $w_{\mathrm{f}}^{\mathrm{o}}$ of the limestone under static pure torsion is close to the $w_{\mathrm{f}}^{\mathrm{o}}$ of the marble under static tension in Table 6.

\subsection{Bi- and Tri-axial Compression Tests}

Table 8 shows the $w_{\mathrm{f}}^{\mathrm{o}}$ values of a granite under static triaxial compression tests (Wong 1982) in which each cylindrical rock specimen failed at a certain temperature, at a specific confining pressure and along an inclined failure plane. In other words, those tests were of typical shear failure. The nominal fracture surface area was used. Table 8 indicates that the $w_{\mathrm{f}}^{\mathrm{o}}$ values of Westerly granite under triaxial compression vary from 6500 to $25,500 \mathrm{~J} / \mathrm{m}^{2}$, which are about one to two orders larger than $375 \mathrm{~J} / \mathrm{m}^{2}$, the $w_{\mathrm{f}}^{\mathrm{o}}$ value of the granite under pure shear loading measured by Cox and Scholz (1985).

Table 8 also includes the $w_{\mathrm{f}}$ values of a sandstone under dynamic biaxial compression tests by Liu et al. (2020). In the dynamic tests cubic sandstone specimens were tested by using a triaxial Hopkinson bar system, and high-speed three-dimensional digital image correlation (3D-DIC) and synchrotron-based micro-computed-tomography $(\mu \mathrm{CT})$ were employed. Each damaged rock specimen after dynamic biaxial compression was scanned by the synchrotron radiation to identify the fracture network. The energy absorbed by each rock specimen was determined by the principles of the split Hopkinson pressure bar system, the kinetic energy of spalled fragments was measured using the 3D-DIC techniques, and the surface areas of fractures were determined by synchrotron-based $\mu \mathrm{CT}$. Table 8 shows that the average $w_{\mathrm{f}}$ value of seven sandstone specimens is $2633 \mathrm{~J} / \mathrm{m}^{2}$ under dynamic biaxial compression loads (at impact velocity of $15 \mathrm{~m} / \mathrm{s}$ ). This value is about 3420 times of average specific surface energy $0.77 \mathrm{~J} / \mathrm{m}^{2}$ of all single crystals in Table 1 or Fig. 4.

In summary, from Tables 6, 7 and 8 it can be concluded: (1) the $w_{f}^{o}$ values of rocks tested under pure torsional loading are close to the values of similar rocks under tensile loading. All these test specimens had a precut notch or crack. (2) The $w_{\mathrm{f}}^{\mathrm{o}}$ values of rocks tested under triaxial compression tests are about one to two orders greater than the values of similar rocks under pure torsional loading. All of them did not have a precut notch or crack. (3) The average $w_{\mathrm{f}}$ value of sandstone specimens under dynamic biaxial compression loads is three orders greater than the specific surface energy of single crystals in Table 1 .

Wong (1982) stated that some of the excess energy was due to extensive microcracking off the macroscopic shear failure plane. Cox and Scholz (1985) argued that the interaction between the fracture surfaces close to the crack front might provide a large energy sink particularly under the large normal stresses of triaxial tests. Anyway, the large discrepancy between the fracture energy in tensile fracture and that in compression-caused shear failure needs to be better explained by further investigation.

\section{Specific Fracture Energy under Compression Tests with Single Particles}

In this section, the term single particles includes both regular and irregular samples with different sizes. The single particles are not standard rock samples used for testing mechanical rock properties of rock. They are mainly used to study crushing and grinding.

\subsection{Specific Fracture Energy of Single Particles}

Breakage of single particles has been investigated by many scientists (e.g. Hukki 1943; Axelson and Piret 1950; Gilvarry and Bergstrom 1961; Schoenert 1972; Rumpf 1973; Bergstrom and Sollenberger 1962; Narayanan 1985; Narayanan and Whiten 1988; Fuerstenau and Vazquez-Favela 1997; Tavares and King 1998; Fuerstenau and Abouzeid 2002; Tavares 2004). Among them, Axelson and Piret (1950) presented their experimental data in detail. They conducted 17 slow compression tests of regular single quartz particles each of which had a weight of 1-2 g. Each quartz particle 
Table 10 Specific fracture surface energy $w_{\mathrm{f}}$ of quartz particle beds under drop weight crushing tests (Gross and Zimmerley 1930)

\begin{tabular}{llllllll}
\hline Test no & $w_{\mathrm{f}}\left(\frac{\mathrm{J}}{\mathrm{m}^{2}}\right)$ & Test no & $w_{\mathrm{f}}\left(\frac{\mathrm{J}}{\mathrm{m}^{2}}\right)$ & Test no & $w_{\mathrm{f}}\left(\frac{\mathrm{J}}{\mathrm{m}^{2}}\right)$ & Test no & $w_{\mathrm{f}}\left(\frac{\mathrm{J}}{\mathrm{m}^{2}}\right)$ \\
\hline A & 51.6 & $\mathrm{E}$ & 52.1 & $\mathrm{I}$ & 60.5 & $\mathrm{M}$ & 53.8 \\
B & 58.3 & $\mathrm{~F}$ & 51.6 & $\mathrm{~J}$ & 58.3 & Average & 55.6 \\
$\mathrm{C}$ & 51.9 & $\mathrm{G}$ & 56.6 & $\mathrm{~K}$ & 60.9 & & \\
$\mathrm{D}$ & 54.1 & $\mathrm{H}$ & 57.6 & $\mathrm{~L}$ & 56.0 & & \\
\hline
\end{tabular}

was crushed in a steel mortar under slow compression. After crushing tests, the fracture surface areas of 7 particles were measured by gas adsorption method. Their results indicated that the average ratio of the gas adsorption area to the nominal area was close to 17 . Using this ratio they calculated the fracture surface areas of other 10 particles according to their nominal fracture areas. The $w_{\mathrm{f}}$ values of the 17 particles are shown in Table 9, varying from 3.8 to $57.4 \mathrm{~J} / \mathrm{m}^{2}$ with an average of $16.4 \mathrm{~J} / \mathrm{m}^{2}$ and a standard deviation of $13.2 \mathrm{~J} / \mathrm{m}^{2}$. Axelson and Piret (1950) reported that particle SQ7 was not broken until the fifth compression. Thus, we exclude the data of SQ7, then we find that the $w_{\mathrm{f}}$ values of the 16 particles are in a range of $3.8-36.0 \mathrm{~J} / \mathrm{m}^{2}$ with an average of $13.8 \mathrm{~J} /$ $\mathrm{m}^{2}$, which is about 23 times greater than the average specific surface energy $0.59 \mathrm{~J} / \mathrm{m}^{2}$ of single quartz crystals (shown in Fig. 4 and Table 1).

Axelson and Piret (1950) noted that small pieces spalled off the particle as the energy input was increased. The pieces spalled off must carry some kinetic energy. This kinetic energy did not help to create new fracture surface area, resulting in higher specific fracture energy $w_{\mathrm{f}}$ at higher total energy input.

\subsection{Energy Utilization in Single Particle Breakage}

Schoenert (1972) conducted the breakage of single-particles of quartz, limestone and cement clinker by static and dynamic compression loads, and Narayanan and Whiten (1988) performed the breakage of single Mount Lyell ore particles in twin pendulum experiments. Both articles reported that energy utilization (ratio of comminution energy to input energy) decreases with increasing energy input. Bergstrom and Sollenberger (1962) found that $45 \%$ of the input energy resulted in kinetic energy of the broken glass balls, and that the fragments from the glass balls broken in gelatine were coarser than the fragments of similar balls broken within a steel ring. The reason was that by breaking the balls within the steel ring, the kinetic energy of flying fragments was partially utilized for secondary fracture as the fragments collided with the steel ring, whereas the balls broken in gelatine could only dissipate their kinetic energy as heat or other forms of energy. They measured energy input from the compression testing machine and the kinetic energy of the fragments from high-speed photography, but rest of the dissipated energy, which includes fracture energy and other forms, is unknown.

Kabo et al. (1977) carried out a series of laboratory tests by the impact of a $6.35 \mathrm{~mm}$ diameter steel sphere on single rock specimens with initial speeds ranging from 50 to $2500 \mathrm{~m} / \mathrm{s}$. The rock specimens were green shale and diorite disks in a diameter of $140 \mathrm{~mm}$ and a thickness over $25 \mathrm{~mm}$. The tests indicated that the ejection velocity of rock fragments from the craters was up to over $200 \mathrm{~m} / \mathrm{s}$. Correspondingly, the kinetic energy carried with the fragments was about 10 percent of the initial energy with the sphere. A notable result from Kabo et al. (1977) is that the ratio of comminution energy to initial input energy was as high as $73-85 \%$. This ratio is probably due to the unique testing system that has not been found in other publications.

\section{Specific Fracture Energy and Energy Efficiency in Comminution of Multiple Particles}

\subsection{Specific Fracture Energy of Particle Beds}

Three different groups of particle bed crushing tests are included in this section. The first group is from the tests by Gross and Zimmerley (1930) who carried out 13 impact tests on quartz particle beds. In the tests a steel ball was dropped at a maximum height of $0.6 \mathrm{~m}$ on to a steel plunger under which quartz particles were placed at the bottom of a chamber. The crushing chamber was placed on the upper part of a mortar. Beneath the mortar were three aluminium wires which were deformed during the impact tests. A portion of the work resulting from the impact of the falling ball causes a deformation of the three aluminium wires between the mortar and the base. This deformation is a measure of the total work of the falling ball if no crushing is done. If crushing is done, the deformation is a measure of the work not used in the crushing. When the quartz particles were placed in the crushing chamber, they were moistened with absolute alcohol. The function of the alcohol was to prevent dust loss. In this way, the weight loss was kept less than $0.1 \%$. The measurement of surface areas was carried out using the dissolution method. The measured specific fracture energy $w_{\mathrm{f}}$ of each particle bed is shown in Table 10, indicating that the 
Table 11 Specific fracture energy $w_{\mathrm{f}}$ of minerals in drop weight crushing
Table 12 Specific fracture energy of quartz particles under drop-weight impact crushing (Johnson et al. 1949)

\begin{tabular}{lllll}
\hline Rock & Specimen no & $w_{\mathrm{f}}\left(\mathrm{J} / \mathrm{m}^{2}\right)^{\mathrm{a}}$ & $w_{\mathrm{f}}\left(\mathrm{J} / \mathrm{m}^{2}\right)$ & References \\
\hline Milky vein quartz (9) & F-N & 172.9 & 84.3 & Kwong et al. (1949) \\
Quartz (crystalline) (2) & Cr1-2 & 143.7 & 73.7 & Kwong et al. (1949) \\
Calcite (4) & C1-4 & 92.4 & 46.2 & Kwong et al. (1949) \\
Fluorite (3) & F1-3 & 63.5 & 31.7 & Kwong et al. (1949) \\
Labradorite (4) & L1-4 & 164.2 & 82.1 & Kwong et al. (1949) \\
Sphalerite (2) & S1-2 & 102.8 & 51.4 & Kwong et al. (1949) \\
Apatite (2) & A1-2 & 128.1 & 64.1 & Kwong et al. (1949) \\
Topaz & T-1 & 196.1 & 98.1 & Kwong et al. (1949) \\
Glass (5) & G1-5 & 162.7 & 81.4 & Kwong et al. (1949) \\
Native Halite (4) & H1-4 & 116.4 & 58.3 & Adams et al. (1949) \\
Synthetic optical crystals & H-5-S & 118.0 & 59 & Adams et al. (1949) \\
\hline
\end{tabular}

${ }^{\mathrm{a}}$ The specific fracture energy data is from permeability

\begin{tabular}{llclllll}
\hline Material & No & $w_{\mathrm{f}}\left(\mathrm{J} / \mathrm{m}^{2}\right)$ & $\begin{array}{l}\text { Number } \\
\text { of drops }\end{array}$ & Material & No & $w_{\mathrm{f}}\left(\mathrm{J} / \mathrm{m}^{2}\right)$ & $\begin{array}{l}\text { Number } \\
\text { of drops }\end{array}$ \\
\hline Crystalline quartz & Q-1 & 76.4 & 10 & Crystalline quartz & Q-14 & 75.2 & 4 \\
Crystalline quartz & Q-3 & 81.6 & 9 & Crystalline quartz & Q-15 & 75.9 & 4 \\
Crystalline quartz & Q-4 & 82.0 & 9 & Crystalline quartz & Q-16 & 67.9 & 2 \\
Crystalline quartz & Q-5 & 87.0 & 1 & Crystalline quartz & Q-17 & 77.2 & 2 \\
Crystalline quartz & Q-8 & 112.4 & 12 & Crystalline quartz & Q-18 & 97.8 & 10 \\
Crystalline quartz & Q-9 & 118.0 & 20 & Massive quartz & HQ-1 & 94.9 & 8 \\
Crystalline quartz & Q-10 & 80.9 & 4 & Massive quartz & HQ-2 & 104.4 & 17 \\
Crystalline quartz & Q-11 & 73.2 & 2 & Milky vein quartz & MQ-1 & 85.1 & 9 \\
Crystalline quartz & Q-12 & 123.0 & 32 & Milky vein quartz & MQ-2 & 79.0 & 5 \\
Crystalline quartz & Q-13 & 83.7 & 6 & & & & \\
\hline
\end{tabular}

average $w_{\mathrm{f}}$ of the particle beds is $55.6 \mathrm{~J} / \mathrm{m}^{2}$, with a standard deviation of $3.4 \mathrm{~J} / \mathrm{m}^{2}$. Each test consisted of several crushing events, so the $w_{\mathrm{f}}$ value of each test was an average $w_{\mathrm{f}}$ of all crushing events in the test.

The second group of particle bed tests is from Kwong et al. (1949) and Adams et al. (1949) who carried out impact crushing tests by a drop weight system similar to that used by Gross and Zimmerley (1930). In each test, a single particle was broken first by an impact load from a weight drop, then the fragments of the broken particle were crushed again. In general, such crushing tests are similar to particle bed crushing. Their measured $w_{\mathrm{f}}$ data is shown in Table 11. Considering that the permeability method was used to determine the surface area by Kwong et al. (1949) and Adams et al. (1949), the original $w_{\mathrm{f}}$ data with a star in Table 11 must be corrected since the surface area measured by adsorption was found to be reliable and about twice of the area measured by permeability according to Johnson et al. (1949). For crystalline quartz, the ratio of the surface area by adsorption to that by permeability is 1.95 ; for massive quartz the ratio is 1.81 and for Milky vein quartz the ratio is 2.05 (Johnson et al. 1949). Thus, in this paper these ratios were

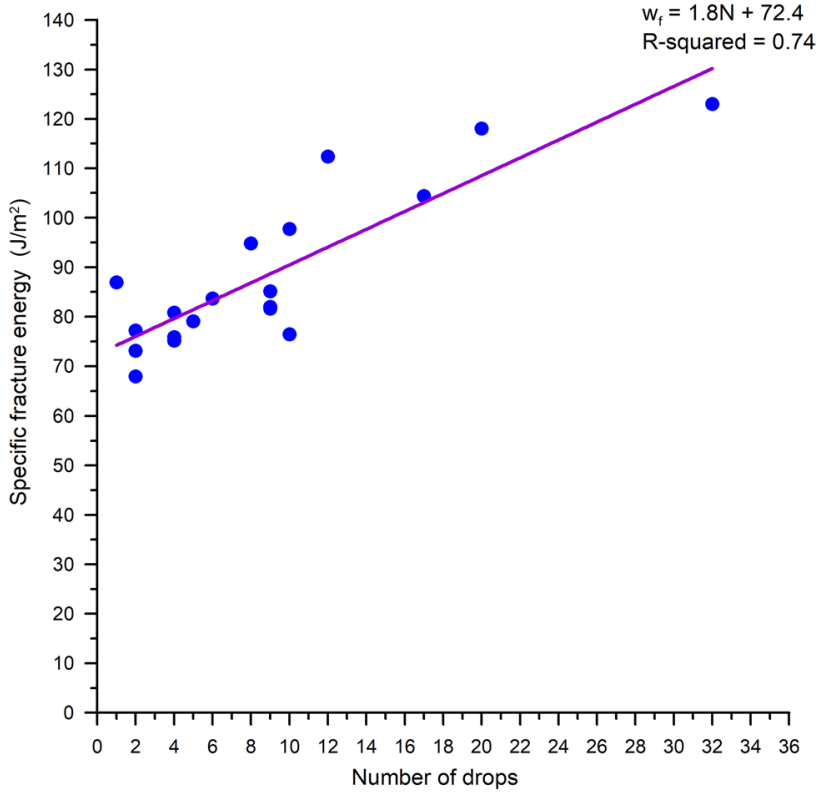

Fig. 10 Specific fracture energy $w_{\mathrm{f}}$ of quartz particles vs. number of drops from drop-weight crushing tests (original data from Johnson et al. 1949) 
Table 13 Specific fracture energy $w_{\mathrm{f}}$ of minerals in small tube mill and small tumbling mill.

\begin{tabular}{lllllll}
\hline Rock & Specimen no & $w_{\mathrm{f}}\left(\mathrm{J} / \mathrm{m}^{2}\right)^{\mathrm{a}}$ & Surface measured by & Crushing method & $w_{\mathrm{f}}\left(\mathrm{J} / \mathrm{m}^{2}\right)$ & References \\
\hline Quartz sand (7) & $145-151$ & 912.7 & Hydrofluoric acid & Tube mill & 136.9 & Martin et al. (1925) \\
Quartz & Q1 & 107.0 & Gas adsorption & Tumbling mill & 107.0 & Schellinger (1952) \\
Pyrite & P1 & 60.0 & Gas adsorption & Tumbling mill & 60.0 & Schellinger (1952) \\
Calcite & C1 & 32.4 & Gas adsorption & Tumbling mill & 32.4 & Schellinger (1952) \\
Halite & H1 & 26.1 & Gas adsorption & Tumbling mill & 26.1 & Schellinger (1952) \\
\hline
\end{tabular}

${ }^{\mathrm{a}}$ Original measurement data

used to modify the original $w_{\mathrm{f}}$ data with the star measured by permeability for crystalline quartz and Milky vein quartz in Table 11. In addition, the ratio 2 was used to modify the data of other materials in Table 11 with permeability. The modified specific fracture energy is still expressed by $w_{\mathrm{f}}$ in the table.

The third group of particle bed tests is from Johnson et al. (1949) who conducted particle bed crushing tests using three different quartz materials and the adsorption method. Different from the first two groups, the third group of tests includes the number of drops in each test, as shown in Table 12 and Fig. 10. Figure 10 indicates that the $w_{\mathrm{f}}$ of the quartz particles increases with increasing quantity of drops in the drop-weight crushing tests by Johnson et al. (1949). The minimum $w_{\mathrm{f}}$ is $67.9 \mathrm{~J} / \mathrm{m}^{2}$ as the quantity of drops is 2 , while the maximum $w_{\mathrm{f}}$ is $123.0 \mathrm{~J} / \mathrm{m}^{2}$ as the quantity of drops is 32 . Since particles are impacted many times by steel balls (or steel rod or other ore particles) in a ball mill or another similar mill, multiple impacts in the drop weight testing is a reasonable model of that process.

The results from the above three groups of particle beds will be summarized in Sect. 8.2.

\subsection{Specific Fracture Energy $w_{f}$ in Ball Milling}

Martin et al. (1925) and Schellinger (1952) performed milling tests in a small tube mill and a small tumbling mill, respectively. In the milling tests, the $w_{\mathrm{f}}$ of several minerals was measured. The measurement results are shown in Table 13.

In Table 13 the $w_{\mathrm{f}}$ data with "a" are original measurement data. The original $w_{\mathrm{f}}$ values from Martin et al. (1925) need to be modified and those values are listed in the column for $w_{\mathrm{f}}$ in Table 13. According to Schellinger (1952), the net energy used to create new surface area should be equal to energy input to the mill minus heat energy from the mill's chamber. This heat energy output from the grinding chamber was measured by a calorimeter assembly and it was up to $80-90 \%$ of the energy input to the mill (Schellinger 1952). Since such heat energy was measured and accounted in the fracture energy determined by Schellinger (1952) but not by Martin et al. (1925), it is assumed that $85 \%$ of the energy

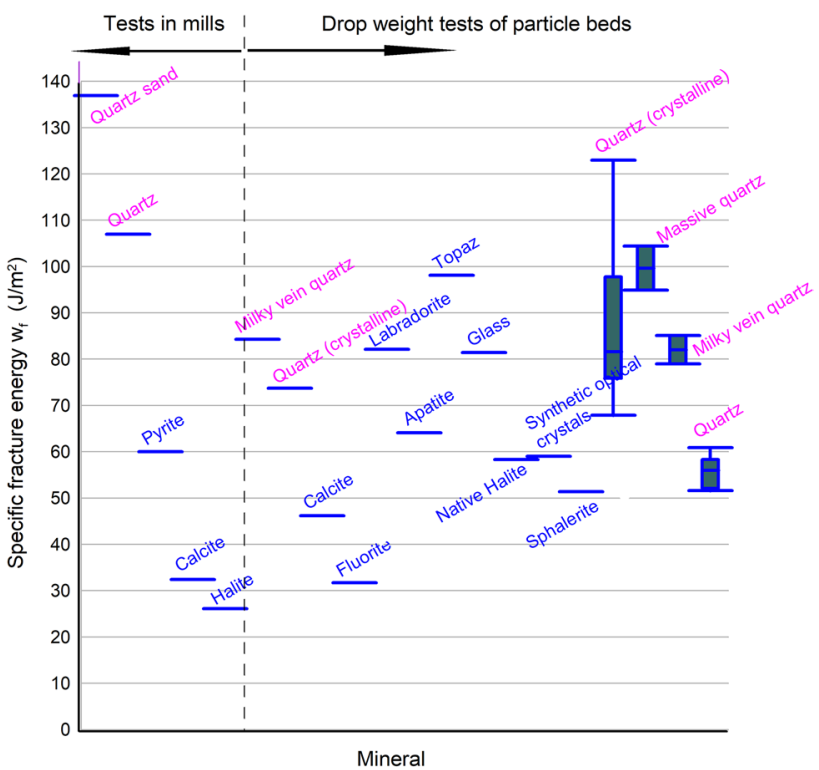

Fig. 11 Box-Whisker plot for specific fracture energy $w_{\mathrm{f}}$ of different mineral particles. The quartz sand, quartz, pyrite, calcite and halite in the most left side of the figure are from small-mill tests (Martin et al. 1925; Schellinger 1952). In the last four groups of the drop weight tests the quartz (crystalline), massive quartz, and Milky vein quartz are from Johnson et al. (1949), and the quartz is from Gross and and Zimmerley (1930). The other minerals among all drop weight tests are from Kwong et al. (1949) and Adams et al. (1949). The specific meaning of Box-Whisker plot is explained in Fig. 4

input to the tube mill was dissipated as heat in the milling chamber, i.e. $15 \%$ of the energy input was used to produce new surface area in the case of Martin et al. (1925). Thus, the modified values are equal to the original ones multiplied by 0.15 .

Figure 11 summarizes all $w_{\mathrm{f}}$ data from drop weight crushing tests and milling tests included in Tables 9, 10, 11, 12 and 13. The following conclusions can be drawn from Fig. 11: (1) quartz sand crushed in the small mill has higher $w_{\mathrm{f}}$ value than all of the mineral particles crushed in the drop weight tests; (2) quartz crushed in the small mill has higher $w_{\mathrm{f}}$ value than most mineral particles crushed in the drop weight tests, excluding a few tests in the last group of the quartz (crystalline); (3) three minerals, pyrite, calcite and 
halite, crushed in the small mill have $w_{\mathrm{f}}$ values on a similar level as several minerals crushed in the drop weight tests; (4) the $w_{\mathrm{f}}$ of the calcite crushed in the mill is smaller than that of the calcite crushed in the drop weight tests. The reason is unknown since the two calcite tests came from different references.

\subsection{Effect of Loading Rate on Comminution}

Sadrai et al. (2011) conducted impact crushing to rock particles (aggregates) in a confined chamber by a $12 \mathrm{~g}$ cylindrical steel projectile at velocities between 100 and $500 \mathrm{~m} / \mathrm{s}$. The target chamber was able to hold 5-50 g of rock particles with a size $\leq 1 \mathrm{~mm}$ and variable depths for the target bed. The air inside the chamber and between particles was evacuated by a pump to a negative pressure to facilitate the launch of the projectile with least air resistance and to transfer the stress wave to particles located behind the point of impact. An interesting result from Sadrai et al. (2011) is that the energy efficiency increases with an increasing impact speed. For example, the energy efficiency of one quartz is increased from $1.57 \%$ at an impact velocity of $80 \mathrm{~m} / \mathrm{s}$ to $5.13 \%$ at an impact velocity of $220 \mathrm{~m} / \mathrm{s}$. This result is opposite to that from dynamic fracture tests using Hopkinson pressure bars with a striker bar speed lower than $40 \mathrm{~m} / \mathrm{s}$ (Zhang et al. $2000,2001)$ in which energy efficiency decreases with an increasing loading rate. These two results are not necessarily contradicitive since they belong to different ranges of loading rates or impact speeds. Another possible reason for the seemingly contradictive results is that the inertial sideways movement has an influence on the results. If so, the mechanism of comminution in such high-speed impact will be different from that in low-speed impact occuring in ball and rod mills.

Another result from Sadrai et al. (2011) is that the thickness of the particle bed in the chamber affects fragmentation, and larger thickness $(150 \mathrm{~mm})$ produces larger particles than thinner $(75 \mathrm{~mm})$. A possible reason is that friction or attrition between particles and particles' displacement might have wasted more energy as the thickness of particle bed increased.

\subsection{Threshold Energy of Single Particles}

Shi and Kojovic (2007) introduced a concept named threshold energy on single particle comminution. The threshold energy means the minimum energy required to break an individual particle by compression under quasi-static loads. Three types of rock samples, two copper-porphyry samples and one iron ore sample, were tested using an MTS piston press with a range of narrow particle sizes by Nadolski et al. (2014). Compression loading was applied to individual particles at a constant displacement rate until particle fracture, nominated as fracture occurring at both loading points, occurred. The test results indicate that: (1) energy thresholds of both iron ore (particle sizes 10-60 mm) and Canadian copper-porphyry ore (particle sizes $10-28 \mathrm{~mm}$ ) markedly decrease with increasing particle sizes, while the energy threshold of Huckleberry copper-porphyry ore (particle sizes $10-35 \mathrm{~mm}$ ) slightly decreases with increasing particle sizes. (2) The energy threshold for $10 \mathrm{~mm}$ particles is $57.6,50.4$ and $32.4 \mathrm{~kJ} / \mathrm{t}$ for iron ore, Canadian copper-porphyry ore and Huckleberry copper-porphyry ore, respectively. (3) The energy threshold varies from 18.0 to $57.6 \mathrm{~kJ} / \mathrm{t}$ for iron ore (particle sizes 10-60 mm), from 21.6 to $54.0 \mathrm{~kJ} / \mathrm{t}$ for Canadian copper-porphyry ore (particle sizes 10-28 mm), and from 21.6 to $36.0 \mathrm{~kJ} / \mathrm{t}$ for Huckleberry copper-porphyry ore (particle sizes 10-35 mm), respectively. (4) These samples are considered to be hard ores in terms of ball mill grinding, having a Bond ball mill work index of $78,120.0 \mathrm{~kJ} / \mathrm{t}$ or $21.7 \mathrm{kWh} / \mathrm{t}$.

\subsection{High Pressure Grinding Roller (HPGR) Mills}

Compared with conventional rod and ball mills, high pressure grinding roller (HPGR) mills, developed in the 1980's and based on fundamental studies on interparticle crushing (e.g. Schönert 1979, 1988), are a relatively new technique in mineral processing. The special feature of HPGR mills is that a bed of particles is compressed between two rollers to a high solid density (Schönert 1988). The milling force must be adjusted to a level so that the particle bed is loaded by a compressive force per unit area exceeding at least $50 \mathrm{MPa}$ and up to 100-300 MPa. The material leaves the mill as flakes, which have to be deagglomerated in a succeeding operation. HPGR mills have less wear and overgrinding. The energy consumption of about $32 \mathrm{kWh} / \mathrm{t}$ for milling quartz of $<2.5 \mathrm{~mm}$ down to $<40 \mu \mathrm{m}$ is much less than that taken by a ball mill (Schönert 1988), i.e. the HPGR mill yields higher energy efficiency than the ball mill. However, the higher energy efficiency of HPGR mills often holds at low reduction ratios but not at high reduction ratios (Fuerstenau and Vazquez-Favela 1997).

\subsection{Energy Efficiency in Comminution}

Comminution efficiency is often defined as the ratio of the energy used to create the new fracture surface during size reduction to the mechanical energy supplied to the machine performing the size reduction (Fuerstenau and Abouzeid 2002). Energy efficiency in comminution has been studied for several decades (Prasher 1987; Narayanan and Whiten 1988; Napier-Munn et al. 1996; Chi et al. 1996; Steiner 1998; Stamboliadis et al. 2009; Tromans and Meech 2002; Tromans 2008; Fuerstenau and Abouzeid 2002; Sadrai et al. 2006; Shi 2016). In terms of the above definition, the energy 
introduced into comminution systems that actually results in the formation of new fracture surface is usually less than 1\% (Chi et al. 1996; Fuerstenau and Abouzeid 2002), and theoretically the efficiency of a ball mill is $0.6 \%$ (Lowrison 1974).

Fuerstenau and Abouzeid (2002) summarized the energy efficiency data on quartz comminution from many previous experiments and found that the energy efficiencies were in the order from lowest to highest: ball mill—grindability test-single-particle-impact crushing-single-crystal-slow compression-irregular-single-particle-slow compressionparticle-bed compression.

Similarly, as mono-size dolomite was crushed in a ball mill, a high-pressure roll mill and a single-particle roll mill at the low reduction ratio of six, the energy expended was 1.7, 1.0 and $0.7 \mathrm{kWh} / \mathrm{t}$, respectively (Fuerstenau and Vazquez-Favela 1997), meaning that the most efficient method for comminuting the dolomite is the single-particle roll mill. This is followed by the high-pressure roll mill and then the ball mill.

To study the different energy efficiencies between different crushing or comminution methods, Oettel et al. (2001) carried out quasi-static compressive experiments on particle bed comminution. Their results show that: (1) the maximum growth of the specific surface area is attained in the fully confined particle bed. As the lateral extension of the mould increases, the specific surface growth diminishes significantly. (2) The energy absorption is a linear function of the applied force. This linear energy-force relationship holds well even if the mould diameter and/or additive amount are changed. (3) Increasing energy absorption leads to decrease of the energy utilization. Without additive, the comminution in the fully confined particle bed succeeded at the highest energy utilization compared to those in open particle beds.

\subsection{Mechanism of Comminution}

Two major mechanisms of comminution circuits such as ball and rod mills are tensile failure and attrition (shear crushing between media sliding over each other). Rittinger (1867) determined that more specific input energy is required as particle size decreases since smaller particles inevitably contain fewer and smaller flaws as Griffith (1921) later stated. In comminution such as in ball and rod mills, the balls or rods hit the rock particles in the mill with impact velocities ranging from 1 to $10 \mathrm{~m} / \mathrm{s}$, and apply an impact load to the rock particles to be broken. As balls or rods fall down and impact on the rock particles, the localized loading of particles in the bed causes displacement gradients and shear movements between them. These movements result in friction work and attrition. In addition, kinetic energy carried with the newly-produced flying particles is wasted to a certain extent since the rock particles are not fully confined. This is one of main reasons why a high pressure grinding roller (HPGR) mill has higher energy efficiency, because the HPGR mill provides high confinement to the rock particles and the wastage of such kinetic energy is limited. In addition to the attrition mentioned above, one part of the rock particles in an operating mill is always rotating together with the steel balls or rods in the mill, resulting in attrition between those particles.

\section{Specific Fracture Energy and Energy Efficiency in Rock Drilling}

\subsection{Characteristics of Percussive Drilling}

Percussive drilling has been a dominant method in the history of rock drilling due to its flexibility, especially for small holes. In percussive drilling input energy is transferred from the hammer to the drill bit by stress waves. This has been studied by many scientists (e.g. Fairhurst 1961; Hustrulid and Fairhurst 1971a, b; Lundberg 1973, 1976; Xu and Yu 1984; Li 1994). Experiments of rock breakage in split Hopkinson pressure bar (SHPB) systems indicated that the energy transmission efficiency was dependent on the shape of incident wave (Lundberg 1976; Li 1994) and the loading rate (Zhang 1994). Two interesting results by Lundberg (1976) are: (1) if the incident wave amplitude increases beyond the yield stress of the rock, the energy absorption by the specimen increases steeply; (2) the relative energy absorption, $W_{\mathrm{L}} / W_{\mathrm{I}}$, where $W_{\mathrm{L}}$ is energy absorbed by the rock and $W_{\mathrm{I}}$ is input energy, attains a maximum value of $50 \%$ when the incident pulse amplitude is twice the yield stress, and then asymptotically approaches zero. The latter is confirmed by similar experiments by $\mathrm{Li}$ (1994). The first result indicates that to destroy rock efficiently the amplitude of incident wave should be larger than the yield stress of the rock. The second result shows that energy absorption will be maximally $50 \%$ of input energy. Since energy efficiency cannot be greater than $W_{\mathrm{L}} / W_{\mathrm{I}}$, the energy efficiency in this SHPB case will be limited to $50 \%$ as maximum. Notice that this SHPB case is different from a real drilling case.

In percussive drilling, as energy is transferred from drill bit to the rock, some energy is used to break the rock into different pieces and powder, and the rest must be carried by the stress waves propagating into the rock and dissipated in other forms such as particle movement, heating, friction, etc. To figure out how the energy transmitted to the rock is distributed, the fracture and damage pattern caused in the rock beneath an indenter or a cutter has been widely investigated (e.g. Lundberg 1974; Kumano and Goldsmith 1982a, b; Lindqvist and Lai 1983; Lindqvist et al. 1984, 1994; Xu and Yu 1984; Rogers et al. 1986; Howarth and Bridge 1988; Pang et al. 1989; Zhang 1994, 2016; Kou 1995; Liu et al. 2008; Franca 2011; Entacher et al. 2015; Nariseti et al. 2015; 


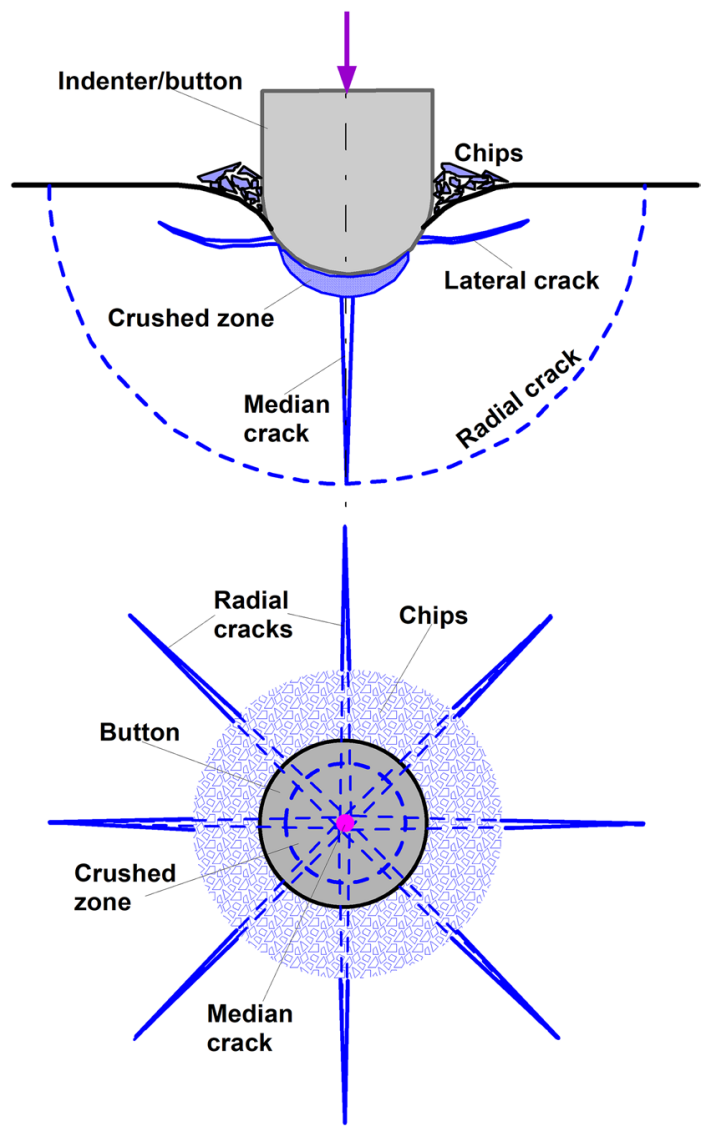

Fig. 12 Schematic of fracture and damage pattern of indentation into rock

Stoxreiter et al. 2019a). Based on the previous studies, the fracture and damage pattern under indentation can be simplified as shown in Fig. 12 where many small cracks starting from the crushed zone are not shown. Such a pattern is basically consistent with a practical fracture and damage pattern caused by a spherical button on one cutter of a boring machine during underground excavation (Zhang et al. 2003).

Figure 12 indicates that the energy transferred to the rock beneath the indenter or button is used partly to create median, lateral and radial cracks, partly to produce fragments (debris or chips), partly to build up a compacted crushed zone, partly to eject fragments, and partly to be dissipated in the other forms of energy such as heat, friction, etc. Relatively little is known how these energy forms are related in the case of rock. Work to establish this is well motivated because the potential to increase drilling and boring speeds of current drill and boring machines is still large (Zhang 2016).

To perform a thorough study in the future, mechanical analysis, numerical simulation and experiments are all necessary. For elastic stress or strain in the pre-penetration stage, analytical solutions for uncracked half spaces can be found for point-load indenter (Boussinesq 1885), for flat circular and conic indentations (Sneddon 1951), and for parabolic and spherical indentation (Zhang 2016). For indentation in a linear elastic-plastic material, a semi-empirical relation between indentation force and median crack length was developed by Kou (1995), and two relations between indentation force and radial crack length and lateral crack length developed by Marshall et al. (1982), Marshall (1984). Note that the theoretical length of a median crack is for a given normal force always several times larger than the actual length measured from in-situ rock samples (Zhang 2016), possibly due to some factors dealing with differences in the boundary conditions in the laboratory and in the field.

\subsection{Specific Fracture Energy $w_{\mathrm{f}}$ from Projectile Impact Tests}

Experimental studies on the specific fracture energy under indentation or projectile impact are very rare. The only study we found is the indentation experiments by Kumano and Goldsmith (1982a). Their study indicates that: (1) the geometry of projectile's tip has a significant effect on the strain wave shapes, crater production, the generation of crack networks below the crater and the ejecta's size distribution; (2) the kinetic energy of the ejecta 'cloud' is less than $2 \%$ of the initial projectile energy; (3) the $w_{\mathrm{f}}$, defined as the ratio of projectile energy to new surface produced, was found to be highest for the flat-headed and the least for the hemispherical-tipped projectiles; (4) the energy used in new surface generation is up to $75 \%$ of the initial energy, which is very high; (5) the $w_{f}$ of rock under projectile impact is large, lying in the range from 1790 to $68,700 \mathrm{~J} / \mathrm{m}^{2}$.

Bear in mind that the $w_{\mathrm{f}}$ required for creating unit new surface area in indentation fracture should be based on the crater surface area, the surface areas of the ejected particles and the crack surface area below (or surrounding) the crater by sectioning. However, in Kumano and Goldsmith (1982a), for both large projectiles and small projectile, the surface area of the crater was neglected. In addition, indentation usually causes a compacted crushed zone, as shown in Fig. 12, beneath the indenter or projectile (e.g. Xu and $\mathrm{Yu}$ 1984; Zhang 1994; Kou 1995; Nariseti et al. 2015). Because neither the crater area nor the crushed zone was included in the determination of the specific fracture energy by Kumano and Goldsmith (1982a), the $w_{\mathrm{f}}$ values given in their paper are certainly much larger than the actual specific fracture energy. Accordingly, a comparison of their data with other fracture energy values studied in this paper should be made with caution.

In rock drilling, the energy required to excavate a unit volume of rock is often defined as the specific energy (Teale 1965). We use $w_{\mathrm{fv}}$ to express the specific energy in the unit of $\mathrm{J} / \mathrm{m}^{3}$. This definition is useful in practice to a certain 
extent, but it is not suitable for evaluating energy efficiency in rock drilling since a given volume of fragments (e.g. drill cuttings) may contain surface areas of very different magnitudes.

One issue to investigate in rock drilling is the behaviour of the rock beneath a drill bit. As long as rock drilling starts at the collar of a drill hole, a cyclic load is applied to the rock beneath the drill bit. The studies on this issue are still scarce outside the laboratories of the drill manufacturers. Another issue is the repeated breakage of cuttings or debris in various kinds of rock drilling and rock boring due to insufficient flushing that often makes a part of the cuttings remain at the bottom of drill hole. Their repeated breakage is a substantial energy loss. According to field measurement of the broken volume under the cutter buttons of a boring machine, the boring speed (penetration per revolution of the boring machine) has the potential of being increased by 4 times from the current level (Zhang 2016). To realize this, one of important tasks is to ensure sufficient and efficient flushing so that repeated breakage can be avoided or at least reduced.

\subsection{Specific Energy $w_{f v}$ in Indentation Tests and in Percussive Rock Drilling}

Reported measurements on specific energy in percussive drilling or similar indentation tests are few. Stoxreiter et al. (2019a) performed indentation tests with a bullet-shaped tungsten carbide indenter on Neuhauser granite specimens with a diameter of $220 \mathrm{~mm}$ and a height of $90 \mathrm{~mm}$. The specimens were mounted in a steel ring and the annular space was filled with mortar. This test condition is similar to real percussive drilling to a certain extent. The test result from 30 indentation tests indicates that the specific energy $w_{\mathrm{fv}}$ varies from 150 to $670 \mathrm{MJ} / \mathrm{m}^{3}$ with the average value of $406 \mathrm{MJ} / \mathrm{m}^{3}$. Teale (1965) condcuted percussive drilling tests in Pennant sandstone and found that the specific energy was $173 \mathrm{MJ} / \mathrm{m}^{3}$, which is close to the lowest Neuhauser indentation value. The average specific energy value for all 30 indentation test and percussive data is equal to $399 \mathrm{MJ} / \mathrm{m}^{3}$.

\subsection{Energy Efficiency of Percussive Drilling}

Carrol (1985) stated that only $10 \%$ of the input energy was used to fracture rock in rock drilling, while most of the input energy was wasted as heat or other forms of energy. However, this value must be verified by experimental studies. Many previous studies involved energy efficiency in percussive drilling (e.g. Simon 1964; Lundberg 1973; Xu and Yu 1984; Karlsson et al. 1989; Li 1994; Lundberg and Okrouhlik 2006; Lundberg and Collet 2015; Lundberg and Huo 2017; Hashiba et al. 2015), but the study on the energy efficiency has been far from complete. For example, in the study by Lundberg and Okrouhlik (2006), the efficiency of a percussive drilling process is defined as the ratio of the crushing work (determined by the force-displacement curve of the drill bit) to the impact energy per impact cycle. Using this definition they found that the efficiency of churn/percussive drilling is quite high, up to $40-60 \%$. However, the high efficiency found by them arises because their crushing work contains not only the energy used in fracturing the rock but also the kinetic energy expended in the ejecta of fragments, the non-elastic work dissipated in the crushing zone, and so on. Accurate ways to measure these forms of energy haven't been developed.

Energy efficiency in percussive drilling is dependent on incident wave shape and on the ratio of the slope of the loading curve to the slope of the unloading curve, and it increases with a decreasing value of this ratio (Lundberg and Collet 2015). In practice the optimum energy efficiency of percussive drilling is constrained by the maximum force and bit displacement that a given drill piston, drill string and bit design can deliver (Lundberg and Huo 2017).

\section{Specific Energy $w_{\mathrm{fv}}$ in Rock Cutting and Rotary Drilling}

Boring machines for both tunnel excavation and raise boring use rotating cutters to break the rock beneath them, and the loading rate in such cutting is called quasi-static (Zhang 2004, 2016). Similar to the boring machines, a rotary drilling machine with a tri-cone bit breaks the rock as the bit rotates under a thrust and a torque. In this sense, the mechanism of rock breakage in boring machines can be considered to be the same as in rotary drilling. However, the mechanism of rock cutting with a scratch or cutting device that doesn't roll over the surface, such as a poly-crystalline diamond compact (PDC) cutter is different since the fixed cutter shears of a ledge in the rock under the application of a vertical load.

The studies on rock cutting and rotary drilling have increased in recent years, probably due to the increasing demand on mechanical rock excavation. Specific energy in full-scale rock cutting and rotary drilling has been investigated by many investigators (e.g. Teale 1965; Fowell and Ochei 1984; Detournay and Defourny 1992; Bilgin et al. 2006; Tuncdemir et al. 2008; Munoz et al. 2016; He and Xu 2016; Wang et al. 2018; Dehkhoda and Detournay 2019; Stoxreiter et al. 2019a, b). The full-scale cutting and drilling tests often used large rock samples that were confined.

Table 14 summarizes the measured specific energies in full-scale rock cutting and rotary drilling from the previous studies mentioned above. According to these and Table 14, the following conclusions can be found: (1) larger cut depth expends much less specific energy than smaller cut depths (Fowell and Ochei 1984; Bilgin et al. 2006; Tuncdemir et al. 2008). (2) The specific energy depends on the type of 
Table 14 Specific energy in full-scale rock cutting and rotary drilling

\begin{tabular}{|c|c|c|c|}
\hline Method of rock breakage & Rock & $\begin{array}{l}\text { Specific energy (MJ/ } \\
\left.\mathrm{m}^{3}\right)\end{array}$ & References \\
\hline Full-scale cutting with chisel pick & Greywacke & 41.8 & Tuncdemir et al. (2008) \\
\hline Full-scale cutting with chisel pick & granite & 118.8 & Tuncdemir et al. (2008) \\
\hline Full-scale cutting with V-disc & Gypsum & 37.8 & Tuncdemir et al. (2008) \\
\hline Full-scale cutting with V-disc & Greywacke & 360.4 & Tuncdemir et al. (2008) \\
\hline Full-scale cutting with PDC cutter & Tuffeau limstone & 19.0 & Munoz et al. (2016) \\
\hline Full-scale cutting with PDC cutter & Hawksbury sandstone & 97.0 & Munoz et al. (2016) \\
\hline Full-scale cutting with PDC cutter & Brukunga Phyllite & 205.0 & Munoz et al. (2016) \\
\hline Full-scale cutting with PDC cutter & Mantina basalt & 495.0 & Munoz et al. (2016) \\
\hline Full-scale cutting with PDC cutter & Savonnieres limestone & 36.0 & He and Xu (2016) \\
\hline Full-scale cutting with PDC cutter & Tuffeau limestone & 20.0 & $\mathrm{He}$ and $\mathrm{Xu}(2016)$ \\
\hline Full-scale cutting with disc cutter & Limestone & 6.0 & Dehkhoda and Detournay (2019) \\
\hline Average & & 130.6 & \\
\hline Rotary drilling with cutter & Sandy shale & 50.4 & Teale (1965) \\
\hline Rotary drilling with cutter & Sandstone & 89.7 & Teale (1965) \\
\hline Rotary drilling with cutter\# & Concrete & 97.7 & Teale (1965) \\
\hline 32-mm rotary drilling & Darley Dale sandstone (block) & 43.1 & Teale (1965) \\
\hline 32-mm rRotary drilling & Chislet shale & 40.7 & Teale (1965) \\
\hline Rotory drilling with tri-cone bit & Pennant sandstone & 129.0 & Teale (1965) \\
\hline Rotory drilling with tri-cone bit & Pennant sandstone & 91.8 & Teale (1965) \\
\hline Rotory drilling with tri-cone bit & Concrete & 44.2 & Teale (1965) \\
\hline Rotory drilling with tri-cone bit & Concrete & 40.5 & Teale (1965) \\
\hline Rotory drilling with tri-cone bit & Neuhauser granite & 166.1 & Stoxreiter et al. (2019b) \\
\hline Rotory drilling with tri-cone bit & Neuhauser granite & 167.7 & Stoxreiter et al. (2019b) \\
\hline Rotory drilling with tri-cone bit & Neuhauser granite & 168.6 & Stoxreiter et al. (2019b) \\
\hline Rotory drilling with tri-cone bit & Neuhauser granite & 187.3 & Stoxreiter et al. (2019b) \\
\hline Rotory drilling with tri-cone bit & Neuhauser granite & 198.9 & Stoxreiter et al. (2019b) \\
\hline Rotory drilling with tri-cone bit & Neuhauser granite & 211.1 & Stoxreiter et al. (2019b) \\
\hline Rotory drilling with tri-cone bit & Neuhauser granite & 345.6 & Stoxreiter et al. (2019b) \\
\hline Rotory drilling with tri-cone bit & Neuhauser granite & 367.8 & Stoxreiter et al. (2019b) \\
\hline Rotory drilling with tri-cone bit & Neuhauser granite & 382.8 & Stoxreiter et al. (2019b) \\
\hline Average & & 156.8 & \\
\hline
\end{tabular}

\#median value

cutters, indicating that the design of cutters plays an important role in rock cutting and rotary drilling. (3) The magnitude of the specific energy depends on the nature of the rock, the surrounding pressure on the rock surface and the drilling technique being used (e.g. Teale 1965; Detournay and Defourny 1992; Munoz et al. 2016). (4) The specific energy in cutting increases with increasing back-rake angle of the cutter (Munoz et al. 2016). (5) Specific energy decreases with increasing drill bit weight in rotary drilling, as shown in Fig. 13. (6) The specific energy in tri-cone rotary drilling is dependent on the mechanical power of the drill machine. Larger mechanical power yields smaller specific energy and vice versa. (7) The specific energy of rock cutting varies in a large range of 6-495 MJ/m³ , with an average of $131 \mathrm{MJ} /$ $\mathrm{m}^{3}$. (8) The specific energy of rotary drilling varies from 41 to $383 \mathrm{MJ} / \mathrm{m}^{3}$, with an average of $157 \mathrm{MJ} / \mathrm{m}^{3}$.

In ordinary rotary drilling experiments by Stoxreiter et al. (2019b), the specific energy (based on thrust and rotary force components) is shown in Table 14 and Fig. 13. In addition to the mechanical power, an assisting high-pressure fluid jet with one or two nozzles was also used in some tests. Figure 13 shows that (1) the mechanical specific energy decreases with increasing bit weight for both standard drilling (with no high pressure jet assistance) and jet-assisted drilling, and (2) the mechanical specific energy of the standard drilling is larger than that of the jet-assisted drilling at a specific bit weight. However, Fig. 13 only shows the mechanical 


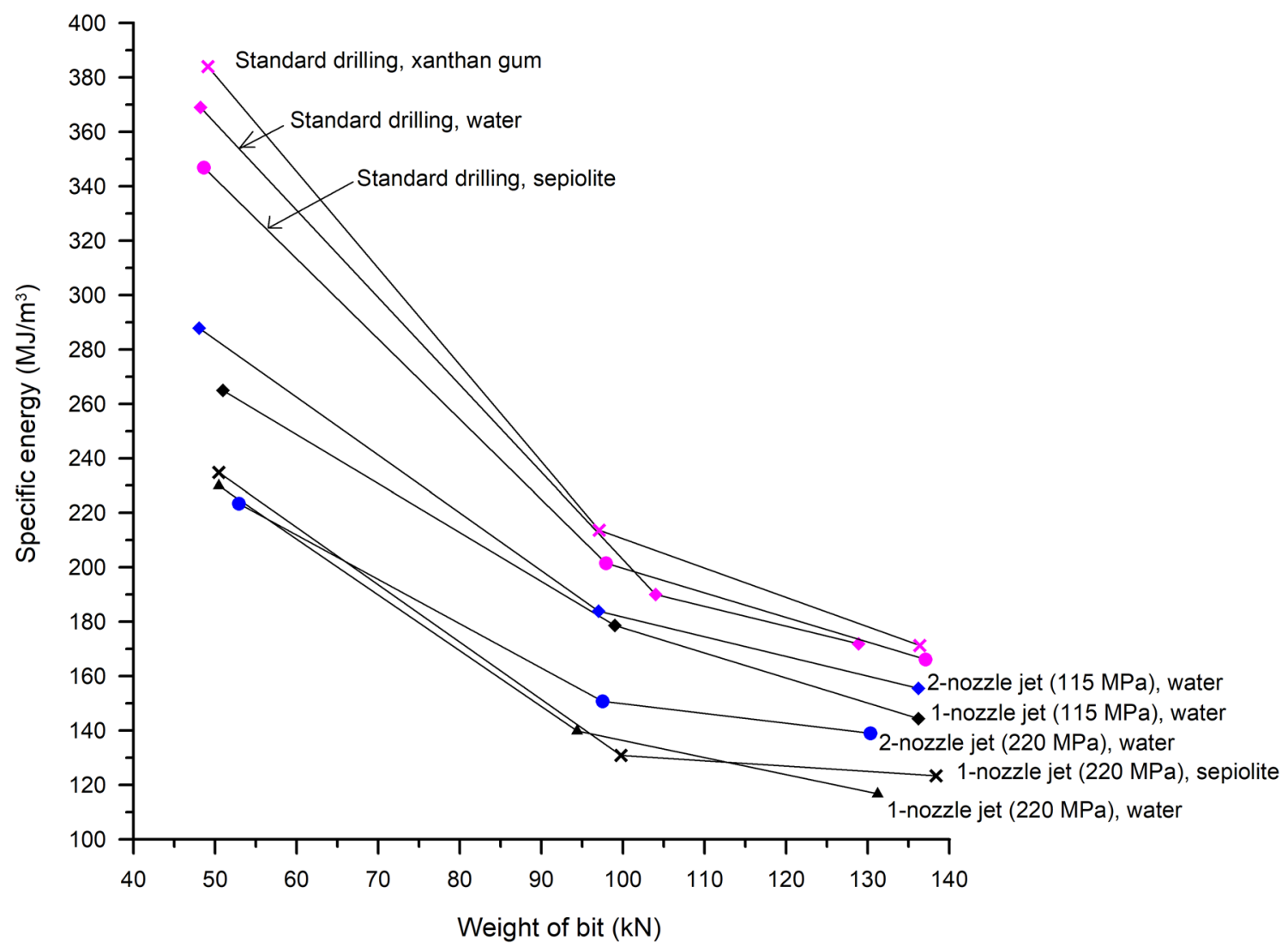

Fig. 13 Mechanical specific energy vs. weight of drill bit (based on the data in Stoxreiter et al. 2019b). Three groups of drilling tests are shown in upper part (standard drilling), middle part (1- and 2-nozzle

specific energy while the specific energy used in jet cutting is not included. The fact is that the specific energy for the jet cutting was found to be much higher than that for the rotary drilling, based on the combined excavation volume (Stoxreiter et al. 2019b). Therefore, the combination of the ordinary drilling and the jet cutting is not energy-efficient.

\section{Fracture Energy and Energy Efficiency in Rock Blasting}

\subsection{Mechanism of Rock Fragmentation by Blasting}

The mechanism of rock fragmentation by blasting is a complicated interdisciplinary problem dealing primarily with chemical reactions, detonation, shock waves, nearfield stress waves, crack growth, and fragment throw. Energy components like far-field stress waves, i.e. seismic waves or ground vibrations, blasthole pressure losses due to poor stemming retention, air shock waves and dust, i.e. airborne fine fractions are also important. In normal jet-assisted drilling with $115 \mathrm{MPa}$ jet pressure) and lower part (1- and 2-nozzle jet-assisted drilling with $220 \mathrm{MPa}$ jet pressure). The drilling fluids such as water, xanthan and sepiolite are indicated

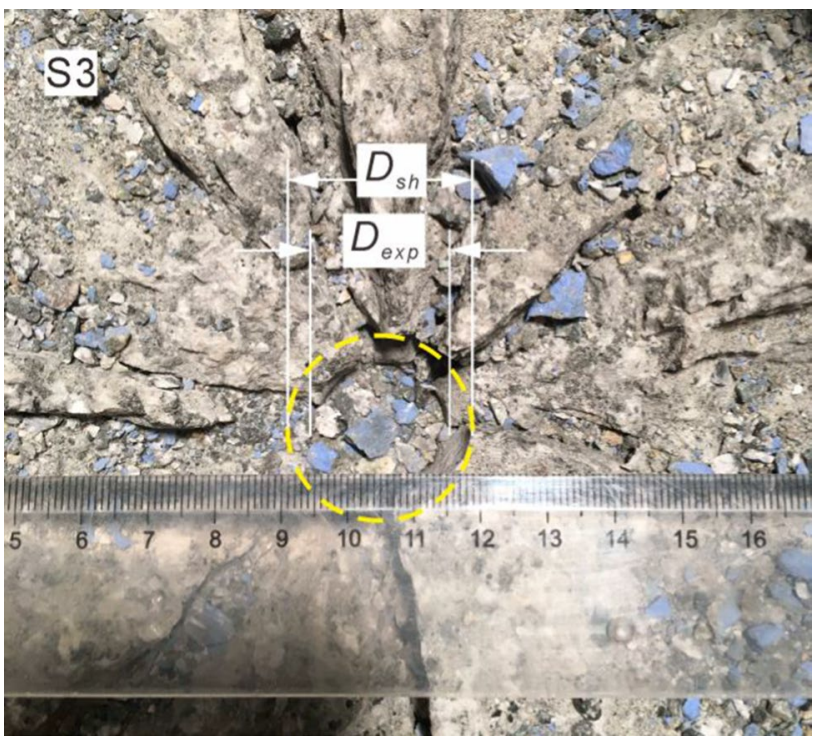

Fig. 14 Crushing and fracturing pattern in granite with decoupled explosive charge (after Chi et al. 2019a) 
blasting all energy supplied to rock fracture and fragmentation comes from the detonation of explosive charges in the drill holes. The detonation may be either an ideal detonation or a non-ideal detonation. The ideal (i.e. onedimensional) detonation theories include the ChapmanJouguet (CJ) theory (Chapman 1899; Jouguet 1905) and the Zeldovich-Neumann-Döring (ZND) theory (Zeldovich 1940; von Neumann 1942; Döring 1943). In most rock blasting, the detonation behaves in a more or less non-ideal manner. Accordingly, 2D or quasi-2D detonation theories using direct numerical solution (DNS) (Bdzil et al. 2001; Sharpe and Braithwaite 2005), detonation shock dynamics (DSD) (Bdzil and Stewart 1986), and the streamline approach (Watt et al. 2012) have been developed in last decades. The 1D detonation theory can be found in more detail in Fickett and Davis (2000), Davis (1997), Cooper (1996) and Zhang (2016). For rock fracture and fragmentation studies, one of challenges is to determine how the explosive energy has been partitioned during a blast.

Johansson and Persson (1970) found that in their singlehole detonation tests with high speed photography in cubes of Plexiglas: (1) the original borehole expanded, (2) a fractured zone, that didn't start at the borehole wall appeared around the borehole, and (3) outside the fractured zone was a radially symmetric stress wave front. Since the 1970s, a large number of blast experiments have supported these observations. Figure 14 shows the crushing and fracturing pattern in a blasted cylindrical granite specimen with a diameter of $228 \mathrm{~mm}$ (Chi et al. 2019a). During blasting of the granite specimen in Fig. 14, spalling had ejected the upper part of the specimen. Hence many visible radial cracks, a crushed zone ( $D_{\mathrm{sh}}$ in the picture), some debris and the borehole diameter $\left(D_{\text {exp }}\right)$ may be seen in the remaining lower part.

\subsection{Energy Distribution in Rock Blasting}

Many publications such as Langefors and Kihlström (1978) and Revnivtsev (1988) stated that the energy efficiency of rock blasting was in the range of $5-15 \%$. However, this value needs to be backed up by measurement. To increase energy efficiency in rock blasting, the partitioning of the energy is important. Spathis (1999), Ouchterlony et al. (2003), Ouchterlony et al. (2004a, b), and Sanchidrián et al. (2007) have experimentally investigated the energy components, and Zhang (2016) discussed the energy distribution in rock blasting. This review does not aim to present a complete description of the partitioning, but to introduce main results from previous experimental studies. Here it is assumed that the energy $E_{\mathrm{E}}$ released by the explosive when it detonates is converted into several components, as follows:

$E_{\mathrm{E}}=E_{\mathrm{F}}+E_{\mathrm{K}}+E_{\mathrm{S}}+E_{\mathrm{o}}$ where $E_{\mathrm{F}}$ is fracture energy required to create new external surface areas on fragments. $E_{\mathrm{K}}$ is translational and rotational kinetic energy of fragments in flight. $E_{\mathrm{S}}$ is seismic energy carried by the stress waves out of the fractured zone. $E_{\mathrm{o}}$ is other energies such as energy in creating internal cracks within fragments, gas ejection (e.g. from the collars of blastholes), heating the rock, plastic deformation, and other uncounted energy forms.

\subsection{Energy Components in Rock Blasting}

Energies $E_{\mathrm{F}}, E_{\mathrm{S}}$, and $E_{\mathrm{K}}$ have been measured by Hinzen (1998), Spathis (1999), Ouchterlony et al. (2003, 2004a, b), Moser and Grasedieck (2004), Moser (2004) and Sanchidrián et al. (2007). A series of measurements by Sanchidrián et al. (2007) indicate that $E_{\mathrm{F}}=0.1-6.0 \%$, $E_{\mathrm{S}}=0.6-12 \%$ and $E_{\mathrm{K}}=3.3-39 \%$. An interesting result is that the sum of these three energies was less than $40 \%$ and $35 \%$ of the explosive energy according to the measurements by Sanchidrián et al. (2007) and Moser (2004), respectively, meaning that the unaccounted explosive energy was at least $60 \%$. That is to say, most of the explosive energy must be dissipated as $E_{\mathrm{O}}$. In addition, it can be found that each of the three energies varies over a large range since energy efficiency is affected by many factors such as burden, spacing, confinement, delay time, charge parameters, initiation, and the like. For example, model blasts indicated that: (1) stemming conditions affected the initiation of gas ejection out of blastholes (Zhang et al. 2021); (2) unstemmed holes wasted $25 \%$ of the explosive energy (Zhang et al. 2020a) available for rock fragmentation, compared with partially-stemmed blasts; (3) the specific charge influenced the crack propagation velocity (Chi et al. 2019b). In addition, field measurements by Brinkmann (1990) indicated that unstemmed blastholes in underground mining blasts wasted $50 \%$ of the explosive energy in the form of 'leaking' gases, compared with fully-stemmed blastholes.

Blasting tests indicated that a confined blast gave rise to more seismic energy than other unconfined blasts (Sanchidrián et al. 2007). Similarly, measurements in tunnelling showed that the seismic energy was up to $25 \%$ of the explosive energy in the heavily confined cut holes but below $1 \%$ in the less confined perimeter holes in drifting (Hinzen 1998). This is why in vibration control one should pay much attention to the cut holes in tunnelling or the first-initiated hole in multihole blasting since the firstinitiated hole often has a higher confinement than the other holes. Similarly, it was found that the confining condition had a great impact on rock fragmentation in laboratory model blasting (Chi et al. 2019a; Zhang et al. 2020b). If the confining condition is well used, rock fragmentation can be improved, for example, by impact fracture using 
the kinetic energy carried by the flying fragments (Zhang 2016). Another issue is the percentage of the internal fracturing energy in the total explosive energy. So far this percentage has been unknown, but this does not mean that the internal fracturing energy is a small portion of the explosive energy. Technically, this energy could be estimated by measuring the total surface area or volume of the internal cracks in fragments by microscopic technology or gas adsorption method.

\subsection{Fines Problem in Blasting}

Most mineral processing techniques have problems in the ultra-fine size range (Wills and Napier-Munn 2006), i.e. very small mineral particles, e.g. those smaller than 10 microns $(\mu m)$ are difficult to recover in mineral processing. As a result, a vast amount of minerals resources are lost every year in such fines. Similarly, in aggregate quarries, if the materials (fragments or aggregates) are smaller than a certain size, e.g. $4 \mathrm{~mm}$ in a general case, these materials will normally be useless, as mentioned earlier. In addition, the worldwide production of fines wastes a vast amount of energy. To reduce unwanted fines, it is necessary to perform a series of fundamental studies on size distribution under various blasting conditions. One of challenges is to collect all of particles, especially the fine ones, in blasting since the weight loss in blasting experiments is difficult to reach zero as the specific charge is high. For instance, the weight loss is $0.3-1.2 \%$ in Reichholf (2013), 0.2-2.7\% in Zhang et al. (2020a), and 0-2.7\% in Zhang et al. (2020b). The zero weight loss occurred when the specific charge was small and the specimen was just split into two halves.

Fines come from not only the crushed zone but also crack branching during rock fracture by blasting or stress wave loading. The measurement and analysis by Reichholf (2013) showed that for iron ore, magnesite and limestone, around $50 \%$ weight of the material smaller $1 \mathrm{~mm}$ was generated within the crushed zone of blasthole, meaning that other $50 \%$ fine particles were not from the crushed zone.

\subsection{Energy Efficiency in Blasting}

Although energy efficiency in rock blasting has been investigated by many researchers, the results are still not accurate enough. For example, the relatively comprehensive study by Sanchidrián et al. (2007) indicated that the maximum energy efficiency in blasting, regarding rock fracture (fragmentation), was 6\%. This result was based on two estimations used in determining fracture energy: (1) the inverse of the Rittinger coefficient was used as specific

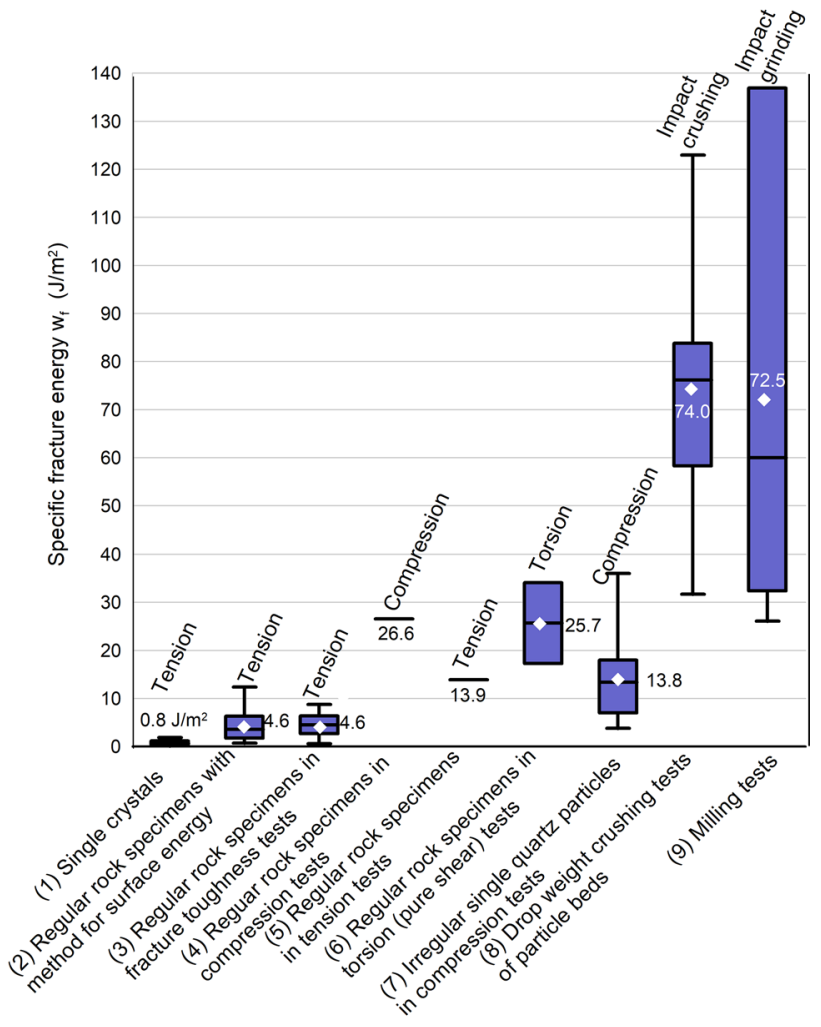

Fig. 15 Box-Whisker plot for specific fracture energy measured from various tests under room temperature and non-confinement conditions. Groups 1-7 are static loading and Group 8 is dynamic loading $(3.5 \mathrm{~m} / \mathrm{s}$ impact speed). The average specific fracture energy of each group is indicated by the small white squares. The specific meaning of Box-Whisker plot is explained in Fig. 4

fracture energy, and (2) the surface area of the fragments was estimated from the muckpile size distribution, assuming that the fragments are spherical or cubic. These two estimations are interesting but may contain errors. Another issue concerning energy efficiency in blasting is how to define useful explosive energy more precisely. In brief, more precise measurements of the fracture surface areas, of rock fracture surface energy as well as of explosive energy are needed in order to determine energy efficiency of rock blasting more reliably in the future.

\section{Comparison of Fracture Energies from Small Scale and Full Scale Tests}

\subsection{Specific Fracture Energy from Single Specimens, Single Particles, Particle Beds and Milling Tests}

The measurement results of specific fracture energy from various tests can be divided into nine groups: (1) single 
Fig. 16 Energy efficiencies in various tests based on measured specific fracture energy

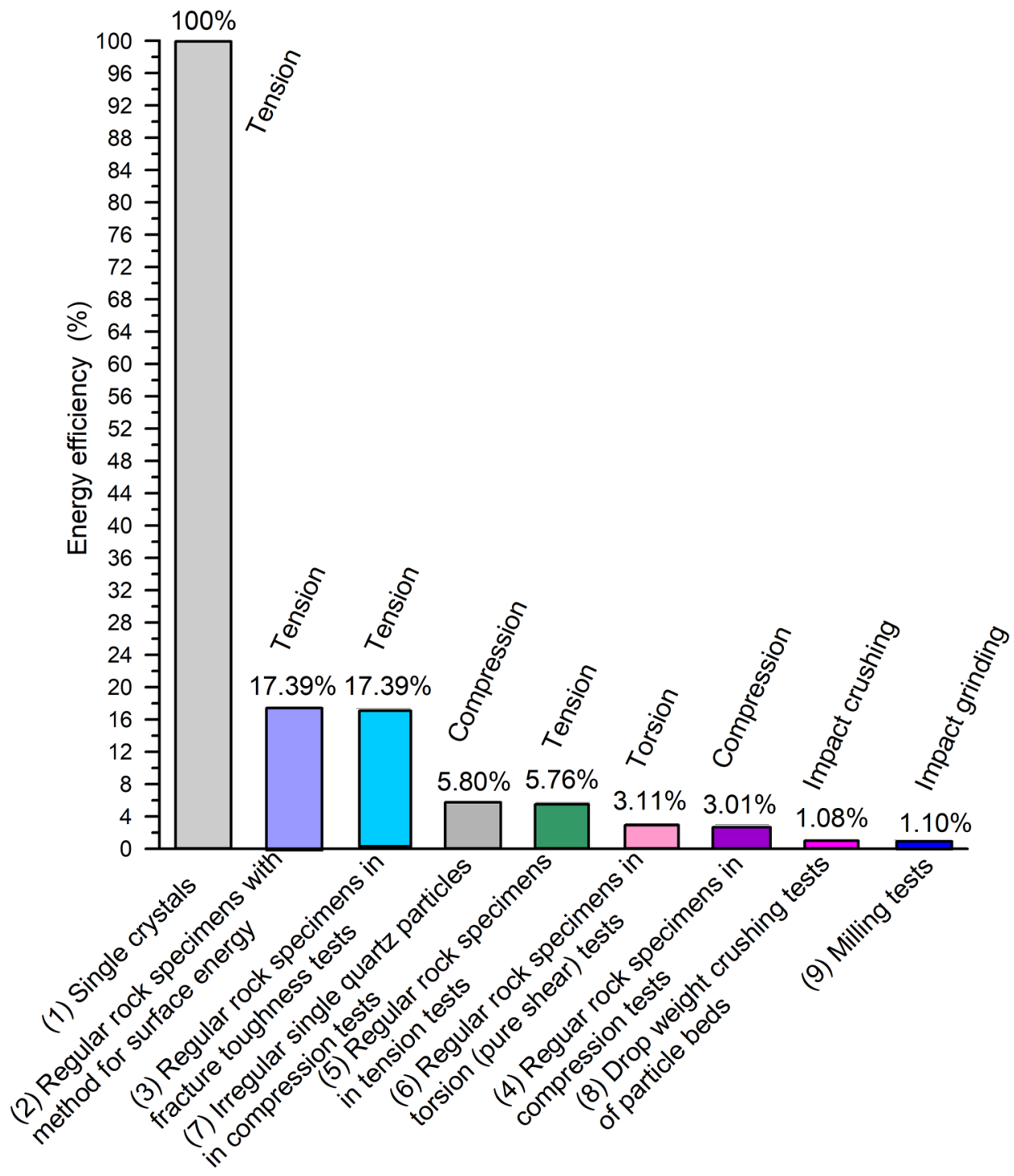

crystals, (2) regular rock specimens for crystal surface energy tests, (3) regular rock specimens for fracture toughness tests, (4) regular specimens for uniaxial compression tests, (5) regular specimens for uniaxial tension tests, (6) regular specimens for pure torsion (shear) tests, (7) single quartz particles in static compression, (8) drop weight crushing tests of particle beds, and (9) milling tests. Among these groups, Group 8 belongs to dynamic loading, having similar loading rate as in the milling tests. The other groups are mostly static or quasi-static loading tests. In all nine groups the confining pressure is zero. Because Groups 2, 3, 5 and 6 do not have the data of measured specific fracture energy $w_{\mathrm{f}}$, it is necessary to convert the measured nominal specific fracture energy $w_{\mathrm{f}}^{\mathrm{o}}$ into $w_{\mathrm{f}}$.

From Sect. 4.2.9, the ratio of the measured surface areas of rock specimens at the 2000 magnification to the nominal areas is 11 (Hoagland et al. 1973). In this paper it is assumed that the 2000 magnification is large enough to approach the true surface areas and the ratio 11 is suitable for converting a nominal surface area to its true area in various small-scale rock fracture tests. Thus, the approximation $w_{\mathrm{f}}=11 \times w_{\mathrm{f}}^{\mathrm{o}}$ was used to convert the $w_{\mathrm{f}}^{\mathrm{o}}$ data to $w_{\mathrm{f}}$ data in Tables 2, 4, 6 and 7. The combined $w_{\mathrm{f}}$ data of all eight groups are shown in Fig. 15.

From Fig. 15 we can conclude: (1) the average $w_{\mathrm{f}}(=\gamma)$ of Group 1 is $0.8 \mathrm{~J} / \mathrm{m}^{2}$, and that of Group 2 is $4.6 \mathrm{~J} / \mathrm{m}^{2}$, which is 5.8 times larger. Notice that Group 1 contains regular single crystals and their fracture surfaces are usually mirror-smooth. Group 2 however contains regular rock specimens, their fracture surfaces are often zig-zag, and they usually have fracture process zones near crack tips. (2) The average $w_{\mathrm{f}}$ of Group 3 is $4.6 \mathrm{~J} / \mathrm{m}^{2}$, equal to that of Group 2. (3) The average $w_{\mathrm{f}}$ of each of Groups 4-6 is 3-6 times larger than those of Group 2 and Group 3. Note that Groups 4-6 consist of uniaxial compression, uniaxial tension and uniaxial shear tests using regular rock specimens 


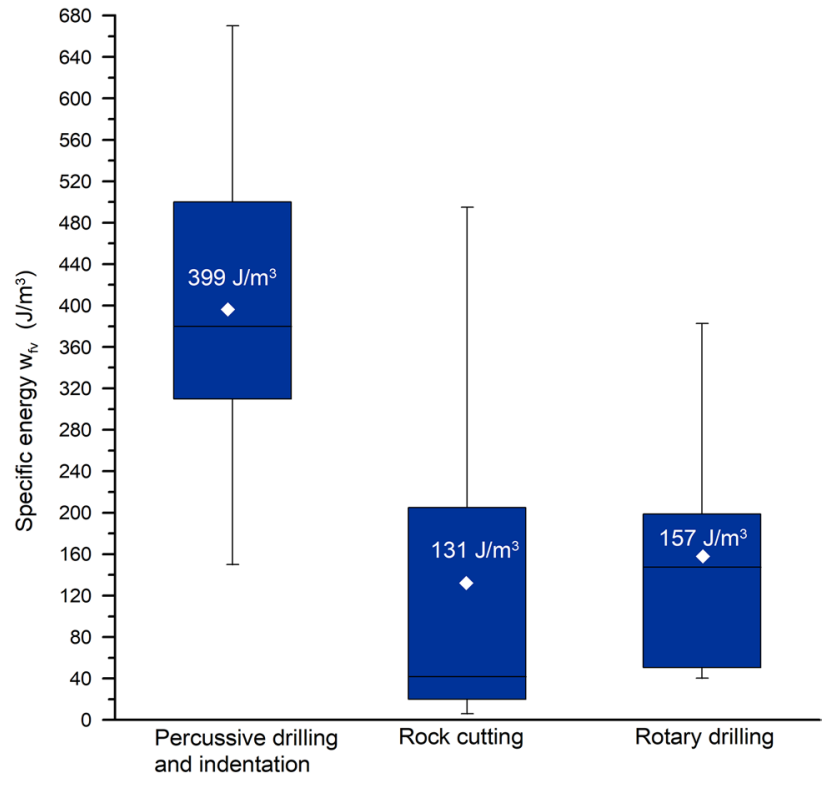

Fig. 17 Box-Whisker plot for comparison of specific energies from percussive drilling, rock cutting and rotary drilling (original data of specific energy is from the references in Sect. 9.3 and Table 14). The specific meaning of Box-Whisker plot is explained in Fig. 4

with neither pre-made cracks nor pre-cut notches, while Groups 2 and 3 are cleavage fracture tests with either premade cracks or pre-cut notches. (4) The average $w_{\mathrm{f}}$ of Group 7 is $13.8 \mathrm{~J} / \mathrm{m}^{2}$, about $3-4$ times larger than the $w_{\mathrm{f}}$ of Groups 2 and 3. This result means that to break irregular single quartz particles under uniaxial compression requires 3-4 times the energy that is needed to break a regular rock specimen with either pre-made crack or pre-cut notch under tension or cleavage loading condition. Notice also that the $w_{\mathrm{f}}$ values of Group 7 cover a wide range from 3.8 to $36.0 \mathrm{~J} / \mathrm{m}^{2}$, probably due to Group 7 consisting of irregular single particles. (5) The average $w_{\mathrm{f}}$ of Group 8 is $74.0 \mathrm{~J} / \mathrm{m}^{2}$, and that of Group 9 is $72.5 \mathrm{~J} / \mathrm{m}^{2}$ and they are essentially equal.

\subsection{Energy Efficiencies in Various Tests}

Taking the average specific surface energy, $0.8 \mathrm{~J} / \mathrm{m}^{2}$, of single crystals as a reference, the energy efficiencies of various failure and crushing tests can be determined as follows. It is defined that the energy efficiency of one group of tests is equal to $0.8 \mathrm{~J} / \mathrm{m}^{2}$ divided by the average $w_{\mathrm{f}}$ of that group. As mentioned before, the $w_{\mathrm{f}}$ data is based on measured true surface area (or converted area) rather than nominal surface area. In this way, the average energy efficiencies of all nine groups of tests (in Fig. 15) can be obtained, as shown in Fig. 16. The order of the energy efficiencies in various tests is clearly shown in Fig. 16, indicating that the lowest efficiencies are from the crushing and milling of multi-particles.

\subsection{Comparison of Percussive Drilling, Rock Cutting and Rotary Drilling}

Section 9.3 shows that the specific energy $w_{\mathrm{fv}}$ in percussive drilling and indentation tests varies from 150 to $670 \mathrm{MJ} / \mathrm{m}^{3}$ with an average of $399 \mathrm{MJ} / \mathrm{m}^{3}$. Section 10 indicates that the specific energy $w_{\mathrm{fv}}$ in rock cutting and that in rotary drilling cover wide ranges, see Fig. 17. Evidently, the minmum, maximum and average specific energies of rock cutting and rotary drilling are much smaller than the corresponding energies of percussive drilling and indentation tests, indicating that rock cutting and rotary drilling are more energyefficient methods than percussive drilling and indentation.

\section{Relation between Fracture Energy and Fragment Size Distribution}

It is important to predict the fragment size distribution and the energy necessary for the size reduction of a given rock in blasting, mechanical crushing and grinding. Due to limited space in this paper, we only give a brief introduction to the main theories or functions concerning fracture energy and size distribution. According to the initial application areas such theories and functions can be divided into three groups: (1) rock fragmentation by blasting, (2) ore comminution, and (3) fragmentation of shells.

\subsection{Models of Fragment Size Distribution in Rock Blasting}

Rock fragmentation by blasting can be described by many distributions such as those proposed by Rosin and Rammler (1933), Weibull (Weibull 1951), the Kuz-Ram model (Cunningham 1983), and the Swebrec function (Ouchterlony 2005). A review on various size distribution functions can be found in Ouchterlony and Sanchidrián (2019). Compared with other models or functions, the Swebrec function often gives better prediction results, especially for fine particles (Sanchidrián and Ouchterlony 2017). To relate fragmentation with energy input to blasting, new concepts have been developed, called the fragmentation-energy fan (Ouchterlony et al. 2017; Ouchterlony and Sanchidrián 2018) and the distribution free fragmentation model (Sanchidrián and Ouchterlony 2017). This fragmentation-energy fan relates the fragment size with explosive energy in the form of the specific charge in bench blasting.

\subsection{Theories and Models in Comminution}

In comminution the earliest theories of size reduction are the energy-new surface, energy-volume, and energy-crack length theories proposed by Rittinger (1867), Kick (1883) and Bond 
(1952), respectively. Slow compression crushing tests with small net energy input per gram of material (Gross and Zimmerley 1930; Johnson et al. 1949) indicated that Rittinger's theory,which assumes that the specific fracture energy is proportional to the newly generated surface area was correct. However, as the net energy input became higher the relationship between the two parameters became nonlinear, probably due to plastic deformation (Adams et al. 1949). These three theories have not been generally applicable to all comminution processes (Awachie 1983). It was found that the Rittinger coefficient $R$ in $\left[\mathrm{cm}^{2} / \mathrm{J}\right]$ could be determined on the basis of the natural, equipment independent, breakage characteristics of a rock and it related the production of new surface to the net energy input (Steiner 1998). Reichholf (2013) obtained that the $R$ values of 5 rocks from comminution tests. Since $w_{\mathrm{f}}=\frac{1}{R}$, we can get that the $w_{\mathrm{f}}$ values of the 5 rocks are 116.1 for dolomite, 180.5 for magnesite, 221.1 for iron ore, 142.7 for sandstone, and $111.9 \mathrm{~J} / \mathrm{m}^{2}$ for limestone. Interestingly, these $w_{\mathrm{f}}$ values are not very far from the maximum $w_{\mathrm{f}}$ values in the milling tests shown in Table 13 and Fig. 15.

To characterize the breakage properties of rock and make better designs of comminution circuits, a laboratory drop weight testing (DWT) system was developed by the JKMRC (Julius Kruttschnitt Mineral Research Centre) (Napier-Munn et al. 1996). Based on a series of studies (e.g. Narayanan 1985; Narayanan and Whiten 1988), a rock breakage model, named JK breakage model, was developed in the JKMRC (Napier-Munn et al., 1996), and then a modified model, called JK size-dependent breakage model was introduced by Shi and Kojovic (2007). A detailed introduction to these models can be found in Shi (2016), and a recent extension of these models in Ouchterlony et al. (2017).

In brief, the models or theories mentioned above have provided necessary tools for studying rock fragmentation by blasting and mechanical loading methods. However, it is still desirable to develop new models or to improve existing models so that fragment size distribution function can be well linked with the energy input and the energy used in fragmentation.

\subsection{Other Models of Fragmentation}

Mott (1943, 1947) studied the fragmentation of idealized geometrical objects such as armament shells. Since then, many fragmentation models have been developed. For example, Shockey et al. (1974) developed an approximate formula to relate the energy used in creating new fracture area with the specific surface energy $\gamma$, the number of activated flaws, the duration of the stress pulse, etc. However, it is difficult to know the number of the activated flaws in applications.

Grady and Kipp (1980) developed two equations, one for calculating the internal energy dissipated in creating cracks and the other for estimating the total fragment surface area.
Since the 1980's more models or theories have been proposed. Major models predicting the rate-dependent average fragment size include: analytical models by Grady (2006) and Glenn and Chudnovsky (1986), models derived from the simulation of expanding brittle rings by Zhou et al. (2006a, b) and Levy and Molinari (2010), modified Grady model and modified Glenn and Chudnovsky model by Hogan et al. (2016). By comparing the experimental fragmentation results with the above models, Hogan et al. (2016) found that: (1) the modified Glenn and Chudnovsky (1986) model tracked with the modified Grady (2006) model for higher strain rates. (2) Both of the modified models predicted smaller fragment sizes than all of the other models for higher strain rates. (3) The modified Glenn and Chudnovsky (1986) model and the models by Zhou et al. (2006a, b) and Levy and Molinari (2010) fit the data adequately at a strain rate higher than $10^{-1} / \mathrm{s}$ but not well for a strain rate smaller than $10^{-1} / \mathrm{s}$. (4) The modified Grady (2006) model appeared to track the best with the experimentally available data.

\section{Discussion}

\subsection{Effect of Inter-granular Displacement on Specific Fracture Energy}

Inter-granular displacements were found within a region of each side of the main crack via experimental observation in DCB specimens by Friedman et al. (1972) who argued that such inter-granular displacements are the main reason for the big discrepancy between the fracture energy of a rock specimen and the surface energy of a crystal. The authors of this paper have not found other publications reporting such an inter-granular displacement, but it is interesting to do an investigation on it.

\subsection{Effect of Confinement on Specific Fracture Energy}

The specific fracture energy of regular rock specimens (Sect. 4.2.7) increase with an increasing confining pressure. In addition, Table 6 and Fig. 15 show that the average $w_{\mathrm{f}}$ of regular rock specimens tested under static uniaxial compression is $26.6 \mathrm{~J} / \mathrm{m}^{2}$, which is only $1 \%$ of the average value $w_{\mathrm{f}}=2632.5 \mathrm{~J} / \mathrm{m}^{2}$ of the rock specimens under dynamic biaxial compression. Such a large difference between the two $w_{\mathrm{f}}$ values may be attributed not only to the dynamic loading plus other factors but also to the confining pressure in the biaxial dynamic compression tests. To confirm this confining pressure effect, more rock compression tests under dynamic loading and different confining pressures are needed in the future. In practical rock drilling and rock blasting a higher confining pressure often makes drilling and 
blasting more difficult. However, in high pressure grinding roller (HPGR) mills, confinement of the rock particles yields better comminution result than conventional ball mills that do not apply any confinement to the particles. One possible reason is that in the ball mills unconfined particles waste the kinetic energy carried by flying particles that don't impact on a hard barrier, while in the HPGR mills this kind of kinetic energy can be partially used in breaking the particles.

\subsection{Effect of Loading Rate on Fracture Surface Energy}

Section 5.2 indicates that loading rate has a great impact on fracture energy under dynamic loading conditions. Figure 9 and Table 5 show that under dynamic loading the fracture energy of rock increases linearly with loading rate. One of reasons is the common phenomenon-crack branching-in dynamic loading. There are possibly other unknown reasons.

As described in Sect. 8.7, a counterintuitive result was found on the effect of loading rate on energy efficiency of rock fragmentation. Sadrai et al. (2011) found that the energy efficiency increased with an increasing impact speed in the range $80-220 \mathrm{~m} / \mathrm{s}$. Zhang et al. $(2000,2001)$ on the other hand had found the opposite effect for impact speeds $<40 \mathrm{~m} / \mathrm{s}$. This seeming contradiction may be an effect of the two different ranges of loading rates, one with shock waves and the other with elastic waves.

\subsection{Effect of Accuracy of Surface Area Measurement on Fracture Surface Energy}

It is important to determine fracture surface area as accurately as possible in both small-scale tests and full-scale or production rock fragmentation, in order to determine fracture surface energy. Technically, fracture surface area can be accurately measured using various methods, for example, gas adsorption, scanning electronic microscope (SEM), profilometers, micro-computed tomography etc., if small specimens are used. However, in large or full scale experiments on rock blasting, it is still difficult to measure all fracture surfaces with an accurate method, in particular for fine particles. For instance, in mining production blasting, various image systems have been used in many mines nowadays, but one shortcoming of such systems is that their relative size ranges rarely go beyond a factor 30 between the maximum and the minimum size.

\subsection{Effect of Premade Crack on Fracture Surface Energy}

In rock fracture toughness measurement, the criteria on specimen pre-cracking essentially aim at producing a geometrically well-defined and sufficiently sharp crack outside the influence of residual stresses and premade notches (Ouchterlony 1982). Figure 5 (or Table 2) and Fig. 7 (or Table 4) indicate that the average $w_{\mathrm{f}}^{\mathrm{o}}$ for all rock specimens with a premade crack is $50.5 \mathrm{~J} / \mathrm{m}^{2}$, and that for all specimens with a pre-cut notch but without a premade crack it is $50.4 \mathrm{~J} / \mathrm{m}^{2}$. The difference between these values is insignificant, meaning that whether or not there is a pre-crack does not affect the nominal specific fracture energy, at least based on all cleavage or mode I fracture tests summarized in this paper. One reason is that in the rock fracture toughness specimens a sharp crack can be well formed during the loading process due to their favourable ligaments (with a triangular or sharp shape at the notch end) even though the specimens do not have a pre-made crack. Thus, a pre-cut notch could help to a certain extent create a pre-crack during loading process and play a similar role as a pre-made crack.

However, either a pre-made crack or a pre-cut notch must take part in the specific fracture energy, as described in Sect. 12.1 where Fig. 14 shows that the average $w_{f}$ values of each of Groups 4-6 is 3-6 times larger than that of Group 2 and Group 3. Groups 4-6 include uniaxial compression, uniaxial tension and uniaxial shear rock specimens with neither a pre-made crack nor a pre-cut notch, while Groups 2 and 3 consist of cleavage or tensile rock specimens with either a pre-made crack or a pre-cut notch. This result indicates that much more energy is required to create per unit fracture surface area in a regular rock specimen having neither a pre-made crack nor a pre-cut notch than that to produce the same area of fracture surface in a rock specimen with such a crack or notch. Since the result is based on a limited number of tests, especially in Groups 4-6 belonging to static loading, more tests are needed including both static and dynamic tests.

\subsection{Effect of Friction or Attrition on Specific Fracture Energy}

Compare the average surface energy $0.8 \mathrm{~J} / \mathrm{m}^{2}$ of all single crystals in Fig. 4 with the average specific fracture energy $w_{\mathrm{f}}=3.9 \mathrm{~J} / \mathrm{m}^{2}$ of all rocks in Fig. 5, the latter is about 5 times greater than the former. Since the testing methods are same in the above single crystals in Fig. 4 and the rock specimens in Fig. 5, the large difference between the two energy values may have several causes: (1) Possible friction or attrition between the two separating fracture surfaces of a rock specimen. In general, the fracture surface of a properly oriented single crystal specimen is an intrinsic crystal' plane that is always mirror smooth. However, the fracture surface of a rock specimen is not a plane, but a zigzag surface along and through different mineral grains. Thus, when a fracture (crack) is formed, friction may exist between the two separating fracture surfaces in a rock specimen, but such friction may be absent in the single crystal fracture. (2) 
Inter-granular displacement in the region close to the crack tip or the fracture surfaces of a rock specimen as discussed in Sect. 14.1. (3) Other unknown factors.

No study has been found concerning the friction energy between two separating fracture surfaces during the fracture of a rock specimen. However, one recent study by Qiao et al. (2019) is somewhat relevant to such friction energy. Their experiments indicated that the frictionally dissipated energy between two fractured surfaces of each cubic granite specimen that was previously split was large. For example, even at the lowest vertical stress, $5 \mathrm{MPa}$, the frictionally dissipated energy per square meter of nominal shearing surface was up to about $3 \times 10^{4} \mathrm{~J} / \mathrm{m}^{2}$. Such frictional energy is much larger than the nominal specific fracture energy under tensile, pure shear (torsional) and uniaxial compressive loads, meaning that friction between two rock surfaces can dissipate much more energy than creation of a new fracture surface. Anyway, all the factors relevant to the friction or attrition mentioned above are worthy of study in the future.

\subsection{Thermal Energy Dissipated in Rock Crushing and Grinding}

A review by Cheatham (1968) indicates that only a small portion of the total energy is utilized as surface energy and much of the energy is dissipated as thermal energy. Measurements by Schellinger $(1951,1952)$ indicate that about $80-90 \%$ of the energy input of a ball mill is finally degraded to thermal energy. Zeleny (1957) shows that most of the energy input to single particle impact crushing is finally degraded into thermal energy, and gives $84 \%$ as the median value of this ratio for five experiments on pyrex spheres. Recent study by Bouchard et al. (2016) indicates that over $75 \%$ of the electrical energy is used to heat the slurry, leaving only a relatively small amount of it to achieve mechanical work $(\sim 9 \%)$ in the semi-autogenous grinding and ball mill circuits. All the above studies show that most of the energy input in crushing and grinding is converted to thermal energy. Unfortunately, this status has not been largely improved since the 1950's. Therefore, how to reduce such heat energy or utilize it is an interesting topic for future research. Similar to crushing and grinding, the thermal energy discussed above certainly exists in rock drilling and rock blasting. Probably, such thermal energy may also be very large. Accordingly, it should be investigated in the future.

\subsection{Data Collection of Fracture Energy and Relation between Fracture Energy and Fracture Toughness}

Since there seems to have been relatively few measurements made of the fracture in rock fracture tests after the year 2000, most $w_{f}$ data were cited from previous references. The authors of this paper have also noted that the fracture energy of other geo-materials such as concrete has also been measured and applied as the fracture index with consideration of the effect of loading rate, specimen geometry, cyclic loading and material component on fracture energy or toughness (e.g. Peterson 1980a, b; Ameri et al. 2016; Aliha et al. 2018; Fakhri et al. 2018a, b; Eghbali et al. 2019; AsdollahTabar et al. 2021).

Using the experimental data of static and dynamic fracture of gabbro and marble in Table 4.3 from Zhang (2016) the authors found an approximately linear relation between mode I fracture toughness and specific fracture energy, indicating that it is possible to present the fracture energy of a rock by its fracture toughness in terms of critical energy release rate. However, since such experimental data are still relatively few, it is necessary to carry out more experiments on other rocks in the future.

\section{Concluding Remarks}

1. The average specific fracture energy (surface energy) of various single crystals is only $0.8 \mathrm{~J} / \mathrm{m}^{2}$.

2. The average specific fracture energy of various rocks with a pre-crack in cleavage tests is $4.6 \mathrm{~J} / \mathrm{m}^{2}$, nearly 6 times greater than the average surface energy of single crystals.

3. The average specific fracture energy of the mode I fracture rock specimens with a pre-cut notch but without pre-crack is $4.6 \mathrm{~J} / \mathrm{m}^{2}$, almost 6 times greater than the average surface energy of single crystals.

4. The average specific fracture energies of regular uniaxial compression, uniaxial tension and uniaxial shear rock specimens without a pre-made crack or a pre-cut notch are $26.6,13.9$ and $25.7 \mathrm{~J} / \mathrm{m}^{2}$, respectively. This is about 33, 17 and 32 times larger, respectively than the average surface energy of single crystals.

5. The average specific fracture energy of irregular single quartz particles under static compression tests is $13.8 \mathrm{~J} / \mathrm{m}^{2}$, which is about 17 times greater than the average surface energy of single crystals.

6. The average specific fracture energy of particle beds under drop weight tests is $74.0 \mathrm{~J} / \mathrm{m}^{2}$ which is about 93 times greater than the average surface energy of single crystals.

7. The average specific fracture energy of multi-particles in the milling tests is $72.5 \mathrm{~J} / \mathrm{m}^{2}$ which is about 91 times larger than the average surface energy of single crystals.

8. Taking the average specific surface energy, $0.8 \mathrm{~J} / \mathrm{m}^{2}$, of single crystals as a reference, we get that the energy efficiency of milling is $1.1 \%$. 
9. The average specific energy of percussive drilling and full-scale indentation tests is $399 \mathrm{MJ} / \mathrm{m}^{3}$, that of full-scale rock cutting is $131 \mathrm{MJ} / \mathrm{m}^{3}$ and that of rotary drilling is $157 \mathrm{MJ} / \mathrm{m}^{3}$, indicating that rotary drilling and cutting are more energy-efficient than percussive drilling and full-scale indentation tests.

10. The data on specific fracture energy of rock drilling in the unit of $\mathrm{J} / \mathrm{m}^{2}$ is scarce, so more measurements are necessary to, hopefully, further improve the technology, machine and tools in rock drilling and boring.

11. The measured specific fracture energy data of rock blasting is very limited due to the big challenges in measuring the total fracture surface areas of all fragments including fines, espacially in full-scale blasting.

12. Effects of intergranular displacement, confinement, loading rate, friction and attrition on the specific fracture energy of rock are worthy of further study.

13. Experimental measurements show that $75-90 \%$ of the energy input in rock crushing and grinding is converted to thermal energy. Therefore, how to reduce such thermal energy or utilize it is an interesting topic for future research. In rock drilling and rock blasting such thermal energy may also exist.

14. Many models or theories have been developed for studying rock fragmentation and energy input in blasting and mechanical crushing and grinding, but it is still desirable to develop new models or to improve existing models in order to well link fragment size distribution function with the energy input or the energy used in fragmentation.

Acknowledgements The first author is grateful to K. H. Renlund Foundation in Finland for the support to this study.

Funding Open Access funding provided by University of Oulu including Oulu University Hospital.

\section{Declarations}

Conflict of interest The authors declare that they have no conflict of interests.

Open Access This article is licensed under a Creative Commons Attribution 4.0 International License, which permits use, sharing, adaptation, distribution and reproduction in any medium or format, as long as you give appropriate credit to the original author(s) and the source, provide a link to the Creative Commons licence, and indicate if changes were made. The images or other third party material in this article are included in the article's Creative Commons licence, unless indicated otherwise in a credit line to the material. If material is not included in the article's Creative Commons licence and your intended use is not permitted by statutory regulation or exceeds the permitted use, you will need to obtain permission directly from the copyright holder. To view a copy of this licence, visit http://creativecommons.org/licenses/by/4.0/.

\section{References}

Adams JT, Johnson JF, Piret EL (1949) Energy—new surface relationship in crushing. Part II. Application of permeability measurement to an investigation of the crushing of halite. Chem Eng Prog 45:655-660

Aliha MRM, Razmi A, Mousavi A (2018) Fracture study of concrete composites with synthetic fibers additive under modes I and III using ENDB specimen. Constr Build Mater 190:612-622

Alvarado S, Algüerno J, Auracher H, Casali A (1998) Energy-exergy optimization of comminution. Energy 23:153-158

Ameri M, Nowbakht Sh, Molayem M, Aliha MRM (2016) Investigation of fatigue and fracture properties of asphalt mixtures modified with carbon nanotubes. Fatigue Fract Eng Mater Struct 39(7):896-906

Anderson TL (2005) Fracture mechanics: fundamentals and applications, 3rd edn. Taylor and Francis Group, London

Asdollah-Tabar M, Heidari-Rarani M, Aliha MRM (2021) The effect of recycled PET bottles on the fracture toughness of polymer concrete. Compos Commun 25:100684

Atkinson BK (1987) Fracture mechanics of rock. Academic press, London

Atkinson BK, Avdis V (1980) Fracture mechanics parameters of some rock-forming minerals determined using an indentation technique. Int J Rock Mech Min Sci Geomech Abstr 17:383-386

Awachie SEA (1983) Development of crusher models using laboraoty particle bereakage data. Doctoral Thesis. Julius Kruttschnitt Mineral Research Centre, University of Queensland.

Axelson JW, Piret DL (1950) Crushing of single particle of crystalline quartz. I\&EC 42:665-670

Baker TC, Preston FW (1946) Fatigue of glass under static loads. J Appl Phys 17:170-178

Barber T, Griffith WA (2016) Experimental constraints on dynamic fragmentation as a dissipative process during seismic slip. Phil Trans R Soc A 375:20160002

BCS Incorperated (2007) Mining industry energy bandwidth study. Industry Technologies Program, U.S. Department of Energy, June 2007

Bdzil JB, Stewart DS (1986) Time-dependent two-dimensional detonation: the interaction of edge rarefactions with finite length reaction zones. J Fluid Mech 171:1-16

Bdzil JB, Stewart DS, Jackson TL (2001) Program burn algorithms based on detonation shock dynamics: discrete approximations of detonation flows with discontinuous front models. J Comput Phys 174:870-902

Bergstrom BH, Sollenberger CL (1962) Kinetic energy effect in single particle crushing. Trans AIME 222:373-379

Bieniawski ZT (1968) Fracture dynamics of rock. Int J Fract Mech 4:415-430

Bilgin N, Demircin MA, Copur H, Balci C, Tuncdemir H, Akcin N (2006) Dominant rock properties affecting the performance of conical picks and the comparison of some experimental and theoretical results. Int J Rock Mech Min Sci 43:139-156

Bond FC (1952) The third theory of comminution. Trans AIME 193:484-494

Bouchard J, LeBlanc G, Germain Y, Levesque M, Tremblay N, Légaré B, Dallaire B, Radziszewski P (2016) The CMIC/CanmetMINES Comminution Energy Recovery Potential Initiative - The Agnico Eagle Goldex Division Case. In: Conference Paper, September 2016. https://www.researchgate.net/publication/ 308901176

Boussinesq J (1885) Application des potentiels à l'étude de l'équilibre et du mouvement des solides élastiques. Paris: Gauthier-Villars, 
1885. Discussed in: Timoshenko SP and Goodier JN. Theory of elasticity. McGraw-Hill, New York, vol 1970, pp 398-402

Brace WF, Walsh JB (1962) Some direct measurements of the surface energy of quartz and orthoclase. Am Miner 47:1111-1122

Brinkmann JR (1990) An experimental study of the effects of shock and gas penetration in blasting. In: The 3 rd international symposium for rock fragmentation by blasting, Brisbane, Australia, pp 55-66

Carrol MM (1985) Mechanics of geological materials. Appl Mech Rev 38:1256-1260

Chapman DL (1899) On the rate of explosion in gases. Philos Mag 47:90-104

Charles RJ (1958) Static fatigue of glass II. J Appl Phys 29:1554-1560

Cheatham JB (1968) Rock breakage by crushing, blasting, and drilling. Eng Geol 2(5):293-314

Chi G, Fuerstenau MC, Bradt RC, Ghosh A (1996) Improved comminution efficiency through controlled blasting during mining. Int J Miner Process 47:93-101

Chi LY, Zhang ZX, Aalberg A, Li CC (2019a) Experimental investigation of blast-induced fractures in rock cylinders. Rock Mech Rock Eng 52(8):2569-2584

Chi LY, Zhang ZX, Aalberg A, Yang J, CC Li (2019b) Fracture processes in granite blocks under blast loading. Rock Mech Rock Eng 52:853-868

Cooper GA (1977) Optimization of the three-point bend test for fracture energy measurement. J Mater Science 12:277-289

Cooper PW (1996) Explosives engineering. Wiley-VCH, New York

Cox SJD, Scholz CH (1985) A direct measurement of shear fracture energy in rocks. Geophys Res Lett 12:813-816

Cunningham CVB (1983) The Kuz-Ram model for prediction of fragmentation from blasting. In: Holmberg R, Rustan A (eds) Proc 1 st int symp on rock fragmentation by blastin. Luleå University of Technology, Luleå, pp 439-453

Dai F, Xia K (2013) Laboratory measurements of the rate dependence of the fracture toughness anisotropy of Barre granite. Int J Rock Mech Min Sci 60:57-65

Dai F, Chen R, Iqbal MJ, Xia K (2010) Dynamic cracked chevron notched Brazilian disc method for measuring rock fracture parameters. Int J Rock Mech Min Sci 47:606-613

Davis WC (1997) Shock waves, rarefaction waves, equations of state. In: Zukas JA, Walters WP (eds) Explosive effects and applications. Springer, Berlin, pp 47-113

Dehkhoda S, Detournay E (2019) Rock cutting experiments with an actuated disc. Rock Mech Rock Eng 52:3443-3458

Detournay E, Defourny P (1992) A phenomenological model for the drilling action of drag bits. Int J Rock Mech Min Sci Geomech Abstr 29:13-23

Döring W (1943) On detonation processes in gases. Ann Phys 43:421-436

Eghbali MR, Tafti MF, Aliha MRM, Motamedi H (2019) The effect of ENDB specimen geometry on model fracture toughness and fracture energy of HMA and SMA mixtures at low temperatures. Eng Fract Mech 216:106496

Entacher M, Schuller E, Galler R (2015) Rock failure and crack propagation beneath disc cutters. Rock Mech Rock Eng 48:1559-1572

Fairhurst C (1961) Wave mechanics of percussive drilling. Mine Quarry Eng 27:122-130

Fakhri M, Kharrazi EH, Aliha MRM, Berto F (2018a) The effect of loading rate on fracture energy of asphalt mixture at intermediate temperatures and under different loading modes. Frattura Ed Integrità Strutturale 43:113-132. https://doi.org/10.3221/IGFESIS.43.09

Fakhri M, Kharrazi EH, Aliha MRM (2018b) Mixed mode tensile-in plane shear fracture energy determination for hot mix asphalt mixtures under intermediate temperature conditions. Eng Fract Mech 192:98-113
Fickett W, Davis WC (2000) Detonation: theory and experiment. Dover, New York

Field JE, Freeman CJ (1981) Strength and fracture properties of diamond. Philos Mag A43:595-618

Fowell RJ (1995) Suggested methods for determining mode I fracture toughness using cracked chevron notched Brazilian disc (CCNBD) specimens. Int J Rock Mech Min Sci Geomech Abstr 32(1):57-64

Fowell RJ, Ochei NN (1984) A comparison of dust make and energy requirements for rock cutting tools. Int J Min Eng 2:73-83

Franca LFP (2011) A bit-rock interaction model for rotary-percussive drilling. Int J Rock Mech Min Sci 48:827-835

Friedman M, Handin J, Alani G (1972) Fracture-surface energy of rocks. Int J Rock Mech Min Sci 9:757-766

Fuerstenau DW, Abouzeid AZM (2002) The energy efficiency of ball milling in comminution. Int J Miner Process 67:161-185

Fuerstenau DW, Vazquez-Favela J (1997) On assessing and enhancing the energy efficiency of comminution processes. Miner Metall Process 14(1):41-48

Gillis PP, Gilman JJ (1964) Double cantilever cleavage mode of crack propagation. J Appl Phys 35(3):647-658

Gilman JJ (1960) Direct measurements of the surface energies of crystals. J Appl Phys 31:2208

Gilvarry JJ, Bergstrom BH (1961) Fracture of brittle solids II. Distribution function for fragment size in single fracture (experimental). J Appl Phys 32:400-410

Glenn LA, Chudnovsky A (1986) Strain and energy effects on dynamic fragmentation. J Appl Phys 59(4):1379-1380

Gong F, Jia H, Zhang Z, Hu J, Luo S (2020) Energy dissipation and particle size distribution of granite under different incident energies in SHPB compression tests. Shock Vibr 2020:8899355

Grady DE, Kipp ME (1980) Continuum modelling of explosive fracture in oil shale. Int J Rock Mech Min Sci Geomech Abstr 17:147-157

Grady DE (2006) Fragmentation of rings and shells: the legacy of N.F. Mott. Springer, Germany.

Griffith AA (1921) The phenomena of rupture and flow in solids. Philos Trans R Soc Lond Ser A 221:163-198

Griffith AA (1924) The theory of rupture. Proc First Int Congress Appl Mech Delft 1924:55-63

Gross J, Zimmerley SR (1930) Crushing and grinding: III. Relation of work input to surface produced in crushing quartz. Trans AIME 35-44. Milling Methods, New York

Hartley NEW, Wilshaw TR (1973) Deformation and fracture of synthetic -quartz. J Mater Sci 8:265-278

Hashiba K, Fukui K, Liang YZ, Koizumi M, Matsuda T (2015) Forcepenetration curves of a button bit generated during impact penetration into rock. Int J Impact Eng 85:45-56

He X, Xu C (2016) Specific energy as an index to identify the critical failure mode transition depth in rock cutting. Rock Mech Rock Eng 49:1461-1478

Hertz H (1881) Über die berührung fester elastischer Körper. Journal Für Die Reine Und Ange Math 92:156-171

Heuze FE (1983) High-temperature mechanical, physical and thermal properties of granitic rocks-a review. Int J Rock Mech Min Sci Geomech Abstr 20:3-10

Hinzen KG (1998) Comparison of seismic and explosive energy in five smooth blasting test rounds. Int J Rock Mech Min Sci 35:957-967

Hoagland RG, Hahn GT, Rosenfield AR (1973) Influence of microstructure on fracture propagation in rocks. Rock Mech 5:77-106

Hogan JD, Farbaniec L, Daphalapurkar N, Ramesh KT (2016) On compressive brittle fragmentation. J Am Ceram Soc 99(6):2159-2169

Homand-Etienne F, Houpert R (1989) Thermally induced microcracking in granites: characterisation and analysis. Int J Rock Mech Min Sci Geomech Abstr 26:125-134 
Howarth DF, Bridge EJ (1988) Microfracture beneath blunt disc cutters in rock. Int J Rock Mech Min Sci Geomech Abstr 25:35-38

Hukki RT (1943) An experimental study of the principles of comminution, Doctoral Thesis, Massachusetts Institute of Technology, Cambridge

Hustrulid WA, Fairhurst C (1971a) A theoretical and experimental study of the percussive drilling of rock. Part I-theory of percussive drilling. Int J Rock Mech Min Sci Geomech Abstr 8:311-333

Hustrulid WA, Fairhurst C (1971b) A theoretical and experimental study of the percussive drilling of rock. Part II-force-penetration and specific energy determinations. Int J Rock Mech Min Sci Geomech Abstr 8:335-356

Irwin GR (1956) Onset of fast crack propagation in high strength steel and aluminum alloys. Sagamore Res Conf Proc 2:289-305

Irwin GR (1948) Fracture dynamics. Fracturing of Metals, American Society for Metals, Cleveland, pp147-166

Janach W (1977) Failure of granite under compression. Int J Rock Mech Min Sci Geomech Abstr 14:209-215

Johansson CH, Persson PA (1970) Detonics of high explosives. Academic Press, London

Johnson JF, Axelson J, Piret EL (1949) Energy—new surface relationship in crushing. Part III. Application of gas adsorption measurement to an investigation of the crushing of quartz. Chem Eng Prog 45:708-715

Jouguet E (1905) On the propagation of chemical reaction in gases. J De Math Pures Et Appl 1:347-425

Kabo M, Goldsmith W, Sackman JL (1977) Impact and comminution processes in soft and hard rock. Rock Mech 9:213-243

Karlsson LG, Lundberg B, Sundin KG (1989) Experimental study of a percussive process for rock fragmentation. Int J Rock Mech Min Sci Geomech Abstr 26:45-50

Kick F (1883) Contribution to the knowledge of brittle materials. Dinglers J 247:1-5

Kou SQ (1995) Some basic problems in rock breakage by blasting and by indentation. Doctoral Thesis, Luleå University of Technology

Kranz RL (1979) Crack growth and development during creep of Barre granite. Int J Rock Mech Min Sci Geomech Abstr 16:23-35

Krech WW (1974) The energy balance theory and rock fracture energy measurements for uniaxial tension. In: Proc 3rd Int Congr ISRM, Vol 2A, Washington DC, pp 167-173

Kumano A, Goldsmith W (1982a) Behavior of diorite under impact by variously-shaped projectiles. Rock Mech 15:25-40

Kumano A, Goldsmith W (1982b) An analytical and experimental investigation of the effect of impact on coarse granular rocks. Rock Mech 15:67-97

Kuruppu MD, Obara Y, Ayatollahi MR, Chong KP, Funatsu T (2014) ISRM-suggested method for determining the mode I static fracture toughness using semi-circular bend specimen. Rock Mech Rock Eng 47:267-274

Kwong JNS, Adams JT, Johnson JF, Piret EL (1949) Energy—new surface relationship in crushing. Part I. Application of permeability methods to an investigation of the crushing of some brittle solids. Chem Eng Prog 45:508-516

Labuz JF, Shah SP, Dowding CH (1985) Experimental analysis of crack propagation in granite. Int J Rock Mech Min Sci Geomech Abstr 22:85-98

Langefors U, Kihlström B (1978) The modern technique of rock blasting. In: 3rd ed. AWE/GEBERS, Stockholm

Lankford J (1981) The role of tensile microfracture in the strain rate dependence of compressive strength of fine-grained limestoneanalogy with strong ceramics. Int J Rock Mech Min Sci Geomech Abstr 18:173-175

Levy S, Molinari JF (2010) Dynamic fragmentation of ceramics, signature of defects and scaling of fragment sizes. J Mech Phys Solids 58(1):12-26
Li XB (1994) Impact rock dynamics. Press of South-Central University of Technology, Changsha (in Chinese)

Lindholm US, Yeakley LM, Nagy A (1974) The dynamic strength and fracture properties of Dresser basalt. Int J Rock Mech Min Sci 11:181-191

Lindqvist PA, Lai HH (1983) Behaviour of the crushed zone in rock indentation. Rock Mech Rock Eng 16:199-207

Lindqvist PA, Lai HH, Alm O (1984) Indentation fracture development in rock continuously observed with a scanning electron micropscope. Int J Rock Mech Min Sci Geomech Abstr 21:181-191

Lindqvist PA, Suarez del Rio LM, Montoto M, Tan X, Kou SQ (1994) Rock indentation database-testing procedures, results and main conclusions. SKB project report, PR44-94-023.

Liu HY, Kou SQ, Lindqvist PA (2008) Numerical studies on bit-rock fragmentation mechanisms. Int J Geomech 8(1):45-67

Liu K, Zhao J, Wu G, Maksimenko A, Haque A, Zhang QB (2020) Dynamic strength and failure modes of sandstone under biaxial compression. Int J Rock Mech Min Sci 128:104260

Lowrison GC (1974) The size reduction of solid materials. Crushing and grinding. Butterworth, London, pp 49-66

Lundberg B (1973) Energy transfer in percussive rock destruction-I, II and III. Int J Rock Mech Min Sci Geomech Abstr 10:381-399

Lundberg B (1974) Penetration of rock by conical indenters. Int J Rock Mech Min Sci 11(6):209-214

Lundberg B (1976) A split Hopkinson bar study of energy absorption in dynamic rock fragmentation. Int J Rock Mech Min Sci Geomech Abstr 13:187-197

Lundberg B, Collet P (2015) Optimal wave shape with respect to efficiency in percussive drilling with detachable drill bit. Int J Impact Eng 86:179-187

Lundberg B, Huo J (2017) Biconvex versus bilinear force-penetration relationship in percussive drilling of rock. Int J Impact Eng 100:7-12

Lundberg B, Okrouhlik M (2006) Efficiency of a percussive rock drilling process with consideration of wave energy radiation into the rock. Int J Impact Eng 32:1573-1583

Mahanta B, Tripathy A, Vishal V, Singh TN, Ranjith PG (2017) Effects of strain rate on fracture toughness and energy release rate of gas shales. Eng Geol 218:39-49

Marshall DB (1984) Geometrical effects in elastic-plastic indentation. J Am Ceram Soc 67(1):57-60

Marshall DB, Lawn BR, Evans AG (1982) Elastic/plastic indentation damage in ceramics: the lateral crack system. J Am Ceram Soc 65(11):561-566

Martin G, Bowes EA, Turner FB (1925) Researches on the theory of fine grinding - part III: connection between the surface area produced and the work done in the tube-mill grinding of quartz sand. Trans Ceram Soc 25:63-81

Messmer C, Bilello JC (1981) The surface energy of Si, GaAs, and GaP. J Appl Phys 52:4623

Moavenzadeh F, Kuguel R (1969) Fracture of concrete. J Mater 4:497-519

Moser P (2004) Less fines production in aggregate and industrial minerals industry. Int Soc Explos Eng 2004:1

Moser P, Grasedieck A (2004) Rock specific breakage energy functions derived from lab scale blast experiments. Int Soc Explos Eng 2004:2

Mott N (1943) A theory of the fragmentation of shells and bombs. Technical Report AC4035, United Kingdom Ministry of Supply

Mott N (1947) Fragmentation of shell cases. Technical Report A189: 300308, Proceedings of the Royal Society

Munoz H, Taheri A, Chanda E (2016) Rock cutting characteristics on soft-to-hard rocks under different cutter inclinations. Int J Rock Mech Min Sci 87:85-89

Nadolski S, Klein B, Kumar A, Davaanyam Z (2014) An energy benchmarking model for mineral comminution. Miner Eng 65:178-186 
Nakayama J (1965) Direct measurement of fracture energies of brittle heterogeneous materials. J Am Ceram Soc 48:583-587

Napier-Munn TJ, Morrell S, Morrison RD, Kojovic T (1996) Mineral comminution circuits: their operation and optimization. Julius Kruttschnitt Mineral Research Centre, University of Queensland. ISBN $064628861 \mathrm{x}$

Narayanan SS, Whiten WJ (1988) Determination of comminution characteristics from single particle breakage tests and its application to ball mill scale-up. Trans Inst Min Metall 97:C115-C124

Narayanan SS (1985) Development of a laboratory single particle breakage technique and its application to ball mill scale-up. PhD thesis, Julius Kruttschnitt Mineral Research Centre, University of Queensland.

Nariseti C, Mohanty B, Peterson K (2015) Crack visualization and mapping in rock samples due to impact loading with tungsten carbide bits. Blast Fragm 9:125-138

Natural Resources Canada (2011) Energy efficiency trend in Canada, 1990 to 2009. http://oee.rncan.gc.ca/publications/statistics/trend s11/chapter5.cfm?attr $=0$

Obreimoff JW (1930) The splitting strength of mica. Proc Roy Soc London A 127:290-297

Oettel W, Nguyen AQ, Husemann K, Bernhardt C (2001) Comminution in confined particle beds by single compressive load. Int $\mathrm{J}$ Miner Process 63:1-16

Olofsson T (1978) Evaluation of fracture parameters and elastic properties of rock materials. Report 1978:195E, University of Luleå, Sweden (in Swedish).

Orowan E (1948) Fracture and Strength of Solids. Rep Progress Phys XII: 185

Ouchterlony F (1982) Review of fracture toughness testing of rock. Solid Mech Arch 7:131-211

Ouchterlony F (1988) Suggested methods for determining the fracture toughness of rock. Int J Rock Mech Min Sci Geomech Abstr 25(2):71-96

Ouchterlony F (2005) The Swebrec function linking fragmentation by blasting and crushing. Min Technol 114:29-44

Ouchterlony F, Sanchidrián JA (2018) The fragmentation-energy fan concept and the Swebrec function in modeling drop weight testing. Rock Mech Rock Eng 51:3129-3156

Ouchterlony F, Sanchidrián JA (2019) A review of development of better prediction equations for blast fragmentation. J Rock Mech Geotechn Eng 11:1094-1109

Ouchterlony F, Nyberg U, Olsson M, Bergquist I, Granlund L, Grind $\mathrm{H}$ (2004a) Where does the explosive energy in rock blasting go? Sci Technol Energetic Mater 65:54-63

Ouchterlony F, Sanchidrián JA, Moser P (2017) Percentile fragment size predictions for blasted rock and the fragmentation-energy fan. Rock Mech Rock Eng 50(4):751-779

Ouchterlony F, Nyberg U, Olsson M (2003) The energy balance of production blasts at Nordkalk's Klinthagen quarry. In: Holmberg $\mathrm{R}$ (ed) Proceedings of the second world conference on explosives and blasting. Balkema, Rotterdam, pp 193-203

Ouchterlony F, Nyberg U, Olsson M, Bergqvist I, Granlund L, Grind $\mathrm{H}$ (2004a) The energy balance of production blasts at Nordkalk's Klinthagen quarry. Bergsprängningskommitten, Stockholm

Ouchterlony F (1980) Fracture toughness measurements on rock cores. Report DS 1980:4, Swedish Detonic Research Foundation, Stockholm (in Swedish)

Pang SS, Goldsmith W, Hood M (1989) A force-indentation model for brittle rocks. Rock Mech Rock Eng 22:127-148

Parks GA (1984) Surface and interfacial free energies of quartz. J Geophys Res 89(B6):3977-4008

Perkins TK, Bartlett LE (1963) Surface energies of rocks measured during cleavage. Soc Petrol Engrs J 3(4):307-314
Perkins TK, Krech WW (1966) Effect of cleavage rate and stress level on apparent surface energies of rocks. Sot Petrol Enars J 6(4):308-314

Persson PA, Holmberg R, Lee J (1994) Rock blasting and explosives engineering. CSC Press, Hoboken

Peterson PE (1980a) Fracture energy of concrete: Method of determination. Cem Concr Res 10(1):79-89

Peterson PE (1980b) Fracture energy of concrete: Practical performance and experimental results. Cem Concr Res 10(1):91-101

Prasher CL (1987) Crushing and grinding process handbook. Wiley, Chichester

Qiao L, Chen L, Dasgupta G, Li Q, Li Y (2019) Surface characterization and frictional energy dissipation characteristics of deep granite under high stress conditions. Rock Mech Rock Eng 52:1577-1589

Reichholf G (2013) Experimental investigation into the characteristic of particle size distributions of blasted material. Doctoral Thesis, Montanuniversität Leoben

Revnivtsev VI (1988) We really need revolution in comminution. In: Proc 16th Int Miner Process Congr. Elsevier Science Publishers, Amsterdam, pp 93-114

Roesler FC (1956) Brittle fracture near equilibrium. Proc Phys Soc (sect B) 69(10):981-992

Rogers CO, Pang SS, Kumano A, Goldsmith W (1986) Response of dry- and liquid-filled porous rocks to static and dynamic loading by variously-shaped projectiles. Rock Mech Rock Eng 19:235-260

Rosin P, Rammler E (1933) The laws governing fineness of powdered coal. J Inst Fuel 7:29-36

Rumpf H (1973) Physical aspects of comminution and new formulation of a law of comminution. Powder Technol 7:145-159

Sadrai S, Meech JA, Ghomshei M, Sassani F, Tromans D (2006) Influence of impact velocity on fragmentation and the energy efficiency of comminution. Int J Impact Eng 33:723-734

Sadrai S, Meech JA, Tromans D, Sassani F (2011) Energy efficient comminution under velocity impact fragmentation. Miner Eng 24:1053-1061

Sanchidrián JA, Ouchterlony F (2017) A distribution-free description of fragmentation by blasting based on dimensional analysis. Rock Mech Rock Eng 50:781-806

Sanchidrián JA, Pablo S, López LM (2007) Energy components in rock blasting. Int J Rock Mech Min Sci 44:130-147

Santhanam AT, Gupta YP (1968) Cleavage surface energy of calcite. Int J Rock Mech Min Sci 5:253-259

Schardin H (1959) Velocity effects in fracture. In: Averbach D et al (eds) Fracture. Technology Press and Wiley, New York, pp 297-330

Schellinger AK (1951) A calorimetric method for studying grinding in a tumbling medium. Trans AIME Min Eng 1951:518-522

Schellinger AK (1952) Solid surface energy and calorimetric determinations of surface energy relationships for some common minerals. Min Eng 4(4):369-374

Schoenert K (1972) Role of fracture physics in understanding comminution phenomena. Trans AIME 252:21-26

Schönert K (1979) Energy aspects of size reduction of brittle materials. Zement-Kalk-Gips 32:1-9

Schönert K (1988) A first survey of grinding with high-compression roller mills. Int J Miner Process 22:401-412

Shand EB (1961) Fracture velocity and fracture energy of glass in the fatigue range. J Am Ceram Soc 44(1):21-26

Sharpe GJ, Braithwaite M (2005) Steady non-ideal detonations in cylindrical sticks of explosives. J Eng Math 53:39-58

Shi F (2016) A review of the applications of the JK size-dependent breakage model. Part 1: ore and coal breakage characterisation. Int J Miner Process 155:118-129 
Shi F, Kojovic T (2007) Validation of a model for impact breakage incorporating particle size effect. Int $\mathbf{J}$ Miner Process $82: 156-163$

Shockey DA, Curran DR, Seaman L, Rosenberg JT, Petersen CF (1974) Fragmentation of rock under dynamic Loads. Int J Rock Mech Min Sci Geomech Abstr 11:303-317

Simon R (1964) Transfer of the stress wave energy of a percussive drill to the rock. Int J Rock Mech Min Sci 1:397-411

Sneddon IN (1951) Fourier transforms. Dover Publications, New York

Spathis AT (1999) On the energy efficiency of blasting. In: Proc 6th int symp rock fragm by blasting. South African Institute of Mining and Metallurgy, Johannesburg, pp 81-90

Stamboliadis E, Pantelaki O, Petrakis E (2009) Surface area production during grinding. Miner Eng 22:587-592

Steiner HJ (1998) Zerkleinerungstechnische Eigenschaften Von Gesteinen 16(5):320-325

Stoxreiter T, Wenighofer R, Portwood G, Pallesi S, Bertini A, Galler $\mathrm{R}$, Grafinger $\mathrm{S}$ (2019a) Rock fracture initiation and propagation by mechanical and hydraulic impact. Open Geosci 11(1):1-45

Stoxreiter T, Portwood G, Gerbaud L, Seibel O, Essl S, Plank J, Hofstätter H (2019b) Full-scale experimental investigation of the performance of a jet-assisted rotary drilling system in crystalline rock. Int J Rock Mech Min Sci 115:87-98

Suzuki T, Takahashi K, Kawasaki M, Kagami T (2014) Specific surface free energy of as-grown and polished faces of synthetic quartz. J Crystal Process Technol 4:177-184

Swan G (1980) Some observations concerning the strength-size dependency of rock. Research Report 1980:01, University of Luleå, Sweden

Tapponier P, Brace WF (1976) Development of stress-induced microcracks in Westerly granite. Int J Rock Mech Min Sci Geomech Abstr 13:103-112

Tavares LM (2004) Optimum routes for particle breakage by impact. Powder Technol 142:81-91

Tavares LM, King RP (1998) Single-particle fracture under impact loading. Int J Miner Process 54:1-28

Teale R (1965) The concept of specific energy in rock drilling. Int J Rock Mech Min Sci 2:57-73

Tromans D (2008) Mineral comminution: energy efficiency considerations. Miner Eng 21:613-620

Tromans D, Meech JA (2002) Fracture toughness and surface energies of minerals: theoretical estimates for oxides, sulphides, silicates and halides. Miner Eng 15:1027-1041

Tuncdemir H, Bilgin N, Copur H, Balci C (2008) Control of rock cutting efficiency by muck size. Int J Rock Mech Min Sci 45:278-288

Turner FJ, Griggs DT, Heard HC (1954) Experimental deformation of calcite crystals. Geol Soc Am Bull 65:883-934

von Neumann J (1942) Theory of detonation waves, OSDR Report 549 (1942), reprinted in Collected Works 1963;6:203-218. Macmillan, New York

von Rittinger RP (1867) Textbook of mineral dressing. Ernst and Korn, Berlin

Wang QZ, Jia XM, Kou SQ, Zhang ZX, Lindqvist PA (2004) The flattened Brazilian disc specimen used for testing elastic modulus, tensile strength and fracture toughness of brittle rocks: analytical and numerical results. Int J Rock Mech Min Sci 41(2):245-253

Wang X, Wang QF, Liang YP, Su O, Yang L (2018) Dominant cutting parameters affecting the specific energy of selected sandstones when using conical picks and the development of empirical prediction models. Rock Mech Rock Eng 51:3111-3128

Watt SD, Sharpe GJ, Falle SA, Braithwaite M (2012) A streamline approach to two-dimensional steady non-ideal detonation: the straight streamline approximation. J Eng Math 75(1):1-14
Weibull W (1951) A statistical distribution function of wide applicability. J Appl Mech Trans ASME 18:293-297

Weng L, Wu Z, Liu Q, Wang Z (2019) Energy dissipation and dynamic fragmentation of dry and water-saturated siltstones under subzero temperatures. Eng Fract Mech 220:106659

Wiederhorn SM (1966) Fracture surface energy of soda-lime glass. Mater Sci Res 3:503-528

Wills BA, Napier-Munn TJ (2006) Wills mineral processing technology: an introduction to the practical aspects of ore treatment and mineral recovery. Butterworth-Heinemann, Oxford

Wong TF (1982) Shear fracture energy of Westerly granite from postfailure behavior. J Geophys Res 81:990-1000

Xia K (2006) Scaling of fracture energies: the rationalization of different laboratory measurements. Geophys Res Letters 33:L01305

Xie H, Li L, Peng R, Ju Y (2009) Energy analysis and criteria for structural failure of rocks. J Rock Mech Geotechn Eng 1(1):11-20

Xu XH, Yu J (1984) Fundamentals of rock fragmentation. Press of Coal Industry of China, Beijing ((in Chinese))

Yang F, Bi J, Li Ma (2019) Dynamic compression damage energy consumption and fractal characteristics of shale. Shock Vib 2019:5792841

Yu Y, Zhang ZX, Yu J, Liao GH (1998) Energy dissipation and damage characters in rock direct tensile destruction. Chin J Rock Mech Eng 17(4):386-392 ((in Chinese))

Zeldovich YB (1940) On the theory of the propagation of detonation waves in gaseous system. Zh Eksp Teor Fiz 10:542-568

Zeleny RA (1957) A study of the dissipation of energy in single particle crushing. PhD Thesis, University of Minnesota

Zgura I, Moldovan R, Negrila CC, Frunza S, Cotorobai VF, Frunza L (2013) Surface free energy of smooth and dehydroxylated fused quartz from contact angle measurements using some particular organics as probe liquids. J Optoelectron Adv Mater 15(7-8):627-634

Zhang ZX (1994) Principles of rock breakage and their applications. Press of Metallurgy Industry of China, Beijing ((in Chinese))

Zhang ZX (2004) Estimate of loading rate for a TBM machine based on measured cutter force. Rock Mech Rock Eng 37(3):239-248

Zhang ZX (2005) Increasing ore extraction by changing detonator positions in LKAB Malmberget mine. Int J Blast Fragm 9(1):29-46

Zhang ZX (2014) Effect of double-primer placement on rock fracture and ore recovery. Int J Rock Mech Min Sci 71:208-216

Zhang ZX (2016) Rock fracture and blasting: theory and applications. Butterworth-Heinemann/Elsevier, Oxford

Zhang ZX, Kou SQ, Yu J, Yu Y, Jiang LG, Lindqvist PA (1999) Effects of loading rates on rock fracture. Int J Rock Mech Min Sci 36(5):597-611

Zhang ZX, Kou SQ, Jiang LG, Lindqvist PA (2000) Effects of loading rates on rock fracture: fracture characteristics and energy partitioning. Int J Rock Mech Min Sci 37(5):745-762

Zhang ZX, Yu J, Kou SQ, Lindqvist PA (2001) Effects of high temperatures on dynamic rock fracture. Int J Rock Mech Min Sci 38(2):211-225

Zhang ZX, Kou SQ, Lindqvist PA (2003) In-situ measurements of cutter forces of boring machine at Äspö underground-II. Characteristics of cutter forces and examination of cracks in rock. Rock Mech Rock Eng 36(1):63-83

Zhang ZX, Hou DF, Guo Z, He Z (2020a) Laboratory experiment of stemming impact on rock fragmentation by a high explosive. Tunnel Undergr Space Technol 97:103257

Zhang ZX, Hou DF, Guo Z, He Z, Zhang Q (2020b) Experimental study of surface constraint effect on rock fragmentation by blasting. Int J Rock Mech Min Sci 128:104278

Zhang ZX, Chi LY, Qiao Y, Hou DF (2021) Fracture initiation, gas ejection, and strain waves measured on specimen surfaces in model rock blasting. Rock Mech Rock Eng 54:647-663 
Zhou F, Molinari JF, Ramesh K (2006a) Analysis of the brittle fragmentation of an expanding ring. Comput Mater Sci 37(1-2):74-85

Zhou F, Molinari JF, Ramesh KT (2006b) Effects of material properties on the fragmentation of brittle materials. Int J Fract 139:169-196

Zhou YX, Xia K, Li XB, Li HB, Ma GW, Zhao J, Zhou ZL, Dai F (2012) Suggested methods for determining the dynamic strength parameters and mode-I fracture toughness of rock materials. Int J Rock Mech Min Sci 49:105-112

Publisher's Note Springer Nature remains neutral with regard to jurisdictional claims in published maps and institutional affiliations. 